\title{
Assessing the perceived impact of Computer-Assisted Instruction on physical therapy education
}

\author{
Mia L. Erickson \\ West Virginia University
}

Follow this and additional works at: https://researchrepository.wvu.edu/etd

\section{Recommended Citation}

Erickson, Mia L., "Assessing the perceived impact of Computer-Assisted Instruction on physical therapy education" (2002). Graduate Theses, Dissertations, and Problem Reports. 2806.

https://researchrepository.wvu.edu/etd/2806

This Dissertation is protected by copyright and/or related rights. It has been brought to you by the The Research Repository @ WVU with permission from the rights-holder(s). You are free to use this Dissertation in any way that is permitted by the copyright and related rights legislation that applies to your use. For other uses you must obtain permission from the rights-holder(s) directly, unless additional rights are indicated by a Creative Commons license in the record and/ or on the work itself. This Dissertation has been accepted for inclusion in WVU Graduate Theses, Dissertations, and Problem Reports collection by an authorized administrator of The Research Repository @ WVU.

For more information, please contact researchrepository@mail.wvu.edu. 
Assessing the Perceived Impact of Computer-Assisted Instruction on Physical Therapy Education

Mia L. Erickson

Dissertation submitted to the College of Human Resources and Education

at West Virginia University in partial fulfillment of the requirements

for the degree of

Doctor of Education

in

Curriculum and Instruction

Patricia Obenauf, Ed.D., Chair

Mary Beth Mandich, Ph.D., PT

Ron Iannone, Ed.D.

Scott Bower, Ed.D.

Sam Stack, Ph.D.

Department of Educational Theory and Practice

Morgantown, West Virginia

2002

Keywords: instructional technology, instructional multimedia, distance learning, problemsolving skills, psychomotor skills, computer-based licensing exam

Copyright 2002 Mia L. Erickson 


\section{ABSTRACT \\ Assessing the Perceived Impact of Computer-Assisted Instruction on Physical Therapy Education}

\section{Mia L. Erickson}

Computer Assisted Instruction (CAI) is becoming more common in allied health education. Research on CAI has provided mixed results. The purpose of this study was to compare uses of CAI in entry-level physical therapist (PT) and physical therapist assistant (PTA) programs. Secondary purposes included determining faculty attitudes toward CAI, determining how faculty select and evaluate CAI, and describing faculty perceptions of CAI and the computer-based licensing exam. Results indicate no significant differences in the amount of CAI in PT and PTA programs. Positive aspects reported include improved knowledge of technology and improved independence with information gathering. Negative aspects reported include cost and lack of time for integration. Respondents indicate that CAI can develop higher-level thinking skills when designed and integrated appropriately, however respondents agree that psychomotor skills should not be taught via CAI. Respondents were unsure whether high or low aptitude students benefit more from CAI, and they were unsure whether one type of learning style (auditory, visual, or kinesthetic) benefits more. Results indicate that programs do not have formal selection criteria, and evaluation procedures reported included student outcomes and course evaluations. Finally, 64\% of PT and 56\% of PTA respondents indicated CAI adequately prepares students for the licensing exam, and 34\% of PT and $40 \%$ of PTA respondents indicated the computer-based licensing exam influenced their decision to integrate CAI. Six concepts describing participant's perceptions of CAI in physical therapy education emerged from qualitative data. They were: 1) CAI develops computer skills, 2) CAI is an instructional tool, 3) CAI improves communication, 4) CAI can provide factual learning, but the instructor must use the CAI so that higher-level skills are attained, 5) Instructors must consider the context before integrating CAI, and 6) CAI has limitations. 


\section{ACKNOWLEDGEMENTS}

I can't believe this is finally over. As I look back on this experience, I feel every possible emotion. Some people said to choose your committee wisely, and I think I did just that. Pat you were so kind and patient, and you always helped to keep me calm whenever it was down to the last few days. Thank you for reading those first drafts, no matter how rough they were and for having confidence that I would finally get it right. Mary Beth, you are an inspiration and a mentor. I appreciate you believing this was important enough to take time from your schedule. I am so glad that you were able to go through this with me. Thank you to all of you for making this a rewarding experience.

I would also like to say thanks to my extended HealthWorks family, especially Jack and John for being flexible with my schedule and allowing me to take on this endeavor. You have been very supportive, and I appreciate that. Also, my suite mates, Ken, Shellie, Nicole, and Julie have been the best, dealing with all of my mood swings. Thank you for your kind words. Shellie thanks for being excited with me and for sharing this with me. I would like to say thanks to the hand team. You have been so great to work with; I also appreciate you flexibility, support, and thoughtfulness. Also, I appreciate the Philadelphia crew who gave me reprieve from this thing when it was getting to be too much.

To my mom and dad, who always taught me that this is what I would do. Thank you for making me be dedicated to what ever I take on, no matter how hard it is. Thank you for understanding how hard this has been, for helping me around the house and with my car, and for entertaining Jeff, when I couldn't. Robin, thank you for making me take study breaks with all of our excursions, no matter how expensive it got. 
Finally, thank you to Jeff, the most wonderful, loving person I know. I know that I could not have finished this without you being as supportive as you have been. You have managed to put your life on hold too, to allow me to reach this goal. Most people would not have done that. Thank you for always having faith that I could finish this and for standing behind me no matter what crazy thing I took on next. Thank you for understanding the last two years when I have had to do school stuff, and for finding hobbies and projects of your own to do when I wasn't around. I have the best yard in the neighborhood. I can't say enough how much it helped when you stayed up late with me in the last couple of months and for managing to give me encouragement to keep writing. You are the best. I can't wait for Hawaii. 


\section{TABLE OF CONTENTS}

ABSTRACT................................................................................................................................................. ii

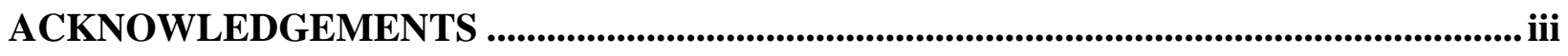

ТАВLE OF CONTENTS .................................................................................................................. V

НIST ОЕ ТАВЕES

HIST OF FHGRES.

HST OF SYMBOLS, ABBREVHATHONS, AND NOMENCLATURE ................................ Xi

CHAPTER ONE: INTRODUCHION........................................................................................1

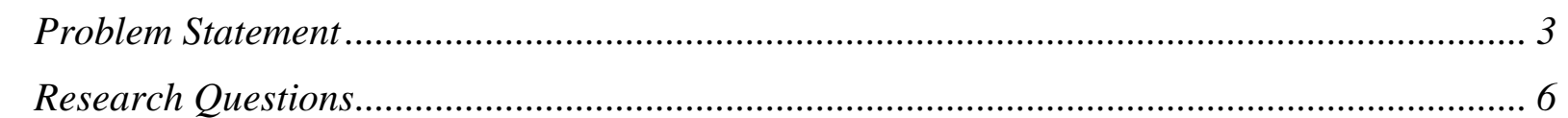

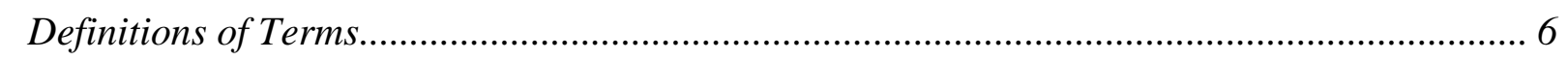

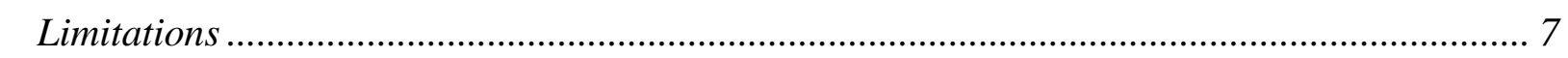

CHAPTER TWO: REVIEW OF LITERATURE ......................................................................9

Overview of Computer-Assisted Instruction ................................................................. 9

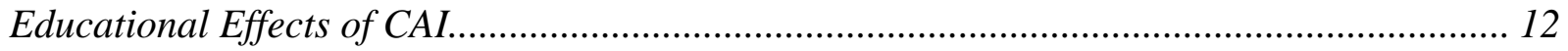

Achievement, Retention, and Attitudes .................................................................. 12

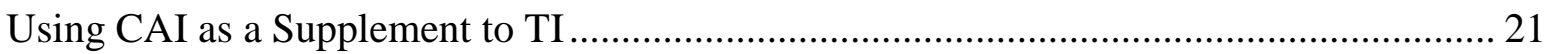

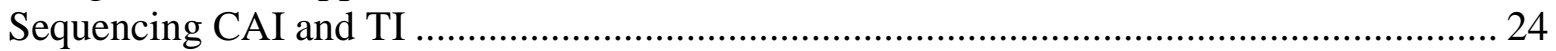

Learner Attributes and CAI ....................................................................................... 27

Aptitude and CAI ............................................................................................................. 28

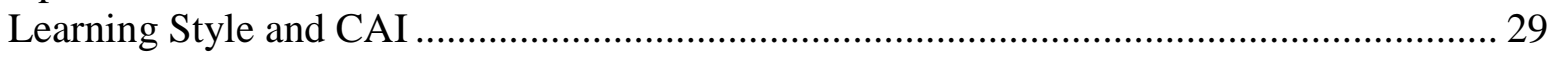

Learning Theory and Instructional Design in Selection of CAI ..................................... 36

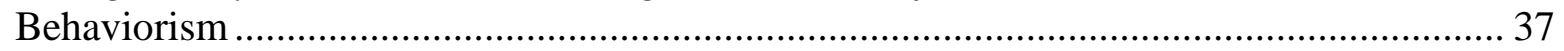

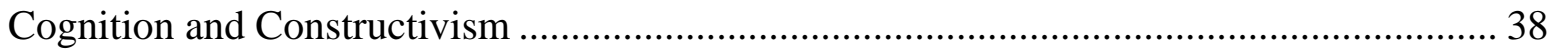

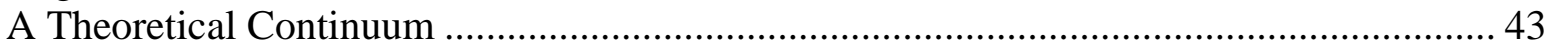

Evaluation of $C A I$..................................................................................................... 44

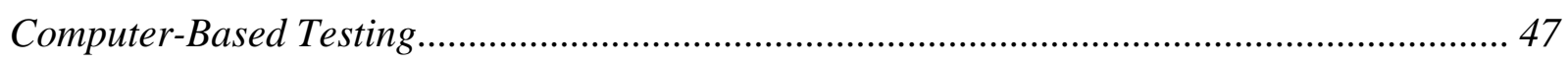

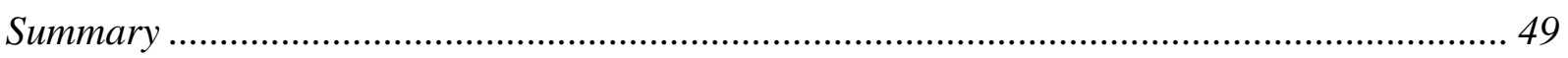

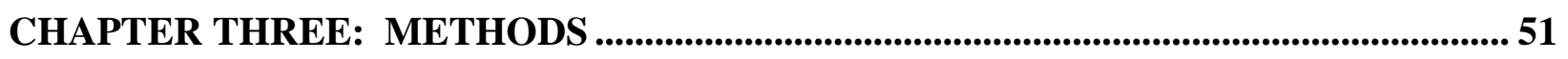

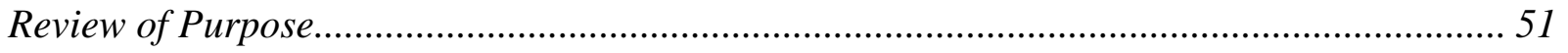

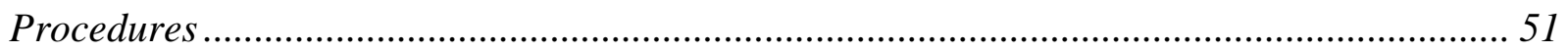

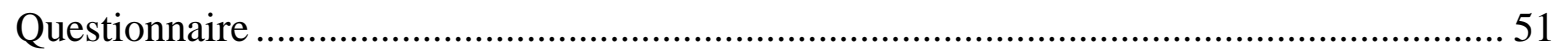




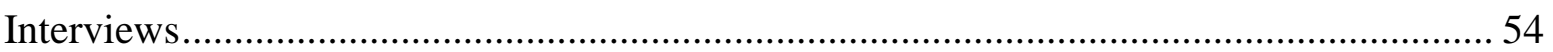

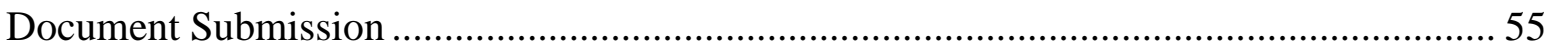

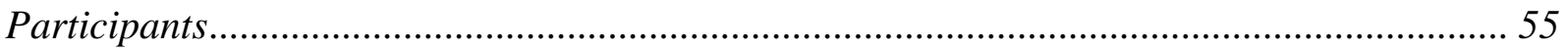

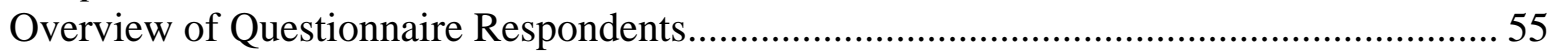

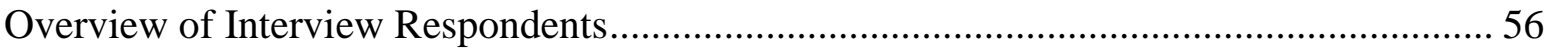

Overview of Documents Submitted ......................................................................... 58

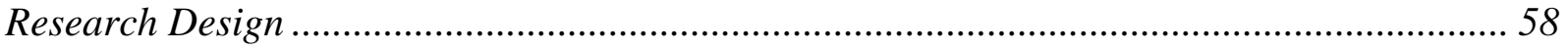

Data Analysis ...................................................................................................................... 59

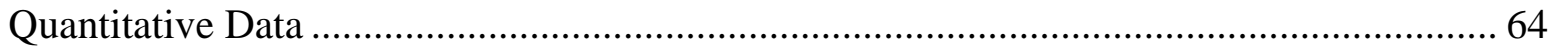

Research Question \#1 ............................................................................................ 64

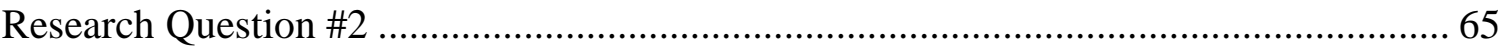

Research Question \#3 ........................................................................................... 65

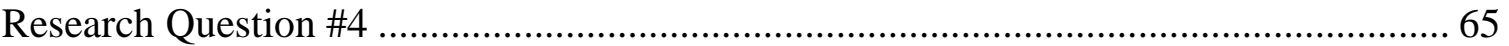

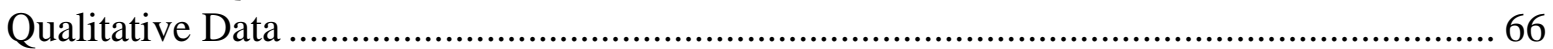

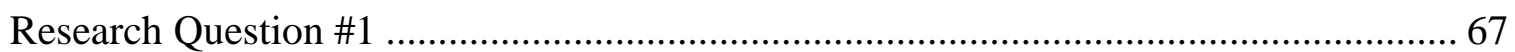

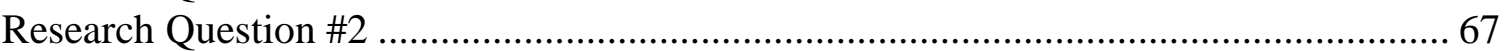

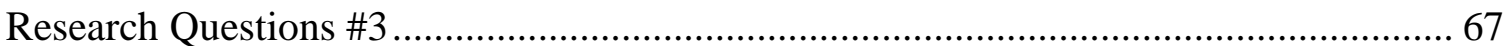

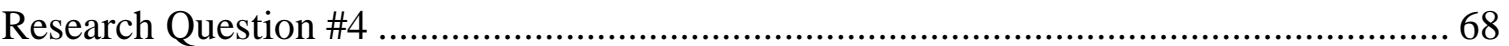

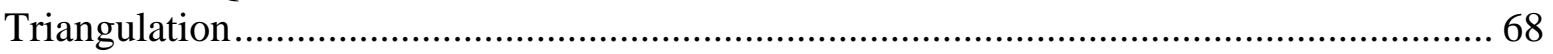

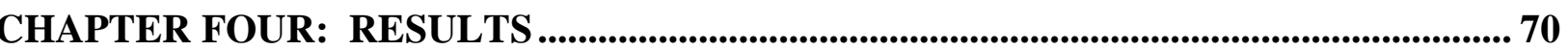

Research Question \#1 .......................................................................................... 70

Quantitative Bata...........................................................................................70

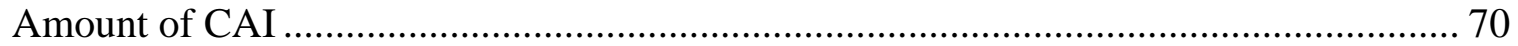

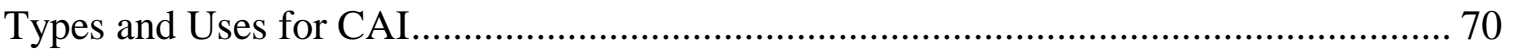

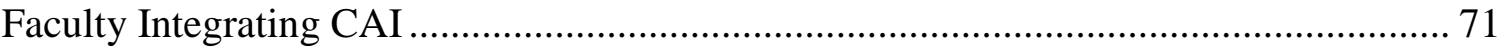

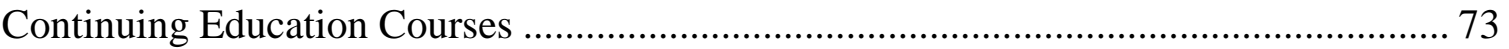

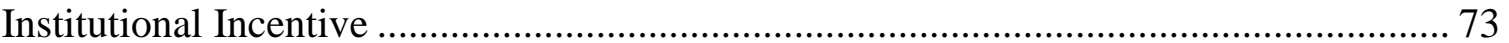

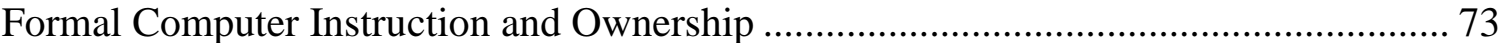

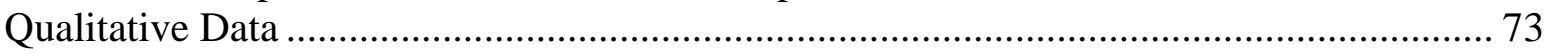

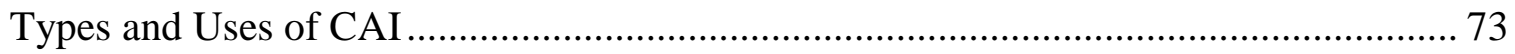

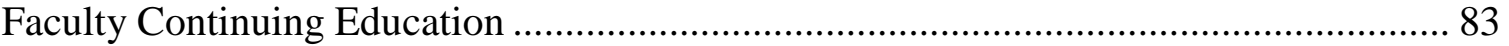

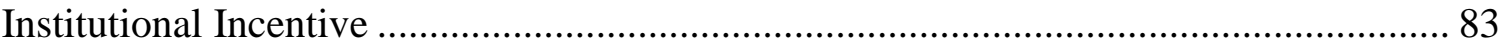

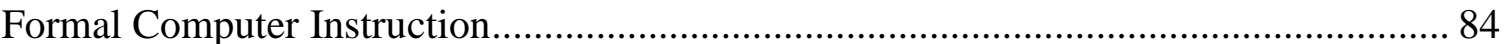

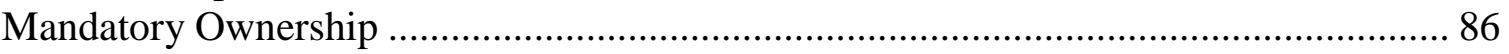

Research Question \#2 ........................................................................................... 87

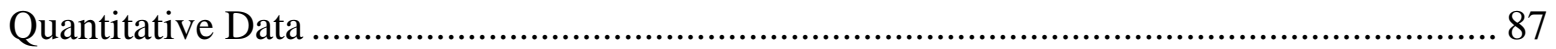

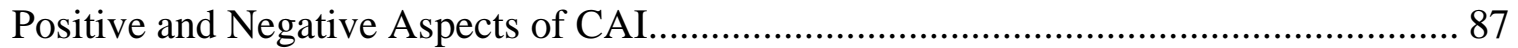

Type of Learning that Occurs with CAI ........................................................... 90

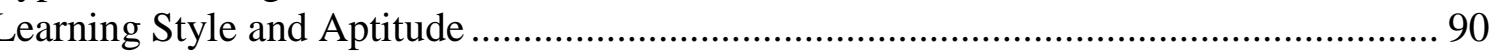

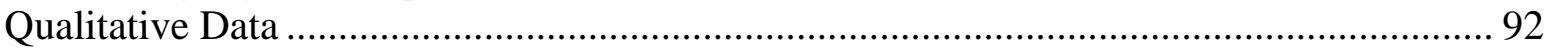

Positive Aspects of CAI................................................................................... 92

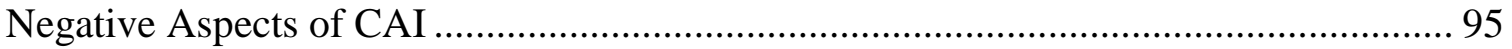

Overcoming Barriers Related to CAI .............................................................. 97 


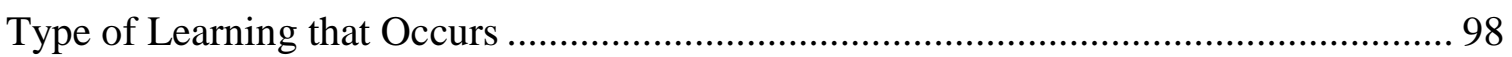

The Perceived Impact of CAI on Physical Therapy Education ................................... 101

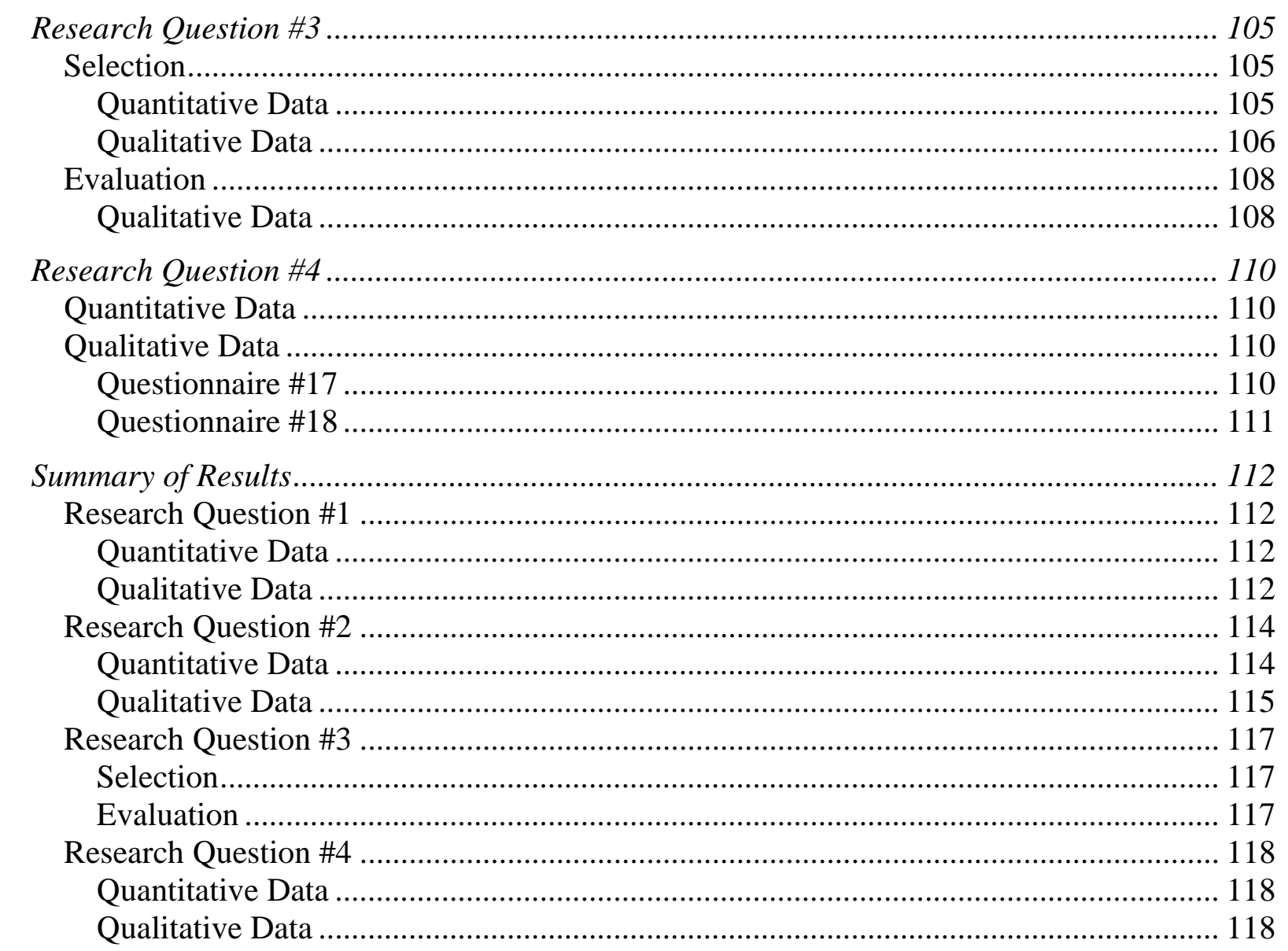

CHAPTER FIVE: INDUCTIVE ANALYSIS AND DISCUSSION....................................... 119

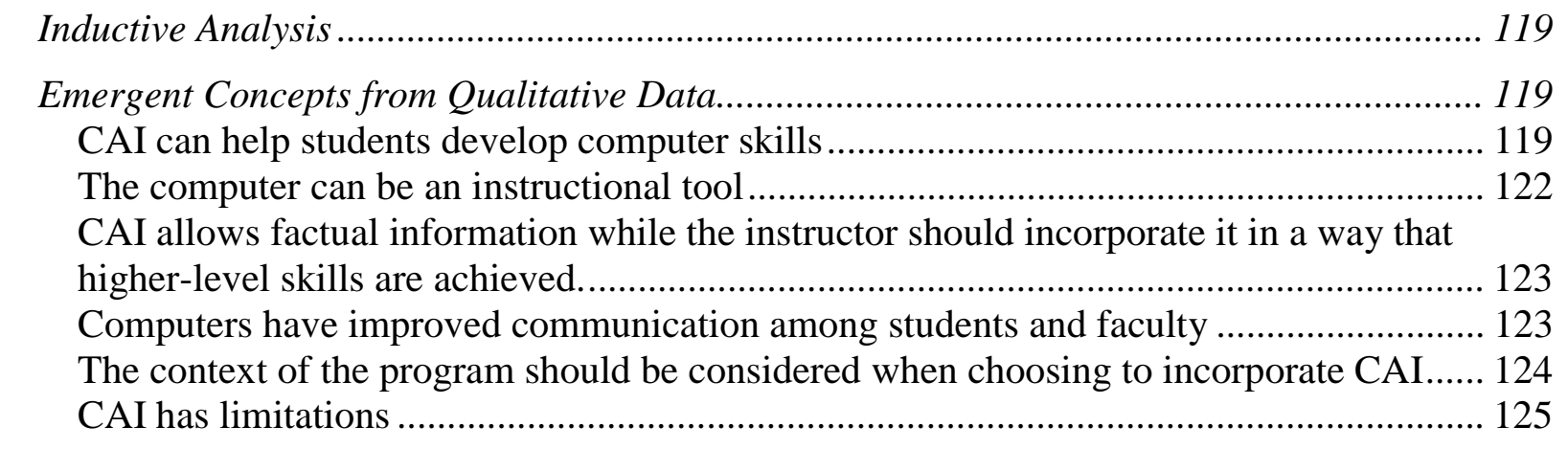

Methodological Triangulation of the Emergent Concepts................................................. 126

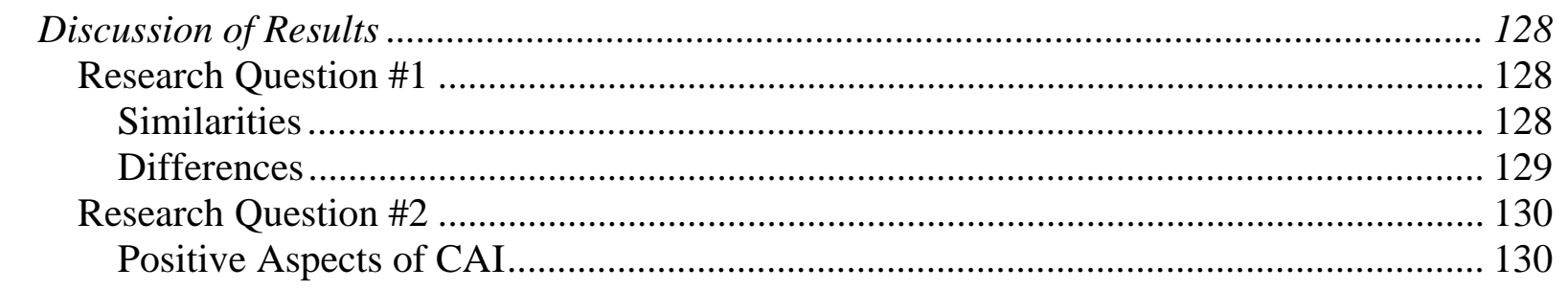




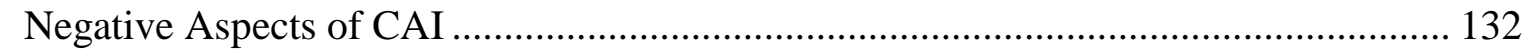

Type of Learning that Occurs with CAI ............................................................. 134

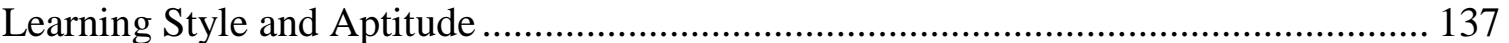

Perceived Impact of CAI on Physical Therapy Education ................................. 137

Research Question \#3 ........................................................................................ 139

Selection Criteria …................................................................................................. 139

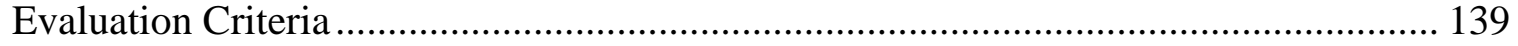

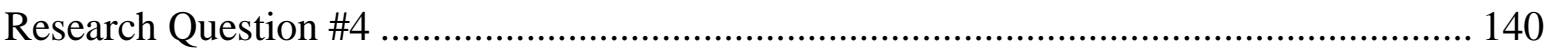

Programs Providing Adequate Preparation .................................................... 140

The Decision to Integrate Computers ............................................................ 140

CHAPTER SIX: IMPLICATIONS, FUTURE RESEARCH, AND CONCLUSIONS ..... 142

Imptications for Physicat Therapy Education ............................................................ 142

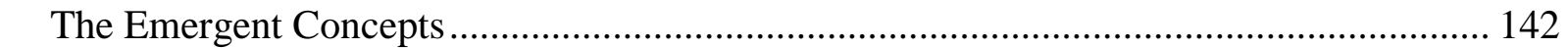

Selection, Learning Theory, and Instructional Design ...................................... 144

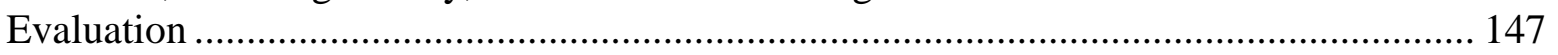

Future Research.......................................................................................... 148

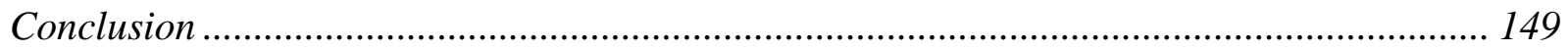

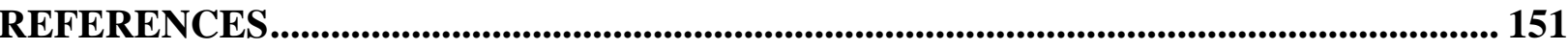

APPENDHXES ................................................................................................................................. 161

Appendix A Questionnaire ................................................................................ 162

Appendix B Table of Specifications .......................................................................... 166

Appendix C Interview Protocol.......................................................................... 169

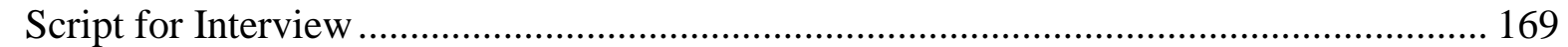

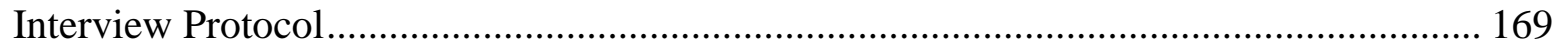

Appendix D Document Analysis Checklist.......................................................... 170

Appendix E Outline of Results ..................................................................................... 172

Appendix F Independent t-test ................................................................................ 175

Appendix G Type of CAI Matched by Content Area for PT and PTA Programs................... 176 


\section{LIST OF TABLES}

Table 2.1 Authors Examining the Effects of CAI and TI on Achievement, Retention, and

Attitudes...................................................................................................................................... 14

Table 2.2 Authors Examining the Effects of CAI when used as a Supplement to TI.......... 21

Table 2.3 Authors Examining the Sequencing Effects of CAI........................................... 25

Table 2.4 Description of Kolb's Identified Learning Styles................................................ 31

Table 2.5 Questions Asked During Evaluation of CAI...................................................... 45

Table 3.1 PT Program Interview Participants .............................................................. 57

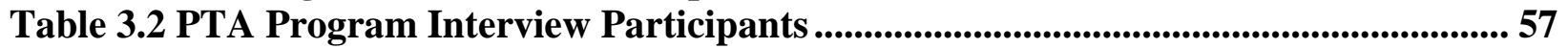

Table 3.3 Research Question \#1 Data Analysis.............................................................................6 60

Table 3.4 Research Question \#2 Data Analysis............................................................................ 61

Table 3.5 Research Question \#3 Data Analysis...................................................................6 62

Table 3.6 Research Question \#4 Data Analysis..........................................................................6 63

Table 4.1 Positive Aspects of CAI................................................................................. 88

Table 4.2 Negative Aspects of CAI ...................................................................................... 89

Table 4.3 Types of Software Purchased for PT and PTA Programs .................................. 106

Table 4.4 Instructional Software Selection Criteria for PT and PTA Programs and

Frequency of Responses .................................................................................................. 107

Table 4.5 CAI Evaluation Procedures for PT and PTA Programs and Frequency of

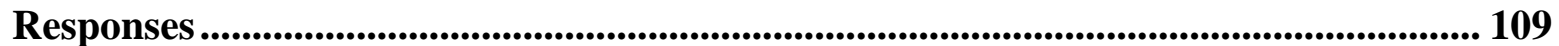

Table 4.6 Overview of Quantitative Results for Research Question \#1............................... 113

Table 5.1 Frequency of Appearance of Major Concepts in all Qualitative Data................. 120

Table 5.2 Particular Concepts Subsumed by More General Ones.................................... 121

Table 5.3 Methodological Triangulation .................................................................................. 127

Table 6.1 Data to be Collected During Educational Evaluation.............................................. 148

Table B.1 Research Question \#1 ............................................................................................... 166

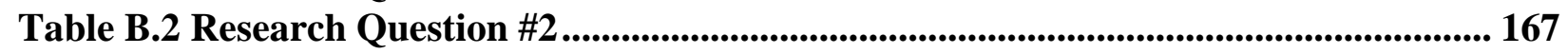

Table B.3 Research Question \#3................................................................................................... 168

Table B.4 Research Question \#4 .................................................................................... 168

Appendix F Amount of CAI Used in PT and PTA Programs $(t$-test) .................................... 175

Table G.1 Courses Matched with Type of CAI used in PT Programs (n = 85)................... 177

Table G.2 Courses Matched with Type of CAI used in PTA Programs $(n=116) \ldots . . . . . . . . . . . .178$ 


\section{LIST OF FIGURES}

Figure 4.1 Uses of CAI Reported PT and PTA Respondents ............................................... 72

Figure 4.2 Perceptions of Learning Styles That Benefit Most Using CAI........................... 91

Figure 4.3 Perceptions of Student Aptitude and Benefit of Using CAI ............................... 91 


\section{LIST OF SYMBOLS, ABBREVIATIONS, AND NOMENCLATURE}

$\begin{array}{ll}\text { CAI } & \text { Computer Assisted Instruction } \\ \text { WWW } & \text { World Wide Web } \\ \text { WBI } & \text { Web-based Instruction } \\ \text { TI } & \text { Traditional Instruction } \\ \text { CD-ROM } & \text { Compact Disc Read Only Memory } \\ \text { ANOVA } & \text { Analysis of Variance } \\ \text { MANOVA } & \text { Multivariate Analysis of Variance } \\ \text { ANCOVA } & \text { Analysis of Covariance } \\ \text { GPA } & \text { Grade Point Average } \\ \text { PSI } & \text { Keller's Personalized System of Instruction } \\ \text { PLS } & \text { Programmed Learning Sequence } \\ \text { Kolb's LSI } & \text { Kolb's Learning Style Inventory } \\ \text { GEFT } & \text { Group Embedded Figure Test } \\ \text { ARCS } & \text { Keller's ARCS Models: Attention, Relevance, Confidence, and Satisfaction } \\ \text { PT } & \text { Physical Therapist } \\ \text { PTA } & \text { Physical Therapist Assistant }\end{array}$




\section{CHAPTER ONE: INTRODUCTION}

Physical therapy is a profession that deals with human movement, restoration of function, and promotion of the highest level of health and wellness possible. Physical therapy education is based on a basic science background and includes both clinical sciences and physical therapy procedures. It also includes development of affective behaviors like professionalism, ethical behavior, and therapeutic communication. Educating individuals to practice physical therapy must include all three domains of learning. Cognitive skills are necessary to learn the substantial amount of material, including factual information and problem solving skills. Psychomotor skills are also important because individuals must be able to perform procedures like gait training, therapeutic exercise, manual therapy, and tests and measurements. Affective domain skills are needed because of relationships developed with patients who are often suffering from disease.

There have been a wide variety of educational methods and materials used in physical therapy education to increase knowledge, skills, and attitudes needed for the profession. These include problem-based learning, cooperative learning, case examples, videos, and more recently, computer-assisted instruction (CAI). CAI can be defined as using the computer to disseminate course information. CAI can range from computer-enhanced courses, that is, enhancement of a traditional course through instructional software or web pages, to distance learning, where all course information is provided through a medium such as televisions or the Internet. In higher education, there has been a recent trend to integrate more computers and online courses into existing programs. Yet educators are not convinced this means of instruction is superior to traditional methods. Also, there is some argument regarding the need for development of psychomotor and affective skills in physical therapy professionals. This argument surrounds an idea that CAI cannot provide these types of learning experiences. 
There are two individuals eligible to carry out physical therapy procedures. They are the physical therapist (PT) and the physical therapist assistant (PTA). The PT is either prepared through entry-level master's or doctoral training. Required courses for acceptance into a physical therapy program can take two to five years to complete, depending on the particular program. Some PT programs may even require the applicant to have a Baccalaureate degree. Prerequisites include intense, basic science courses in biology, chemistry, physics, math, statistics, anatomy, and physiology. Admission to PT school is competitive and requires high science and overall grade point averages. Once admitted, the physical therapy student completes two and one-half to three years of intense classroom and clinical work. This time is spent learning patient evaluation skills, therapeutic procedures, testing and measurement procedures, and affective behaviors. But, most importantly, the PT student learns to design a treatment plan based on patient impairments and functional limitations. The PT is responsible for all patient care decisions and for carrying out all patient evaluations.

The other individual, the PTA, is a technically trained individual, educated at the associate's degree level. The PTA carries out the physical therapy plan of care under the direction and supervision of the PT. The PTA may assist the PT in patient treatment and data collection, but does not make any interpretations regarding patient care. Also, any PTA decision to progress or change a patient's treatment must be stated within the plan of care. In addition, the PTA must realize when delivering a particular treatment is outside their scope and training, and they must also know when a patient should be seen by the PT for re-evaluation, or discharge.

PTA education is much different than PT education. PTA education can be completed in two years. The science consists of introductory biology courses, anatomy, physiology, pathology, and kinesiology. PTAs receive training focusing on carrying out physical therapy procedures 
such as therapeutic exercise, data collection, electrotherapy, and functional training. PTA education also includes development of affective behaviors like professionalism, ethics, and communication skills.

In summary, physical therapy education requires a blending of the three learning domains. Education to practice within the field must include knowledge, application, and affective behaviors. The difference between PT and PTA education is that PT students focus on "why" a particular treatment is performed, whereas PTA students focus "how" a treatment is performed. We need to determine a mechanism for educating PTs and PTAs that will be effective, consistent with the degree, and support the skills needed for competence in the profession.

\section{Problem Statement}

For the last five decades, physical therapy educators have attempted to develop methods for providing students with necessary knowledge and skills for the profession. Traditional instruction (TI) includes lecture, discussion, cooperative groups, and case studies. More recently, many allied health education programs have integrated CAI into existing curricula. Yet there is little evidence supporting this new means of delivery. In fact, Croft (1993) suggested that we consider the computer's value in providing an educational experience. He also suggests that we ask whether the computer is a more effective tool than less-costly instructional materials. Croft goes on to say unless the computer increases effectiveness and enhances meaning better than less-expensive tools, then it is "pointless to spend the money on it" (p. 302). With software availability increasing, we must pause to think about whether we really have a purpose for providing this type of learning experience, or if it is no more than another passing trend. 
Authors in both education and allied health fields have attempted to evaluate the efficacy of CAI through comparing student achievement, retention, and attitudes. Results indicate that CAI is at least as effective as TI. However, it is important to point out a potential ceiling effect. Allied health students must be high achievers in order to gain acceptance and be successful in their respective program. A study that finds no difference between CAI and TI should point out these students might do well no matter what type of instruction is used; thus indicating a strong selection bias in subjects who participated in many of the studies.

Additionally, there are some associate's degree level programs, such as PTA programs, that do not have the rigorous admission requirements, curriculum, or basic science foundation as these professional master's or doctorate degree level programs. There is no research that examines the effects of CAI in these associate degree level programs. In addition, there is no research that compares types and uses of CAI in PT education with that of PTA education.

The use of instructional technology in physical therapy education was reported in the literature as early as the 1970s. Earlier reports show that educators based the decision to integrate technology on increased medical information, increasing class sizes, and higher student teacher ratios (Bishop, 1970; Williams, Chalmers, \& Salter, 1982; Christie, 1990). Today, the decisions to integrate computers also include better technology, increasing access, and pressing institutional demands. Additional decisions to utilize computers today have evolved from society's demands for graduates to be computer literate, proficient in accessing information, and skilled in computer-based communication. While decisions to integrate computers are different today than three decades ago, problems remain the same. These include faculty training, time, cost, and rapid obsolescence of hardware and software. It would be interesting to determine how 
individuals are overcoming the negative aspects associated with CAI so that students attain the educational benefits from this type of instruction.

In addition, some authors have pointed out that students' learning styles have a significant impact on their performance when using CAI. Research has shown that students perform better when the learning style is matched with the type of delivery. However, most research regarding learning style has focused on Kolb's Learning Style Inventory, field dependence, and inductive-deductive approaches. Many educators have used yet a different approach to describe students' learning styles. This includes whether they prefer auditory, visual, or kinesthetic situations. Again, there is no evidence to support which type(s) of these learners would prefer CAI or have better educational outcomes with this type of instruction.

There are still other issues that remain unexplained specifically in terms of CAI used in physical therapy education. As pointed out earlier, physical therapy education requires a blend of the three learning domains: cognitive, psychomotor, and affective. Also, the educational process must develop problem-solving skills and make connections between basic and clinical sciences. There is little evidence that supports superiority of CAI in developing these higher-level thinking skills.

There is an abundance of literature that describes models to effectively design instructional software, and educational research has outlined benefits to having both a learning theory and sound instructional design. Authors have used behaviorism, cognition, and constructivism to bridge the gap between CAI and learning. Nevertheless, there is little evidence that supports faculty consideration of learning theory or instructional design when selecting, designing, or evaluating CAI. 
Finally, the recent trend in physical therapy education is for state licensing agencies to use computer-based licensing exams for both PTs and PTAs. Yet, there is no report in the literature of how CAI during the academic program influences students' scores on these computerized exams, nor is there evidence that a relationship even exists. It is interesting to point out that research evaluating computerized licensing exams and their influence on faculty decisions to integrate CAI does not exist.

\section{Research Questions}

After identifying gaps in the literature, several research questions emerge:

1. What are the similarities and differences in types and uses of CAI between physical therapist and physical therapist assistant education programs?

2. What are faculty's perceptions regarding:

a. the positive and negative aspects of CAI?

b. the type of learning provided with CAI?

c. the relationship between the benefits of CAI and learner attributes such as aptitude and learning style?

d. the overall impact of computers on PT education?

3. How are faculty selecting and evaluating CAI?

4. Do computer-based licensing exams influence faculty decisions to integrate CAI?

\section{Definitions of Terms}

Computer-assisted instruction (CAI)-the utilization of a computer to disseminate course information.

Computer-based instruction-instruction that occurs entirely by way of a computer 
Instructional Software-Software that includes didactic or laboratory content, used to disseminate information, provide review, or provide interactive patient simulation experiences

Patient Simulation-An opportunity for students to work with "fake" patients so that they are able to apply didactic material without harming or inconveniencing real patients

Web-based Instruction-Instruction that occurs entirely over the World Wide Web, without traditional classroom meetings. Web-based instruction is one example of computer-based instruction

Web-enhanced Instruction-Traditional classroom instruction that is supplemented by portions of course content and/or information that is posted to the World Wide Web. This can include things like the course syllabus, handouts, class notes, and/or exams.

Physical Therapist-An individual who provides services to individuals with impairments, functional limitations, and disabilities resulting from disease through use of exercise, mobility and functional training, modalities, and manual therapy techniques

Physical Therapist Assistant-A technically trained individual who provides physical therapy services under direction and supervision of a licensed physical therapist

\section{Limitations}

Although this study has important implications for CAI use in physical therapy education, limitations exist. First, results indicate similarities and differences between PT and PTA programs regarding the amount and types of CAI being used. However, it does not provide proof that one group would benefit more than the other.

Also, this study was designed to capture participant's perceptions of types of students benefiting from CAI (aptitude and learning style). Results do not indicate whether high or low aptitude students benefit more, nor do they determine what type of learning style benefits more.

The present study only describes the current perception of CAI in these terms.

Results also indicate physical therapy educators' perceptions of CAI and development of psychomotor and problem solving skills. It does not provide evidence that CAI is or is not effective in teaching these skills. Participant's uses of CAI for teaching psychomotor and 
problem solving skills are described through presentation of specific case examples. These case examples describe how PT and PTA educators relate psychomotor and problem solving skills to CAI.

Another limitation is that programs not using CAI may have decided not to respond to the survey. This would impact the average number of CAI being used in PT and PTA programs. Although this could have happened, I did receive surveys from respondents indicating they did not use any CAI, but still provided information regarding their perceptions. Also, some of these included information regarding their decisions as to why or why not to integrate CAI. 


\section{CHAPTER TWO: REVIEW OF LITERATURE}

The literature review provides an overview of CAI, including a brief historical perspective, primarily in medical and allied health education. It outlines the positive and negative aspects of CAI and how institutions have overcome obstacles for CAI integration. Also, this chapter provides a review of literature describing effects of CAI on achievement, retention, and student attitudes. The documented relationships between student aptitude and learning styles with CAI are also discussed and implications are made that CAI may affect different students in different ways. The literature review summarizes learning and instructional design theories that have been suggested for designing CAI. Also, methods of CAI evaluation are proposed, with specific examples included. Finally, advantages of computer-based testing are outlined, and a summary of research regarding the relationship of computer anxiety and test performance is discussed.

\section{Overview of Computer-Assisted Instruction}

CAI is becoming more popular in medical and allied health education. Due to the rapid increase in medical knowledge, research, and technology over the last 20 years, educators have been forced to change their teaching approaches. The computer's ability to manipulate and store large amounts of data stimulated an interest in its use for educational activities (Coggan, Hoppe, \& Hadac, 1984). With more disciplines integrating computers into clinical practice, Croft (1993) suggested that schools have a responsibility to teach students about their use, and in turn this might improve computer use in the disciplines and society.

Benefits of CAI in medical and health education have been widely reported. For example, Henry (1990) indicated that computers could manage information and deal with the problem of 
information growth. He also indicated that computers afford students ways to access information and decrease the amount of rote memorization associated with medicine and allied health professions. Additional benefits outlined by Henry include connectivity between basic and clinical sciences by the use of nodes and links, interactivity between students and the material, and promotion of lifelong learning. Chodorow (1996) reported that CAI increases communication between faculty and students, increases efficiency of learning, increases effectiveness of class time, and provides review sessions. Henry and Chodorow agree that computers also provide students with individualized learning experiences.

Regardless of the positive aspects of CAI that have been reported in the literature, authors have reported many negative aspects as well (Christie, 1990; Chodorow, 1996; Coggan, Hoppe \& Hadac, 1984; Friedman, 1996; Hoffer, 1986; Piemme, 1988; Rizzolo, 1990; Weiss, 1990). These problems can be categorized into cost, production, and integration.

First, the cost of new hardware, software, faculty continuing education, technical support, and computer facilities hinder institutions, programs, and faculty from integrating instructional technology. One author reported that in 1990, development of a single interactive videodisc used to teach orthopedic content to physical therapy students cost over $\$ 13,000$ and required approximately 500 hours to complete. The same author indicated that every one-hour of instruction required 100-150 hours of programming (Christie, 1990). In addition, the rapid obsolescence of computers can be burdensome to many programs and institutions due to costs for purchasing and updating hardware and software programs (Chin \& Horton, 1993; Chodorow, 1996; Friedman, 1996; Hoffer, 1986; Rizzolo, 1990; Weiss, 1990). Christie reported that since most software is sold in a read-only format, modification is limited. This further complicates the rapid obsolescence problem, since there is rapidly changing information in the medical field. 
Second, production and development of quality CAI materials are limited (Chin \& Horton, 1993; Coggan, Hoppe \& Hadac, 1984; Friedman, 1996; Piemme, 1988; Rizzolo, 1990; Weiss, 1990). For example, few faculty members have software design expertise, and there is little technical support for software and hardware applications. Lack of technical support; teacher anxiety; and lack of in-service training, facilities, and equipment provide additional reasons for why production of quality items is limited (Chin \& Horton). There is also some debate over whether development of CAI materials should be equal to that of research and publications in terms of promotion and tenure (Coggan, Hoppe \& Hadac, 1984; Piemme, 1988; Rizzolo, 1990). Furthermore, some CAI materials lack a sound instructional design, clear goals, and objectives. Therefore, students spend more time on program manipulation and less time on content (Coggan, Hoppe \& Hadac, 1984; Friedman, 1996; Piemme, 1988; Rizzolo, 1990). Finally, there are no gold standards for faculty to evaluate existing CAI materials (Friedman), and there is still little evidence that supports CAI being superior to traditional teaching methods (Coggan, Hoppe \& Hadac, 1984; Friedman, 1996; Garg, 1998; Rizzolo, 1990).

Probably the most important issue raised in the literature regarding CAI is curricular integration. One should ask whether the computer is enhancing and supplementing the existing curriculum, or if it is merely another requirement for both students and faculty. Some authors agree that when technology is not fully integrated into the curriculum, many students will either skip its important aspects, or not use the computer at all (Chodorow, 1996; Friedman, 1996). In addition, when technology is not fully integrated for skill acquisition and content delivery, faculty too will not see the importance of computer integration into the curriculum.

Authors have attempted to provide strategies for solving problems associated with CAI. (Friedman, 1996; Hoffer, 1986; Rizzolo, 1990; Weiss, 1990). These strategies include sharing 
costs with multiple institutions (Hoffer, Rizzolo), exploring alternative financial resources, providing faculty with continuing education, and providing technical support (Weiss). The idea has also been raised that faculty be provided with incentive for software or web page design equal to that of research and publication (Hoffer, Rizzolo). Another strategy includes educating faculty regarding production, learning theories, instructional design, and integration of computer applications into existing curricula (Friedman, Rizzolo). Finally, authors believe that faculty should focus educational efforts on objective research to substantiate the efficacy of CAI (Friedman, Hoffer, Rizzolo).

\section{Educational Effects of CAI}

\section{Achievement, Retention, and Attitudes}

Researchers have attempted to determine the efficacy of CAI in terms of student achievement, retention, and attitudes. Two meta-analyses indicated moderate effect sizes (.45 and .48) when comparing CAI with traditional instruction (TI), where TI was defined as classroom lectures, discussions, demonstrations, and laboratories (Cohen \& Dacanay, 1994; Liao, 1998). Both of these authors used effect sizes described by Glass et al (1986).

Cohen and Dacanay (1994) examined research in the field of nursing and reported an overall moderate effect size (.45) for achievement, measured by end-of-unit examinations. This effect size (.45) indicates a moderate between group difference between CAI and TI for achievement. Cohen and Dacanay indicated that $52 \%$ of this effect size could be determined by (a) whether the course was required and (b) the type of CAI used. For example, there was a larger effect size among classes that were electives than those that were required. They also reported larger effect sizes for interactive videos when compared to tutorials, computer managed 
instruction, and simulations. These authors reported no differences between CAI and TI when retention or student attitudes were used as dependent variables.

Liao (1998) compared studies in all areas of education and at a variety of age levels. He also reported a moderate effect size (.48) for student achievement. However, Liao indicated simulators were superior when compared to both interactive video and instructional multimedia with no difference between the two latter forms of instruction. Liao also reported that studies with less than 80 subjects had a much larger effect size (.78) when compared to studies with greater than 80 subjects (effect size $=.06)$. Results indicate that CAI might only effect achievement in small to medium sized groups. Liao (1998) did not report on retention or student attitudes for CAI.

Additional research comparing CAI and TI on student achievement, retention, and attitudes has produced mixed results (Table 2.1). Many authors have reported no significant differences in these outcome variables when comparing CAI with TI (Clark \& Raffin, 1992; Day \& Payne, 1984; Halloran, 1995; Kinney, Keskula, \& Perry, 1997; Mulligan \& Wood, 1993; Rasheed \& Cohen, 1990; Schmidt, Arndt, Gaston, \& Miller, 1991). Rasheed and Cohen compared the number of modules passed among dental hygiene students who used paper-based study guides and those who used computer-based study guides. Data collection occurred over one semester in two consecutive years, and the authors indicated no pre-existing differences between the two groups. Results showed no significant difference in the number of unit tests passed between the two groups. 
Table 2.1 Authors Examining the Effects of CAI and TI on Achievement, Retention, and Attitudes

\begin{tabular}{|c|c|c|c|c|c|c|c|c|c|}
\hline & \multicolumn{3}{|c|}{ Achievement } & \multicolumn{3}{|c|}{ Retention } & \multicolumn{3}{|c|}{ Attitudes } \\
\hline & $\begin{array}{c}\text { CAI }= \\
\text { TI }\end{array}$ & $\begin{array}{c}\text { CAI> } \\
\text { TI }\end{array}$ & $\begin{array}{c}\text { CAI }< \\
\text { TI }\end{array}$ & $\begin{array}{c}\text { CAI }= \\
\text { TI }\end{array}$ & $\begin{array}{c}\text { CAI> } \\
\text { TI }\end{array}$ & $\begin{array}{c}\text { CAI }< \\
\text { TI }\end{array}$ & $\begin{array}{c}\text { CAI }= \\
\text { TI }\end{array}$ & $\begin{array}{c}\text { CAI> } \\
\text { TI }\end{array}$ & $\begin{array}{c}\text { CAI }< \\
\text { TI }\end{array}$ \\
\hline $\begin{array}{l}\text { Day } \\
(\mathbf{1 9 8 4})\end{array}$ & $\mathrm{X}$ & & & & N/A & & & & $\mathrm{X}$ \\
\hline $\begin{array}{l}\text { Rasheed } \\
(\mathbf{1 9 9 0 )}\end{array}$ & $\mathrm{X}$ & & & & N/A & & $\mathrm{X}$ & & \\
\hline $\begin{array}{l}\text { Schmidt } \\
(1991)\end{array}$ & $\mathrm{X}$ & & & & N/A & & & & \\
\hline $\begin{array}{l}\text { Clark } \\
\text { (1992) }\end{array}$ & $\mathrm{X}$ & & & & N/A & & & $X$ & \\
\hline $\begin{array}{l}\text { Mulligan } \\
\text { (1993) }\end{array}$ & $\mathrm{X}$ & & & & N/A & & $\mathrm{X}^{\mathrm{a}}$ & $X^{b}$ & \\
\hline $\begin{array}{l}\text { Cohen } \\
\text { (1994) }\end{array}$ & & & & $\mathrm{X}$ & & & $\mathrm{X}$ & & \\
\hline $\begin{array}{l}\text { Napholz } \\
\text { (1994) }\end{array}$ & & $\mathrm{X}$ & & $\mathrm{X}$ & & & & $\mathrm{X}$ & \\
\hline $\begin{array}{l}\text { Halloran } \\
\text { (1995) }\end{array}$ & $\mathrm{X}$ & & & & N/A & & & N/A & \\
\hline $\begin{array}{l}\text { Kinney } \\
\text { (1997) }\end{array}$ & $\mathrm{X}$ & & & & N/A & & & N/A & \\
\hline $\begin{array}{l}\text { Liao } \\
(\mathbf{1 9 9 8})\end{array}$ & & & & & N/A & & & N/A & \\
\hline $\begin{array}{l}\text { Faux } \\
(2000)\end{array}$ & & & $\mathrm{X}$ & & N/A & & & & $\mathrm{X}$ \\
\hline
\end{tabular}

${ }^{a}$ whether or not the information was new or useful, whether CAI helped make decisions with actual patients, convenience, or recommendations to peers

${ }^{\mathrm{b}}$ interest, effectiveness, enjoyment, and desire for additional learning experiences 
Schmidt, Arndt, Gaston, and Miller (1991) compared two groups of students who were enrolled in an Introduction to Nursing Research course. One group took the course through CAI, and the other group received TI. Results indicated no difference in final grade between the two groups when attitude toward computers, satisfaction with course, age, grade point average, and pre-test score were used as covariates. These authors did not report relationships between covariates and the dependent variable (final grade in course), but a backward regression indicated age to remain longest, although it was not significant at the .05 level. They concluded their results affirm the effectiveness of CAI; however, it is interesting to note that when comparing final grade means of the CAI and TI group, the mean of the CAI group was $88.9 \%$ and the mean for the TI group was $90.3 \%$. Although this difference was not significant, a more appropriate conclusion would have been that the two methods are equally effective.

Kinney, Keskula, and Perry (1997) compared pre and post-test scores on a multiplechoice exam in physical therapy students after a unit on "Carpal Tunnel Syndrome.” Five students were in a CAI group, using Physical Therapy Patient Simulator software. The instructor gave the other five students the same case information verbally. Members of the latter group used role-play and lecture/discussion in addition to the verbal presentation. Results indicated that both groups significantly improved from the pre-test to post-test; however, there were no significant differences in test scores between the group that received CAI and the group that received TI. The interaction between the pre-post test changes and the instructional method were not significant. These authors concluded that the non-significant difference might have been due to low power (.20) because of the small sample size.

Some authors have examined student attitude toward CAI in addition to studying achievement variables (Clark \& Raffin, 1992; Day \& Payne, 1984; Halloran, 1995; Mulligan \& 
Wood, 1993). Early research suggests that students did not have favorable attitudes toward CAI. In 1984, Day and Payne reported that when CAI was used for one semester in a nursing health assessment course, there were no differences in test scores between groups receiving CAI and those receiving TI. Also, these authors reported that students showed a less favorable attitude toward CAI than TI, as reported on a Semantic Differential Scale. Day and Payne reported that students felt that the CAI was more useless, inappropriate, frustrating, slow, disturbing, exhausting, inconvenient, discouraging, and ineffective. Further, the majority of students wanted less or no CAI offered in this course. Negative attitudes toward computers may have been present because this study was conducted in the early 1980s. At that time, computers were not as widely accepted by students as they are today. In addition, the software may have been slow, unsophisticated, and non-appealing to the students, whereas today, this is not likely to be the case.

More recent studies have shown positive feelings toward computers (Table 2.1) (Clark \& Raffin, 1992; Halloran, 1995; Mulligan \& Wood, 1993). Clark and Raffin compared scores on a post-test between two groups of Respiratory Physiology students after one unit on Arterial Blood Gases. One group received TI (lectures and note-taking), and the other group received instruction through a CAI module. Their results indicated no significant difference in test scores between the two groups. However, the results did indicate that students in the CAI group rated their method of instruction higher in terms of organization, information, and enjoyment. These authors did not indicate how students were assigned to groups, and they did not report pre-test group differences. Mulligan and Wood (1993) compared scores of a role-play situation between dental students on a unit in Geriatric Dentistry, obtaining similar results to those of Clark and Raffin (1992). Mulligan and Wood matched participants by grade point average and then randomly 
assigned them to either the control group, which read articles on Geriatric Dentistry or the experimental group, which received CAI on the same topic. Results indicated significant achievement in areas of treatment points, critical errors, and treatment procedures used for both the experimental and the control groups when comparing pre-test and post-test scores. Results of a Multivariate Analysis of Variance (MANOVA) indicated no significant main effect for type of educational unit or interactions between pre-post test and type of educational unit. Mulligan and Wood asked the students to rate their experience with the assigned instructional method on nine positively worded Likert items. Students rated the CAI module significantly higher in terms of interest, effectiveness, overall enjoyment, and desire for additional learning experiences of a similar nature. There were no differences between the two methods in terms of convenience, recommendation to peers, amount of new or useful information provided, and improvement in patient care decision-making. A student rating CAI and TI equal in terms of decision-making has important implications for allied health education because most of the didactic content will be used for making patient care decisions. Results reported by Clark and Raffin (1992) and Mulligan and Wood concur that although there is no difference in achievement between the two methods of instruction, students show a more positive attitude toward the computer-assisted method.

Results of a study by Halloran (1995) also agree with results reported by Clark and Raffin (1992) and Mulligan and Wood (1993). Halloran compared exam scores between two groups of nursing students. She indicated there were no pre-existing differences in grade point average between the two groups. One group received CAI and questions that required keypads to answer, and the other group received TI including lecture, discussion, overheads, and oral questioning. Results of this study showed no significant differences in exam scores between the 
CAI group and the TI group. Halloran pointed out that scores of the CAI group did consistently increase between test one and test three. She concluded that initial scores by the CAI group might have been a result of "vampire video," which occurs when the method of presentation is so exciting that the content is overshadowed. Regardless of the non-significant differences between exam scores for the two methods, Halloran indicated that students felt CAI made class more interesting and organized, allowing them to focus on areas of weakness.

More recent evidence suggests that regardless of non-significant differences between the two methods of instruction on achievement variables, students show more favorable attitudes toward the computerized methods. Respiratory Physiology students found CAI more organized, informative, and enjoyable. Dental students found CAI more enjoyable and more interesting than TI, and they desired similar learning experiences. Nursing students found CAI more organized and interesting, and they reported CAI allowed them to focus on areas of weakness.

Nevertheless, there were no differences between CAI and TI for the dental students in terms of convenience, recommendation to peers, whether or not the information was new or useful, or whether the CAI helped make decisions with actual patients.

Although many articles have reported non-significant differences in achievement between CAI and TI, Napholz and McCanse (1994) found greater improvement in test scores in nursing students who used Interactive Video Discs (IVD) compared to those who received TI. The authors tested 65 students before and after four weeks of instruction with an IVD on Therapeutic Communication. Chi-square analysis indicated the IVD group had greater improvements in their pre-post test scores than the TI group. However, when comparing the group's retention, they found that no differences in post-test to re-test scores or pre-test to re-test scores for CAI and TI groups. These results indicate that although the CAI group did better 
initially, after a period of time, the two groups were equal. These authors felt this was important because the CAI group learned faster than the TI group.

In summary, most authors have reported no difference in achievement when comparing CAI and TI. In addition, these results suggest that students view computer-assisted methods more favorable than traditional methods. Nevertheless, a more recent study by Faux and Hughes (2000) indicates CAI was less effective than TI on achievement, and students showed less favorable attitudes toward CAI.

Faux and Hughes (2000) compared pre-post test scores of three groups of students after a Social Work History lesson. The TI group received lecture followed by discussion, and the Internet group read the material on the course's website and completed a worksheet. The combination (Internet and TI) group read the material on the course's website then participated in a discussion. All groups showed improvement on the post-test, but the group receiving TI scored higher than the other groups. Results from the qualitative portion indicated emerging themes regarding the Internet such as: lack of interaction, feedback, or auditory stimulation encouraging loss of attention. These authors concluded that using the Internet for instruction should be active, include auditory stimuli, and involve participatory interaction with the instructor.

Results of research by Faux and Hughes (2000) raise several issues. First, placing information on the Internet to be read is no more than asking the students to read a textbook or journal article. Second, with the possibilities for interaction using computers and the Internet, there should be no reason why this activity could not be incorporated. In addition, consideration should be given to the types of students in this study. Over half of the subjects were Social Work majors, and these students may be more interested in human relations and interactions rather than 
computers. These findings have important implications for allied health educators in that we must consider both interactivity and the importance of human relations when designing online and computer-assisted instruction.

While a comparison of CAI and TI has provided mixed results, one must consider research designs and variable implementation. First, only two authors reported reliability or validity of their test instrument. Kinney, Keskula, and Perry (1997) reported the test instrument was constructed systematically to maximize validity and was reviewed by experts. However, no reliability measurements were reported, which still allows one to question their instrumentation. Napholz and McCanse (1994), the only authors reporting a significant difference in favor of CAI, determined face and content validity through expert review. They also reported a KuderRichardson reliability coefficient of .81 .

Further, there may be problems with software design. Only two authors provided evidence that software was expert reviewed for content (Kinney, Keskula, \& Perry, 1997; Mulligan \& Wood, 1993), and only three authors described using learning theories in software design (Day \& Payne, 1984; Mulligan \& Wood, 1993; Rasheed \& Cohen, 1990). Day and Payne reported their software was divided into instructional units with objectives, learning resources, and test items. Rasheed and Cohen indicated that both computer and paper-based study guides were based on Keller's Personalized System of Instruction (PSI). Using PSI, students are selftaught through a self-paced, mastery oriented, proctored approach, and they use study guides to learn the material and only hear lectures occasionally. Mulligan and Wood reported their software was based upon the problem-oriented approach to learning described by Weed (1990), which outlines patient problems, needs, goals, and family concerns. 


\section{Using CAI as a Supplement to TI}

Authors have studied whether or not CAI is a more effective supplement to lecture than other methods like cooperative learning, small group work, or individual study (Table 2.2) (Boling \& Robinson, 1999; Gilbert \& Kolacz, 1993; Miller, 1998; Plack, 2000). In a study by Gilbert and Kolacz, 123 nursing students received a 30-minute lecture presentation on clinical calculations and then received 50 minutes of supplemental instruction. Supplemental instruction was provided through either a computer-based tutorial or small group interaction. The computerbased tutorial and small group review were based on Gagne's events of instruction (Gagne, 1988). Students were randomly divided into two groups based on the last four digits of their social security number. Test questions were developed by a group of content experts, thus establishing content validity, and these authors reported a reliability coefficient of .74 for the test instrument.

Table 2.2 Authors Examining the Effects of CAI when used as a Supplement to TI

\begin{tabular}{|l|c|c|c|c|c|c|}
\hline & \multicolumn{3}{|c|}{ Achievement } & \multicolumn{3}{c|}{ Attitudes } \\
\cline { 2 - 7 } & CAI=TI & CAI $>$ TI & CAI<TI & CAI=TI & CAI > TI & CAI<TI \\
\hline $\begin{array}{l}\text { Gilbert } \\
\text { (1993) }\end{array}$ & $\mathrm{X}$ & & & & N/A & \\
\hline $\begin{array}{l}\text { Miller } \\
(1998)\end{array}$ & & & $\mathrm{X}$ & & & $\mathrm{X}$ \\
\hline $\begin{array}{l}\text { Boling } \\
(1999)\end{array}$ & & & $\mathrm{X}$ & & $\mathrm{X}$ & \\
\hline $\begin{array}{l}\text { Plack } \\
(2000)\end{array}$ & & $\mathrm{X}$ & & & N/A & \\
\hline
\end{tabular}

Gilbert and Kolacz (1993) reported a relationship of .51 between scores on the post-test and grade point average (GPA), and therefore GPA was used as a covariate. Results of the analysis of covariance (ANCOVA) indicated no significant difference between the two types of 
supplemental instruction (CAI and small group review) when test score was used as the dependent variable. Gilbert and Kolacz conclude that random assignment to the supplemental instruction group might have affected the results because some students who may have selected the CAI tutorial could not do so.

There are two problems with this study. The authors indicate the CAI group was able to review in the two weeks following the supplemental instruction before the test. Yet the authors did not indicate if students who participated in the small group were able to review. Also, there was not a control group. This leaves one to question whether the 30-minute lecture presentation alone was enough to achieve the desired learning outcome.

Miller (1998) compared the effectiveness of Programmed Learning Sequences (PLS) using book and computer formats on student achievement and attitudes in a sonography class. Miller described PLS as a strategy that introduces content in frames, or discrete steps that can be learned without direct supervision of the instructor. After the TI, the students received supplemental material through book PLS, and then were given an achievement test. Students then participated in TI again but this time, it was supplemented with computer-based PLS. Results of this study indicated that students performed better after both types of PLS than after the TI alone $($ Effect size $=1.42)$. However, scores were higher after the book PLS than they were after the computer PLS (Effect size = 1.11). Students' attitudes were more favorable toward both PLS methods than they were toward the TI. But, students favored the book PLS over the computer PLS (Miller).

In a study by Boling and Robinson (1999), 115 physical education and athletic training students received a distance lecture in an interactive classroom on Heart Disease Risk Factors. Students were then randomly assigned to a group for supplemental instruction. Supplemental 
instruction groups were: an instructional multimedia (IMM) tutorial, a cooperative learning group, or an individual study group. These authors defined IMM as a type of CAI that uses digitally integrated text, graphics, photographs, animation, audio, and motion video in a userfriendly interface. Each group completed a pre-test and a post-test to examine achievement, and they completed a pre-questionnaire and a post-questionnaire to examine attitudes toward the specific method. Authors reported no initial between group differences as indicated by scores on the pre-test. Results of a 2 × 3 analysis of variance (ANOVA) indicated a significant main effect for learning activity. Tukey's post hoc test revealed the cooperative learning group scored better on the post-test than both the IMM group and the individualized instruction group. Also, there was a significant main effect for satisfaction. Results indicated the IMM group was more satisfied with the learning experience than were the other two groups. The interaction between test scores and type of learning activity was not significant. These authors suggest that high satisfaction with IMM may be due to learner control with navigation incorporated into the IMM tutorial not incorporated into the other groups. However, these authors suggest that free software navigation could have posed a problem with learner focus. These authors conclude that IMM should guide students in meaningful ways, while allowing some degree of learner control with navigation.

There are several design issues with this study that should be identified. First, the reliability coefficient for the test instrument was reported to be .66 , yet no validity for the instrument was reported. Further, the authors reported someone with five years experience in developing educational multimedia items developed the IMM tutorial, and then content experts reviewed it. Nevertheless, Boling and Richardson (1990) did not outline a specific learning theory or instructional design for the IMM tutorial. 
Plack (2000) compared four classes of physical therapy students' grades in an Anatomy Course over one semester for a two-year period (Manhattan Campus 1996 and 1997 and Long Island Campus 1996 and 1997). All groups received traditional lectures of anatomical material. Students at the Long Island campus then performed traditional cadaver dissection, and students at the Manhattan campus viewed slides, overhead projections, videotapes, computer software, and cadaver prosections. Students were compared on the basis of practical exams, written exams, and final grades. The author reported no difference in entry-level science and math GPA between students at the two campuses. Statistical analysis revealed no significant differences in the dependent variables (practical exams, written exams, and final grades) between the two groups with one exception. The author reported that in 1997, the Manhattan campus students scored significantly higher on written examinations than students from the Long Island campus. The author concluded that no significant differences exist between the two instructional methods. She also stated, "the use of CAI and prosections was as effective as the traditional lecture-dissection method of instruction in human gross anatomy" (Plack, p. 41).

The author stated that CAI and prosections were as effective as the traditional lecturedissection method; however, she stated in the methods that slides, overheads, and videotapes were also used in this group. In this study, there is an obvious bias toward the CAI and prosections. Perhaps it is actually a combination of all teaching methods including the slides, overheads, and videotapes that make this method of instruction as effective as the traditional lecture-dissection method.

\section{Sequencing CAI and TI}

While the above authors have attempted to determine the efficacy of CAI on achievement, other authors have studied the effects of CAI implemented before and after TI 
(Table 2.3) (Cohen, 1995; Froman, Hence, \& Neafsey, 1993). Froman, Hence, and Neafsey (1993) compared interactive videodisc (IVD) instruction and traditional lecture when the IVD

Table 2.3 Authors Examining the Sequencing Effects of CAI

\begin{tabular}{|l|c|c|c|c|c|c|c|c|c|}
\hline & \multicolumn{3}{|c|}{ Achievement } & \multicolumn{3}{c|}{ Retention } & \multicolumn{3}{c|}{ Attitudes } \\
\cline { 2 - 10 } & $\begin{array}{c}\text { CAI= } \\
\text { TI }\end{array}$ & $\begin{array}{c}\text { CAI> } \\
\text { TI }\end{array}$ & $\begin{array}{c}\text { CAI } \\
\text { TI }\end{array}$ & $\begin{array}{c}\text { CAI= } \\
\text { TI }\end{array}$ & $\begin{array}{c}\text { CAI> } \\
\text { TI }\end{array}$ & $\begin{array}{c}\text { CAI } \\
\text { TI }\end{array}$ & $\begin{array}{c}\text { CAI= } \\
\text { TI }\end{array}$ & $\begin{array}{c}\text { CAI> } \\
\text { TI }\end{array}$ & $\begin{array}{c}\text { CAI } \\
\text { TI }\end{array}$ \\
\hline $\begin{array}{l}\text { Froman } \\
(1993)\end{array}$ & & $\mathrm{X}^{\mathrm{a}}$ & & $\mathrm{X}$ & & & & N/A & \\
\hline $\begin{array}{l}\text { Cohen } \\
(1995)\end{array}$ & & $\mathrm{X}^{\mathrm{b}}$ & & & $\mathrm{N} / \mathrm{A}$ & & & $\mathrm{X}$ & \\
\hline
\end{tabular}

${ }^{\mathrm{a} C A I}$ implemented after TI in area of self-efficacy

${ }^{\mathrm{b}}$ CAI implemented after TI

was implemented before and after the lecture. Test scores were taken from a content test and a perceived self-efficacy test. These authors defined self-efficacy as the ability to put knowledge into practice. Validity and reliability were established for both test items. Participants were 68 nursing students, and the instruction was a single unit on Intravenous Therapy. Authors used a pre-test, post-test, delayed post-test design. A pre-test was given, then one group received the IVD instruction, and the other group received the lecture instruction, followed by post-test. The groups were switched, and the group that received the IVD instruction then received the lecture instruction and the group that received the lecture instruction received the IVD instruction. After the final type of instruction, a delayed post-test was given to the participants. No significant differences were found between the two groups at the pre-test. A 2 x 2 ANOVA revealed a significant main effect for time indicating improvement in scores for both groups from pre-test to post-test for both content and self-efficacy. Main effects for type of instruction (IVD or lecture) and interaction between time and type of instruction were not significant. The intervention 
sequence was not significant for either dependent variable. However, the interaction between the time and sequence was significant for the self-efficacy variable. Their results indicated that having lecture instruction before the IVD has the strongest influence on student perceptions of self-efficacy (Froman, Hence, \& Neafsey, 1993).

Results reported by Cohen (1995) support Froman, Hence, and Neafsey’s (1993) conclusion that TI should take place before CAI. Cohen implemented a CAI module before and after TI for anatomy and kinesiology of the elbow. The author used a pre-test, post-test experimental design. This author also allowed the students to rate their experiences with the CAI module. Results indicated no significant difference in post-test scores between the two groups when the CAI was implemented before the TI. However, when comparing the post-test scores of the two groups when the CAI was implemented after the TI, the CAI group had a significantly higher score than the control group. These results concur with the results of Froman, Hence, and Neafsey (1993) that CAI has a better effect on achievement when presented after TI. However, these authors did not indicate validity or reliability of the test items, nor did they discuss learning theory or instructional design of the computer software.

In addition to achievement, Cohen (1995) examined the students' attitudes in the experimental and control groups. He reported that students in the experimental group reported more favorable attitudes toward the activity than students in the control group. The experimental group rated the activity significantly higher in terms of clarity, interest, usefulness, would use again, visualization, lower waste of time, and less confusing. Responses from the open-ended items given by the CAI group included things like: visual, concise, self-paced, feedback, selftest, review, and new learning method. Learning detractors given by the CAI group included slow screen changes, narrow topic focus, difficulty using the mouse, redundant information, and 
hard on the eyes. Again, results of this study support earlier statements that students have favorable attitudes toward CAI.

Results of studies comparing CAI with TI on student achievement, retention, and attitudes have been summarized in Tables 2.1-2.3. Mixed results may be due to experimental design or statistical errors. Nevertheless, most authors agree that CAI is at least as effective as TI and that students show favorable attitudes toward CAI. However, it is important to realize that there may be a selection bias in many of these studies. For example, allied health students are generally high achievers, and there may be a ceiling effect. Their scores may be high already, so changes in instruction will not cause scores to show an additional increase. Also, these students may be successful regardless of the type of instruction used. It is also important to realize that some content may be better suited for CAI and thus may fare better in terms of achievement. Furthermore, some CAI modules are low on the cognitive domain hierarchy and emphasize rote memorization, or learning of factual information. This is important in allied health professional education, because many aspects of the educational program require psychomotor domain skills and higher-level cognitive skills.

\section{Learner Attributes and CAI}

As indicated above there may be evidence that supports CAI influencing different students in different ways. For example, Kinney, Keskula, and Perry (1997) suggest that students' learning styles might influence the educational outcome when using CAI. Halloran (1995) also suggested that CAI might appeal more to visual learners; whereas TI appeals more to auditory learners. In addition, Rasheed and Cohen (199) and Mulligan and Wood (1993) reported that CAI may differentially affect students with varying aptitudes. This section summarizes the 
literature pertaining to CAI, learning style, and aptitude. Also, comparisons across studies are made. This offers important information for CAI design and student use.

\section{Aptitude and CAI}

Controversy exists regarding the relationship between student aptitude and effectiveness of CAI (Rasheed \& Cohen, 1990; Mulligan \&Wood, 1993). Rasheed and Cohen reported that low aptitude students did equally well on the number of modules passed using paper and CAI study guides. Conversely, high aptitude students did significantly better when using the CAI study guides. These authors gave two potential reasons for this result. First, they suggest that paper-based study guides provide students with a hard copy of information to review at their convenience, while the CAI version does not. Any student wanting to review using the CAI version had to be motivated enough to go to the computer lab and repeat the exercise. These authors indicate that only a few students might be motivated to do this. Second, they conclude that CAI challenges the higher aptitude students and maintains their interest more than paperbased study guides, and this in turn leads to higher levels of achievement among higher aptitude students.

Mulligan and Wood (1993) also examined aptitude as a possible indicator of success with CAI. However their results do not agree with those reported by Rasheed and Cohen (1990). Mulligan and Wood report that students who performed poorly on the pre-test did better on the post-test when they were in the CAI group rather than in the control group. For example, in the CAI group, five students received a negative score on the pre-test, but on the post-test, after the CAI, all five of these students scored over 100 (mean change $=191$ points). However, in the control group, four students received negative points on the pre-test, but on the post-test only two 
out of the four scored over 100 (mean change $=134$ points). The other two still scored negative points. The authors did not attempt to explain why they thought this difference occurred.

When comparing the outcomes of these two studies, it is interesting to look at the content and testing methods used. Both studies used CAI to teach a type of clinical skill. However, Rasheed and Cohen (1990) compared written test scores, and Mulligan and Wood (1993) examined scores of actual skill performance. Rasheed and Cohen report that high aptitude students might benefit more from CAI, because they performed better on a written exam. Perhaps, it is not that higher aptitude students benefited more from the CAI, but rather they performed better on the written test because lower aptitude students are not good test takers (and hence they have been deemed low aptitude). Further, Mulligan and Wood indicate low aptitude students benefited more from CAI after examining the actual skill, or psychomotor performance. Maybe the lower aptitude students did better on the actual performance application, because it was determined to be more meaningful to them than taking a written test. We may need to consider CAI content, clinical application, and testing method when making a generalization regarding student aptitude and benefit of CAI.

\section{Learning Style and CAI}

Little research has been done in allied health education regarding learning style and CAI. But in other disciplines, learning style has been used to determine what students perform better with this type of instruction (Brudenell \& Carpenter, 1990; Carlson, 1991; Khine, 1996; Yoon, 2000; McClelland, 2001). In these studies, it is important to point out that authors have used several different ways to describe students' learning styles. Brudenell and Carpenter and McClelland used Kolb’s Learning Style Inventory (Table 2.4), Carlson used inductive and 
deductive descriptions of students' learning, and Khine and Yoon used field-dependence to describe students' learning styles.

Brudenell and Carpenter (1990) utilized a commercially available computer program for a nursing research course. The purpose of the study was to compare the relationship between learning styles and attitudes toward CAI. Forty registered nurses who were enrolled in the course completed the Attitude Toward CAI Semantic Differential Tool before and after the CAI. This tool includes 14 bipolar adjective scales and three subscales including, comfort, creativity, and function. Content validity and reliability have been established for this scale and reported in the literature. Students also completed a Kolb's Learning Style Inventory (1984) to identify their preferred learning style. Reliability and validity for this tool have also been documented.

At the post-test measurement, all participants had significantly less favorable attitudes toward CAI. Accommodators, convergers, and divergers demonstrated significantly more negative attitudes on the function subscale. Assimilators were more negative in overall attitude and on the subscales of creativity and function. There were no differences in learning style related to previous computer experience. These authors conclude that the negative attitudes were a result of (a) the software not being challenging enough, (b) no feedback provided for incorrect answers, and (c) no rationale for correct answers. Brudenell and Carpenter (1990) did not attempt to explain why certain attitudes were more likely to come from students with various learning styles. One would think that this has important implications for educational methods and designing instructional software. 
Table 2.4 Description of Kolb’s Identified Learning Styles

\begin{tabular}{|c|c|}
\hline Learning Style & Description \\
\hline Converger & $\begin{array}{l}\text { 1. Relies on abstract conceptualizations } \\
\text { 2. Strengths are problem-solving, decision making, and practical } \\
\text { application; prefers technical problems } \\
\text { 3. Does better with one correct answer }\end{array}$ \\
\hline Diverger & $\begin{array}{l}\text { 1. Relies on concrete experiences } \\
\text { 2. Strengths in imaginative ability and awareness of meaning and } \\
\text { values; views concrete situations from several perspectives; does } \\
\text { well in brain storming situations } \\
\text { 3. Prefers to observe rather than take action } \\
\text { 4. Person-oriented }\end{array}$ \\
\hline Accommodator & $\begin{array}{l}\text { 1. Relies on concrete experiences } \\
\text { 2. Strengths are carrying out plans and getting involved in new } \\
\text { experiences; works well where adaptation to changing situations } \\
\text { is required }\end{array}$ \\
\hline Assimilator & $\begin{array}{l}\text { 1. Relies on abstract conceptualization and reflection } \\
\text { 2. Strengths are inductive reasoning and ability to create theoretical } \\
\text { models }\end{array}$ \\
\hline
\end{tabular}

(Taken from: Kolb, D. (1984). Experiential learning: Experience as the source of learning and development. Englewood Cliffs, NJ: Prentice Hall. In: Brudenell, I. \& Carpenter, C. S. (1990). Adult learning styles and attitudes towards computer assisted instruction. Journal of Nursing Education. 29(2), 79-83.) 
More recently, McClelland (2001) evaluated the relationship between students' attitudes and perceptions of a web-enhanced Research Methods course using Kolb's Learning Style Inventory. Results indicated no association between learning style and

1. student's opinion on the website's enhancement to current teaching,

2. student's opinion that the Internet will eventually replace current teaching methods,

3. the interest and challenge students feel is given by the module, and

4. students' views on the appropriateness of the way the module is taught.

MacDonald and Caverly (1999) described math software (Basic Mathematics/PreAlgebra-Interactive Mathematics Series) that asks four questions that correspond with Kolb's accommodators, convergers, divergers, and assimilators. The questions are: "why", "another way", "show how", and "picture this." Although these researchers did not provide evidence of effectiveness or ineffectiveness with this software, they suggest that "little if any research supports the benefits of adapting instruction to fit learning styles. Rather it supports the differentiated instruction that software like this provides all learners" (MacDonald \& Caverly, p. 32).

Carlson (1991) evaluated the effects of matching learning style to type of instruction when developing students' observational skills. Fifty-three elementary teacher education students were classified into two groups based on learning style--inductive learners and deductive learners. Inductive learners were defined as students who wished to create their own concepts after considering the examples, and deductive learners were defined as students who wished to be told what to do with clear instructions. After eight hours of instruction, over a two week period, students were divided into four clusters: two clusters used small group instruction that 
entered data into the computer program and two clusters used the individual format to enter data. The individual group did have a peer manager to assist them with hardware problems. Within both the small group and the individualized format, the instructional design of one cluster was inductive, and the design of the other cluster was deductive. At the conclusion of the instruction, each student was given a content test, an observation skills evaluation, and an attitude inventory. The participants also responded to open-ended questions regarding the effectiveness of their experience. Validity and reliability were reported for the each test. The dependent variables were knowledge of content, observation skills, attitude toward control over pace and sequence of instruction, and overall satisfaction. The independent variables were format (individual and small group), instructional design (inductive and deductive), and match with learning style (match and unmatched).

Results of the MANOVA indicated that match and format had the greatest effect on the dependent variable. For match, there was a significant difference in scores on the observational skills assessment indicating that students with learning style matched to the type of delivery were better able to apply content to a specific situation. For format, significant differences were obtained for attitude and satisfaction. Students in the individual group felt they had more control over the program, while students in the small group were more satisfied than those in the individual program. There were no differences in content scores for the matched and unmatched participants. Responses to open-ended questions that regarded the experience as effective included: enjoyment of using new technology, working with peers, and enjoying realistic examples. Responses that regarded the experience as ineffective included: technical problems and lack of control and pace over the instruction. Carlson (1991) concluded that for these participants, the need for interaction was more important than learner control. Furthermore, the 
use of instructional multimedia is not enough to overcome barriers when students' learning styles are not matched to type of instruction. Finally, Carlson added that it is important to match learning style with type of instruction for improving achievement, developing observational skills, and developing a positive attitude toward the type of instruction.

Khine (1996) investigated the effects of feedback and learning style using an instructional multimedia (IMM) presentation. One hundred and five upper secondary students aged 15-20 participated in the study. Each participated in an IMM presentation on dinosaurs and then completed an on-line test. The student's cognitive style was determined as field-dependent or field-independent based on Group Embedded Figure Test (GEFT). Field independence has been defined as students being autonomous and favoring tasks that require analytical skills, and field dependence has been defined as students being influenced by authority figures and selecting tasks that require interpersonal skills. Scores on the GEFT were divided into thirds and only the two extremes were included in the analysis. The dependent variable was test score and the independent variables were type of feedback (no feedback, knowledge of results, and elaborative feedback) and cognitive style (field-independence and field-dependence).

Results of the 2 x 3 ANOVA indicated a main effect for feedback. Scheffe's post hoc analysis indicated a difference between no feedback and knowledge of results and between no feedback and elaborative feedback, but no difference between knowledge of results and elaborative feedback. Results also indicated a main effect for type of cognitive style. The fieldindependent students performed better with the IMM lesson than the field-dependent students. The interaction between type of feedback and level of field dependence was not significant (Khine 1996). 
Yoon (2000) used computer based drill and practice programs for teaching Korean elementary students math skills in low prior knowledge conditions. She compared post-test scores and time on task between different types of instructional control strategies (program control, learner control, and learner control with advisement) and types of cognitive style (fieldindependence and field-dependence). For low prior knowledge conditions, post-test scores and time on task indicated a significant main effect for control strategy and cognitive style. Also, there was a significant interaction between strategy and cognitive style. Students classified as field-independent scored better in learner-controlled situations where field-dependent students scored better on program-controlled situations. However, for high prior knowledge situations, students were not affected by their cognitive style.

In conclusion, there does not seem to be a relationship between learning style and CAI when using Kolb's Learning Style Inventory. However, Carlson (1991) points out that it is important to match the student's learning style, inductive or deductive, with the type of instruction. She indicates that instructional software does not improve the educational effect when the learning style is not matched with the type of delivery. Khine (1996) reports that fieldindependent students have more favorable outcomes than field-dependent students when using instructional software. Yoon (2000) indicates that field-independent students performed better in learner-controlled situations where field-dependent students performed better in programcontrolled situations. When considering instructional software, perhaps it is more important to identify whether students prefer an inductive or deductive approach, or whether they are fieldindependent or dependent rather than describing them using Kolb's Learning Style Inventory.

Many educators have used auditory, visual, and kinesthetic preferences to describe students' learning styles. Halloran (1995) suggests that CAI might appeal more to visual 
learners, yet there is no evidence to support this. In fact, there is no evidence to support whether students with auditory, visual, or kinesthetic learning styles would prefer or have better educational outcomes with CAI.

\section{Learning Theory and Instructional Design in Selection of CAI}

The integration of learning theory, instructional design, and CAI has become more popular in the last ten years. It is important to point out that some software materials may be better than others in terms of learning theory and instructional design, thus making them more effective educational tools. Mishra (1999) reported that designing software is a complex, interdisciplinary process and should include theory, domain, and technology. In addition, Koller and Frankenfeld (2000) reported instructional design techniques ensure that projects include a needs assessment, a goal and scope, an audience analysis, learning objectives, appropriate instructional strategies, an assessment plan, and formative and summative evaluations.

While some nursing and dental research has shown CAI used was developed according to an instructional design theory (Day \& Payne, 1984; Gilbert \& Kolacz, 1993; Mulligan \& Wood, 1993; Rasheed, \& Cohen, 1990), most disciplines do not provide evidence that software selection has any associated theoretical foundation. Other authors have also attempted to integrate learning theory and CAI (Bailey, 1996; Hardin, 1997; Hartley, 1999; Lawless \& Brown, 1997; Lee \& Boling, 1999; Shellnut, Knowlton, \& Savage, 1999; Sherry, 1998; Sponder \& Hilgenfeld, 1994; Yang, 1996). But, there is still no evidence that any one of these suggested theories is more effective than others when applied to CAI. 


\section{Behaviorism}

In the early 1970s, CAI was becoming more popular in medical and allied health professional educational programs. McGown and Faust (1971) reported that characteristics of CAI should follow principles of programmed instruction that included organization, activity, motivation, and individualization. These authors developed a drill and practice program for anatomy and kinesiology of the knee and found improvements from pre-test to post-test. This research is subject to scrutiny though because of the type of CAI used. It is unlike the type of CAI that is used today, so one should question the generalizability of these results.

In 1975, Mayor outlined steps for construction of a mastery-oriented approach for designing a computer module. He reported that a mastery-oriented teaching unit included: student motivation, student background, functional objectives, criteria for successful completion, a feedback system, opportunity for practice, consideration for length of module, appropriate sequence, consideration of presentation scheme, and a unit evaluation. Although this masteryoriented approach seems appropriate, this author did not provide evidence that this approach would lead to more effective educational CAI units. In addition, even though the mastery oriented approach may have been accepted in the seventies, the environment today has changed, so once again generalizability is debatable.

In 1994, Sponder and Hilgenfeld described a class used to instruct students in designing IMM. Their approach was based upon Bloom's Taxonomy and behavioral objectives. They outlined hierarchical levels of Blooms' Taxonomy (cognitive domain) and described multimedia activities that would be effective for knowledge, understanding, and application.

Hardin (1997) also described a method of designing software based on behavioral objectives and the Tyler Rationale. He reported four fundamental aspects in software design 
including: audience, objectives, methods, and evaluation. He described the importance of knowing your audience and setting goals and objectives for the lessons. He reported that the lesson should contain a broad goal and then contain more specific objectives that would enable the user to meet the broad goal. Like Sponder and Hilgenfeld, (1994), Hardin used behavioral objectives, but he also included affective and psychomotor domains of learning, as well as cognitive. Hardin also described various lesson types for software design including presentation, drill and practice, tutorial, games, simulation, asynchronous communication, and hypermedia. Hardin described different methods for evaluation of the students and the lessons. Although these authors provide logical frameworks based on learning theory and instructional design, neither author used their model to design software, nor did they attempt to evaluate existing software. Neither Sponder and Hilgenfeld nor Hardin provided evidence of how these models prove to be effective. Furthermore, this behavioral oriented approach has been scrutinized throughout the last three decades, and there is little evidence that this approach will lead to improved retention, knowledge transfer, or application.

\section{Cognition and Constructivism}

Authors have used cognitive theories to design and select CAI materials. Hartley (1999) described the Cognitive Load Theory as it relates to web-based instruction (WBI). He described cognitive load as things placing extra demands on the working memory, like content difficulty, instructional design, and distractions. According to Hartley, designers must reduce the amount of cognitive load placed upon students when developing WBI. Hartley also described terminology such as split attention (selectively attending to specific information), redundancy (presenting material in two different ways), the modality effect (simultaneously using different methods of delivery), the goal free effect (de-emphasizing the goal and emphasizing exploration), and 
providing worked examples (example problems that have been completed). Hartley applied these concepts to WBI, and gave ideal applications for using static and animated visual displays, audio, goals, and worked examples. Using the Cognitive Load Theory, this author suggested that static visual displays should not repeat, but present new or supplemental information. Also, animations should be used only to show spatial relationships; audio should replace, not repeat text; goals should be set by students rather than designers to allow free exploration; and finally examples should be either worked or partially worked to allow interactivity between the program and the learner. Regardless of the implications this model could have for CAI and WBI, Hartley did not validate it, nor did he use it to evaluate existing web pages.

There have also been reports in the literature where authors have used Keller's ARCS model to design instructional software. The Keller's ARCS model is based on four principles: attention, relevance, confidence, and satisfaction. Lee and Boling (1999) reported using this model for its appeal toward increasing motivation in students by the screen design. These authors reported that since student motivation is critical, the Keller's ARCS model is extremely useful in designing CAI.

Shellnut, Knowlton, and Savage (1999) applied the ARCS model to a CAI module for manufacturing engineering courses. Activities were adopted into each phase of the design and development was based on recommendations from Keller's model. For attention, they limited the amount of material on the screen and used visual displays where possible. Relevance was obtained by allowing students to choose the module they wanted to work through. Students were provided with instructional support, learning tools, and opportunities for self-check to increase confidence with the modules. Rewarding comments provided at the end of a correctly completed section allowed students to feel positive and satisfied about their work. Their module is still in 
the development phases and both content and instructional design experts have reviewed it. Although they reported there are areas for change, these authors are positive about the model and plan to test it when it is completed (Shellnut, Knowlton, \& Savage).

While some authors use cognitive theory to design CAI, other authors use constructivism to establish a framework for CAI software design (Bailey, 1996; Burgess, 1996; Lawless \& Brown, 1997; Sherry, 1998; Yang, 1996; Koller \& Frankenfeld, 2000). Constructivism emerged from the cognitive learning theory, and the two are complimentary to one another. While cognition emphasizes schema development, constructivism emphasizes the student's role in monitoring his or her own learning (Bruning, Schraw, and Ronning, 1999). Bruning, Schraw, and Ronning define constructivism as an individual's learning and understanding being constructed through their own mental processes and social interaction. Authors suggest the constructivist approach stresses the notions that the learner is active, interactive, and in control. Further, it is representative of real world situations and allows adequate resources for problem solving and associative, or relational thinking. Proponents of applying constructivism to CAI suggest the learner constructs his own meaning, and therefore this approach empowers learners to take initiative, develops flexible thinking, encourages independent thought, and increases motivation. (Burgess, 1996; Yang 1996; Koller \& Frankenfeld, 2000).

Lawless and Brown (1997), Sherry (1998) and Mishra (1999) discussed the rationale for using the constructivist's Cognitive Flexibility Theory for designing CAI modules. These authors point out the usefulness of this theory because of it's flexibility, context-sensitivity, and ability to provide multiple representations of complex issues. For example, Lawless and Brown and Sherry reported that the nature of the subject should define the linearity or non-linearity of the module design. Subjects like history, with an ill-defined regimen should use a non-linear method for 
allowing students to explore concepts. This would allow students to explore multiple perspectives often common with the discipline. On the other hand, in subjects that are well structured, such as math, students should follow a linear pathway in the module, so that important, fundamental information is not lost due to non-linearity of the module.

Yang (1996) suggested ways the constructivist approach could be integrated into CAI. She summarized attributes of "hypermedia" in that it (a) includes networks of ideas created by nodes and links, (b) creates a multimedia information environment, (c) supplies non-linear access to information, (d) controls information through interactivity, and (e) integrates both format and access into programs. Yang also discussed both applications and properties of "constructive hypermedia", as well as the contribution of "constructive hypermedia" to learning. She concluded that the ability to link networks provides a multi-layered information base and allows deeper processing. In addition, she stated that hypermedia allows both synchronous and asynchronous conversations with resources within the learning community.

Bailey (1996) outlined six constructivist principles for designing instruction that have been found in the literature. She reports that by using these principles with technology, students and teachers can become involved in the process together, thereby stimulating further interest. The six principles are:

1. Set the stage, but have the students generate the knowledge.

2. Anchor the knowledge in authentic situations and activities.

3. Use the cognitive apprenticeship methods of modeling, scaffolding, fading, and coaching to convey how to construct knowledge in authentic situations and activities.

4. Situate knowledge in multiple contexts to prepare for appropriate transfer to new contexts. 
5. Create cognitive flexibility by ensuring that all knowledge is seen from multiple perspectives.

6. Have the students collaborate in knowledge construction.

Lawless and Brown (1997) discussed using the constructivist's approach and learner control with CAI. Using this approach, the learner is able to explore and make connections between content independently, and by increasing learner control, learner satisfaction and interest also improves. Hsin and Brown (1995) suggested that learner-controlled situations were superior to program-controlled situations in improving, displaying a more positive attitude toward, and feeling more confident in novel procedural task performance. Boling and Richardson (1999) also indicated that students using CAI that allows independent navigation (i.e. learner control) were more satisfied with the lesson, however in this study, students did not perform as well on a written post-test.

Lawless and Brown (1997) point out the importance of background knowledge with learner control. They gave specific examples of research where learner control mostly benefits students who already have a good background of information in that area. Further, they report that students with no background information may actually become confused with learnercontrolled approaches, and leave out important information. Gay (1986) also reported that students with low conceptual knowledge scored significantly lower in learner-controlled situations. She suggests that students with low conceptual knowledge did not know which areas to emphasize and had difficulty determining how much time to spend on various sections. In addition, she concludes that students with low conceptual knowledge use poor sequencing decisions in learner-controlled situations. 
While authors have suggested that background knowledge influences learning in learnercontrolled situations, Hsin and Brown (1995) indicated no significant difference in performance when comparing amount of prior knowledge and amount of learner control on a similar but different procedural task. Furthermore, Yoon (2000) reported that in low prior knowledge situations, students who demonstrate field-independent qualities might be more successful in a learner-controlled situation.

There seems to be conflicting evidence regarding background knowledge requirements and the importance of using the constructivist, learner-control approach with CAI. Yoon (2000) concluded that mixed results might be due to differences among student's level of field dependence (field-dependent or field-independent). Mixed results may also be due to whether achievement will be measured (via task performance or through written exam), the type of material presented, and the goal of the instruction. Some material may be better suited for a learner-controlled approach than others. Therefore, teachers must consider the material, the goal of the instruction, the type of assessment, and prior knowledge when selecting software.

\section{A Theoretical Continuum}

Sherry (1998) reported using a "theoretical continuum" as a framework for teaching educators how to design instructional software (p. 3). This approach accounts for the entire teaching-learning continuum. Sherry reported three phases of teaching software design. In the first phase, subjects were exposed to basic concepts. This established foundational information and allowed all learners to be at the same level regarding the topic. In phase two, "cognitivist 'notions' were integrated into the course through the use of a modified version of Reigeluth's Elaboration Theory" (p. 4). The elaboration theory is where students are given a simple concept and then asked to elaborate on it with specific examples. In this phase, students analyzed 
modules to discover applications of specific principles. Phase three included the constructivist approach where the students became more integrated into the actual development process, and students were also asked to reflect upon their work. This model was applied to a group of teacher education students, and the results indicated that it effectively increased intellectual curiosity, satisfaction, awareness of collaboration, and depth of understanding.

Existing research integrating learning theory, instructional design, and CAI focuses largely on instructional software, such as CD-ROMs, interactive videodiscs, and simulation software. However, CAI can also include Internet activities, such as interactive web pages and online instruction. Some of the above learning theories and instructional design principles could be applied to these Internet activities as well.

\section{Evaluation of CAI}

Evaluation of CAI has included pre-post test designs, pre-post and delayed-post test designs, student attitude questionnaires, and teacher questionnaires. However, these summative evaluation methods have not produced adequate evidence to support the efficacy of this type of instruction, nor do they provide insight to the learning processes students undergo with CAI. Further, these methods may not provide a gold standard for evaluation if (a) statistical and research design flaws exist, (b) learner attributes are unaccounted for, or (c) there is lack of an underlying learning theory or instructional design. In order for educators to prove CAI effectiveness, there must be adequate evaluation methods.

Authors have reported that evaluation is a necessary component of CAI integration. English, Harrison, and Hart (1998) reported that outcomes data must be used to support faculty decisions regarding continuing, expanding, and modifying CAI initiatives. McNaught (1999) indicated that evaluation should be an important part of the planning and teaching process. She 
also advocated for both formative and summative CAI evaluations that are constructed from a variety of quantitative and qualitative sources. These sources include review by experts, student observation, think aloud videos, investigation of options, review with educational theories/models, reflection, application of total quality management principles, logging, interviews, performance testing, and questionnaires. She reported a strong link between content, design of CAI materials, and student learning, and therefore, evaluation should reflect these three variables. McNaught reported on her experience using this type of evaluation process and showed how data generated allowed for useful decision-making regarding CAI.

Kaufman and Lee (1993) also reported that evaluation should be both formative and summative. These authors advocated using Stake's dimensions of evaluation classification: formative or summative, product or process, descriptive or judgmental, preordained or responsive, internal or external. Questions asked during the evaluation process reported by McNaught (1999) and Kaufman and Lee are reported in Table 2.5.

\section{Table 2.5 Questions Asked During Evaluation of CAI}

\begin{tabular}{|l|l|}
\hline McNaught (1999) & $\begin{array}{l}\text { Evaluation Questions } \\
\text { 2. How can the usability be improved? } \\
\text { 3. What instructional transactions or interactions are available to } \\
\text { learners? } \\
\text { 4. What types of learning outcomes are addressed? } \\
5 . \text { To what extent does the design of the material reflect }\end{array}$ \\
\hline
\end{tabular}




\section{Table 2.5 Questions Asked During Evaluation of CAI}

\begin{tabular}{|c|c|}
\hline & Evaluation Questions \\
\hline & $\begin{array}{l}\text { articulation among objectives, instructional transactions, and } \\
\text { assessment? } \\
\text { 6. How are materials used by different types of learners in } \\
\text { different contexts? } \\
\text { 7. What types of learning outcomes are accomplished by } \\
\text { different types of learners? } \\
\text { 8. What are the attitudes express and approaches adopted by } \\
\text { different types of learners? }\end{array}$ \\
\hline Kaufman and Lee (1993) & $\begin{array}{l}\text { 1. How well does the program meet its learning objectives? } \\
\text { 2. What were the perceptions and opinions of students about the } \\
\text { following aspects of the program: content, presentation, } \\
\text { technical aspects, and support materials? } \\
\text { 3. What were the students' experiences while working through } \\
\text { the program? } \\
\text { 4. What were the perceptions and opinions about the program of } \\
\text { experts in particular areas? } \\
5 \text {. What improvements need to be made to various aspects of the } \\
\text { program, such as hardware, software, and design? }\end{array}$ \\
\hline
\end{tabular}


Abdullah (1998) and Branch, Kim, and Koenecke (1999) suggested ways teachers could evaluate Internet resources. These evaluation criteria emphasize both instructional and web page design, accuracy of information, bias, level for audience, relationship to purpose, depth and breadth of content, gaps in content, activities of the site, sequence of information, links, and references. It is however interesting to point out that these existing evaluation criteria do not include the type of learning (factual, understanding, or application), learning strategies (memorization, rehearsal, etc.), or learning theory (behaviorism, cognitive, etc).

\section{Computer-Based Testing}

Over the last five to ten years, more disciplines have started using computerized licensing exams. Advantages to this method include increased access to testing centers, immediate feedback, decreased costs related to scoring, improved test items through the addition of graphics, and increased flexibility by allowing testing at various times of the day and days of the week. Data can also be gathered from computerized tests not available on paper tests. For example, the time it takes an examinee to answer a question and the number of times returned to an item can both be monitored via computerized testing. Also, establishing and updating databases can readily be accomplished through computer-based testing.

Both equivalency and computer anxiety have been examined when comparing computerized exams to paper exams (Wise \& Plake, 1990; Dillon \& Clyman, 1992; Bugbee, 1996). Dillon and Clyman compared traditional multiple-choice questions with computer-based multiple-choice questions among medical students in obstetrics and surgery. They found a high correlation in students' scores for the paper and computerized tests (.99). However, they also found a large difference between mean test scores when comparing paper and computerized results. A statistical test was not performed to determine whether a significant difference existed 
between means. Regardless of the high correlation, these authors report that because of the large mean difference in scores; computer and paper-based tests should not be viewed as equivalent. Wise and Plake also indicated computer and paper-based should not be viewed as equivalent unless certain psychometric properties exist. They suggested that rank orders of scores, means, dispersions, and shapes of score distributions should closely approximate one another.

Computer anxiety and test performance have also been studied. There is conflicting evidence regarding the relationship between test and computer anxiety, student computer use, and success on computerized exams. Wise and Plake (1990) reported there is no evidence to suggest that either variable influences the others. More recently, a literature review by Bugbee (1996) indicated a higher level of anxiety with the computer-based method than the paper-based method. Also, Bugbee reported that students with more computer experience had a less negative attitude toward computer-based testing. However, more experience did not increase the likelihood that a student would select a computer-based test over a paper-based test. He concluded that test anxiety, computer anxiety, and computer experience might all affect the test taker. Bugbee went on to say that:

As the world becomes more computer-oriented, so does testing. It is not unreasonable to expect that although test anxiety will never disappear, computer (based) test anxiety could become extinct in the near future with increased computer knowledge and comfort...Computerized testing is in ascendancy, especially in distance education, certification, and licensure, and will probably eclipse paper-and-pencil testing in the near future (p. 289).

Studies reported here are from a time when computer use was not as well accepted as it is today, and there is no recent research in any allied health profession that examines the 
relationship between computer anxiety and performance on the computer-based licensing exam. In physical therapy, most states have a formal, licensing examination process for both physical therapists and physical therapist assistants. Of these, many offer the exam via computer. These licensing exams will become more advanced as technology improves. For example, in the next one to two years, graphics, including photographs, videos, and motion clips will be integrated where computerized exams are given. Regardless of these innovations with the licensing exam, there is no evidence that physical therapy education provides students with strategies to be more comfortable with computers, in turn decreasing anxiety associated with this mode of testing.

\section{Summary}

There has been an extensive amount of research done regarding uses of CAI in the allied health professions and in other disciplines as well. Authors have evaluated CAI in terms of achievement, retention, and attitudes with mixed results. Furthermore, authors have attempted to determine the effects of CAI when combined with other variables like learning style and aptitude. Models for CAI design that are based on learning theories have been introduced, and evaluation procedures have been suggested. Finally, advantages of computer-based testing are well documented, yet anxiety with this mode of testing might interfere with performance. Information obtained and synthesized in this literature review has important implications for implementation of CAI. Several conclusions can be drawn based on current research, including the following points:

1. Students have shown favorable attitudes toward CAI.

2. CAI can be an effective supplement to TI.

3. CAI has a more positive effect on achievement when combined with and presented after TI. 
4. Because of interactions found when comparing CAI and TI with varying types of instruction, learning style, and aptitude, it is obvious that CAI may not be appropriate for all students, and therefore, CAI should not be the only form of instruction used.

5. Integration of CAI has the potential to increase comfort with computers and decrease computer anxiety during testing. 


\section{CHAPTER THREE: METHODS}

\section{Review of Purpose}

The primary purpose of this study was to compare and contrast types and uses of CAI in physical therapist (PT) and physical therapist assistant (PTA) education. Additional aspects of CAI were also examined, and therefore secondary purposes were:

1. describing faculty perceptions of: positive and negative aspects of CAI; the type of learning that occurs; learning style; aptitude; and the overall impact of CAI on physical therapy education;

2. describing how faculty select and evaluate CAI; and finally

3. determining if computer-based licensing exams have influenced faculty decisions to integrate CAI.

\section{Procedures}

\section{Questionnaire}

A questionnaire to determine the types and uses of CAI in physical therapy education was developed based on the available literature. An expert in testing and measurement procedures, one PT program director, and one PTA program director reviewed the questionnaire. To further assure content validity, the questionnaire was pilot tested during the spring of 2001 with an additional 25 PT and 25 PTA programs. The questionnaire included a statement asking for feedback on unclear items and format. Committee members further reviewed the questionnaire at the Prospectus Defense, and changes were made to reflect feedback from all individuals. The final questionnaire can be found in Appendix A.

The questionnaire was used to collect the following data: 
1. types of CAI used (i.e. internet, CD-ROM)

2. content area where CAI is used (i.e. Anatomy, Procedures)

3. uses of CAI (i.e. tutorials, testing)

4. perceptions of positive and negative aspects of CAI

5. number of faculty using CAI

6. recent software purchases

7. faculty designing CAI

8. selection criteria and methods of evaluation

9. faculty continuing education in the area of CAI development and implementation

10. institutional incentive for CAI development and implementation

11. computer prerequisite courses

12. formal computer instruction provided within the program

13. ownership policies

14. perception of CAI in relation to learning styles and aptitude

15. perceptions of the relationship between CAI and the computer-based licensing exam

16. strategies used to overcome barriers associated with CAI

17. the overall impact of CAI on physical therapy curriculum

18. licensure exam pass rate

Both open and closed-ended questions were used on the questionnaire. Closed-ended questioning uses a deductive approach based on answers the researcher thinks the respondent might give according to preconceived theories or evidence found in the literature. Closed-ended questions included six multiple-choice items and ten yes-no items. Closed-ended questions elicited information regarding how CAI is being used, positive and negative aspects, number of 
faculty integrating, recent software purchases, development of CAI materials, CAI continuing education courses, institutional incentive, formal computer instruction, ownership policies, student learning styles and aptitude, and board exam influence. The questionnaire also contained a table that allowed the respondents to match the type of CAI with the content area of physical therapy education where it is being used.

Open-ended questioning was also used. Open-ended questions were particularly important because data that emerged from open-ended questions may not have been captured in closed-ended questioning, thus losing potential effects of the research. These were developed based on the qualitative paradigm, as described by Patton (1990). The ten yes-no items included a line where the participant could explain his or her answer. These yielded open-ended explanations. An additional five open-ended items elicited information regarding the overall impact of computers on PT and PTA education, selection and evaluation criteria, reasons for integration, and how schools overcome barriers associated with CAI integration. See Table of Specifications, Appendix B, for categorization of questionnaire item by research question.

The schools and names of program directors for PT and PTA programs, accredited by the Commission on Accreditation in Physical Therapy Education (CAPTE), were taken from the American Physical Therapy Association's website (www.apta.org. Program directors were selected because of their knowledge of CAI in their respective programs. Each questionnaire was coded with a number, and the researcher kept a master list that matched the school with the number. Three hundred and eighty-nine surveys were mailed $(\mathrm{PT}=162 ; \mathrm{PTA}=227)$. Respondents were given four weeks to respond, and then a second mailing occurred for PT programs only to increase the return rate. All participants were informed that the nature of this 
research was not to evaluate existing CAI programs, but it was to describe and compare current uses of CAI in PT and PTA education.

\section{Interviews}

An interview protocol was developed based on the qualitative paradigm in order to elicit data detailing individual experiences with and perceptions of CAI. The interview protocol served as a guide to ensure repeatability across interviews. It was pilot tested with one PTA program director, one PT program director, and one PT faculty member during the summer of 2001. At the conclusion of the interview, each participant was asked to comment on interview length, content, format, and wording of questions. Committee members also provided feedback at the Prospectus Defense. Changes were made to the interview protocol to reflect feedback from all individuals. The final interview protocol can be found in Appendix C.

As questionnaires were returned, a purposive sample of six PT and five PTA program directors or faculty members was selected to participate in follow-up open-ended, semistructured interviews. This subset was selected based on (a) the uses of CAI as indicated by responses on the mailed questionnaire, (b) the type of institution as classified by the Carnegie Classification of Institutions of Higher Education, (c) gender, (d) location, and (e) willingness to participate. Once a participant was selected to participate in the interview, he or she was contacted via e-mail, and an interview day and time were established. At the onset of the call, the participants were read the script for interview, and then, open-ended, semi-structured interviews were conducted based on the interview protocol (Appendix C). Field notes, and when permitted audiotapes, were used to record interview data. These interviews also solicited specific case examples of CAI in PT and PTA programs. 


\section{Document Submission}

Interview participants were asked to submit documents related to the use of CAI in their program. A document analysis checklist was used to ensure repeatability across documents. The document analysis checklist was also pilot tested during the summer of 2001 using documents submitted by participants in the pilot phase.

Final drafts of the questionnaire, interview protocol, and document analysis checklist were submitted and approved by the West Virginia University Institutional Review Board for Protection of Human Subjects. The questionnaire cover letter was stamped with the approval prior to being mailed.

\section{Participants}

\section{Overview of Questionnaire Respondents}

Questionnaires were mailed to program directors of CAPTE accredited PT and PTA programs. Program directors might have passed the questionnaire to a faculty member with more interest in CAI, and in those cases, faculty members responded. One hundred and seventy-four questionnaires were returned after the first mailing. After the second mailing, an additional 27 questionnaires were returned; therefore the total return was 201 questionnaires (return rate 52\%). This included 85 PT Programs (52\%) and 116 PTA Programs (51\%). Of the PT program respondents, $79.5 \%$ were program directors, $19.2 \%$ were full-time faculty members, and $1.3 \%$ was classified as other. Twenty percent of the PT program respondents represented institutions classified by the Carnegie Classification of Institutions for Higher Education as Doctoral Extensive, $22.5 \%$ were Doctoral Intensive, $36.3 \%$ were Master's Colleges and Universities I, $17.6 \%$ were classified as Specialized Institutions, and 3.8\% were classified as Baccalaureate 
Liberal Arts or Baccalaureate General. Fifty-four percent were public institutions and $46 \%$ were private institutions. Seventy-eight percent of PT programs responding offer a master's degree and $22 \%$ offer an entry-level doctorate degree.

Of the PTA program respondents, $95 \%$ were program directors and $4.8 \%$ were full-time faculty members. Of these institutions, $78.4 \%$ were classified by the Carnegie Classification of Institutions for Higher Education as Associate's Colleges, 2.9\% were Doctoral Intensive, 7.8\% were Master's Colleges and Universities I, 2.0\% were Baccalaureate Colleges-Liberal Arts, 3.9\% were Baccalaureate Colleges-General, 2.0\% were Baccalaureate Colleges-Associates. One hundred percent of PTA programs offer an associate's degree. Respondents of both PT and PTA programs represented a wide geographical distribution.

\section{Overview of Interview Respondents}

A description of subjects who participated in the follow-up interviews can be found in Tables 3.1 and 3.2. Interview participants were labeled as PT1-6 and PTA1-5 according to the order the interview took place. 
Table 3.1 PT Program Interview Participants

\begin{tabular}{|cccc|}
\hline Location & Gender & Carnegie Classification & Position \\
\hline Midwest & Female & Doctoral Extensive & Faculty Member \\
\hline Northeast & Female & Master's Colleges and & Program Director \\
& & Universities I & \\
\hline Mid-Atlantic & Male & Master's Colleges and & Program Director \\
& & Universities I & \\
\hline Midwest & Male & Master's Colleges and & Program Director \\
& & Universities I & \\
\hline Southwest & Female & Specialized Institutions & Program Director \\
& & Medical Schools and & \\
& & Medical Centers & \\
\hline Mid-Atlantic & Female & Doctoral Extensive & Faculty Member \\
\hline
\end{tabular}

Table 3.2 PTA Program Interview Participants

\begin{tabular}{|cccc|}
\hline Location & Gender & Carnegie Classification & Position \\
\hline Northeast & Female & Associate's Colleges & Program Director \\
\hline West & Female & Associate's Colleges & Program Director \\
\hline Mid-Atlantic & Female & Baccalaureate College- & Program Director \\
& & General & \\
\hline Southwest & Female & Associate's Colleges & Program Director \\
\hline Northeast & Male & Associates Colleges & Program Director \\
\hline
\end{tabular}




\section{Overview of Documents Submitted}

The following describes types of documents submitted by interview participants:

Document 1: A list of general computer abilities classified as pre-requisite, entry-level, or advanced used in a PT program, submitted via e-mail

Documents 2 and 3: Faculty-designed web pages, accessed via the Internet (PT)

Document 4: Web sites created by students, accessed via the Internet (PT)

Document 5: Student handbook, accessed via the Internet (PT)

Document 6: Internet search assignments, accessed via the Internet (PT)

Document 7: Course home pages developed using course management software, accessed via the Internet (PTA)

Document 8: Sample online quizzes, accessed via the Internet (PTA)

Document 9: Article written by a participant describing his rationale for integrating CAI, submitted via e-mail (PTA)

Document 10: Slide presentations done by a participant used to teach his approach for designing online instruction (PTA)

\section{Research Design}

This research can be classified as a mixed-method design because both quantitative and qualitative methods were used. The quantitative portion of this study was descriptive in that current uses of CAI in PT and PTA education were described. In addition, there was a component that compared certain aspects of PT and PTA programs; therefore, this contains a post-test only comparison of existing groups. For the qualitative portion, an inductive analysis of 
data gathered from questionnaires, interviews, and documents was used to generate and verify concepts about CAI that emerged from the data.

Patton (1990) describes weaknesses and strengths of using a mixed-method paradigm.

Proponents of methodological purity criticize mixed models based on the idea that it is impossible to test a hypothesis while still being open to what emerges from the qualitative data. However, other researchers argue that a mixed-method paradigm can be effective (Patton, 1990). The quantitative portion can be used to produce valid findings that are potentially generalizable to the population under study; whereas qualitative results can provide vivid descriptions of the phenomenon under study, while allowing the researcher to be open to new concepts that emerge from data.

\section{Data Analysis}

All quantitative data were taken from the closed-ended questionnaire items. Qualitative data were from open-ended questionnaire responses, interviews, and document analysis. Each research question includes variables that were analyzed using both quantitative and qualitative methods. Tables 3.3- 3.6 summarizes quantitative and qualitative data analysis for each research question, respectively. 


\begin{tabular}{|c|c|c|}
\hline \multicolumn{3}{|c|}{ Table 3.3 Research Question \#1 Data Analysis } \\
\hline Variables under investigation & Quantitative Data & Qualitative Data \\
\hline Amount of CAI & $\begin{array}{l}\text { Closed-ended item \#2 } \\
\text { (course matched by type) } \\
\text { Frequency, Mean, Independent t-test }\end{array}$ & \\
\hline Types, courses, and uses of CAI & $\begin{array}{l}\text { Closed-ended item \#2 and \#3 } \\
\text { (multiple choice) } \\
\text { Frequencies, Percentages, and Mode }\end{array}$ & $\begin{array}{l}\text { Interview Data } \\
\text { Document Analysis }\end{array}$ \\
\hline Faculty integrating CAI & $\begin{array}{l}\text { Closed-ended item \#6 (multiple choice), } \\
\text { Frequencies, Percentages, and Mode }\end{array}$ & \\
\hline Faculty taking continuing education courses & $\begin{array}{l}\text { Closed-ended item \#9 (yes-no), } \\
\text { Frequencies and Percentages }\end{array}$ & $\begin{array}{l}\text { Open-ended explanation accompanying } \\
\text { closed-ended item \#9 }\end{array}$ \\
\hline Institutional incentive & $\begin{array}{l}\text { Closed-ended item \#11 (yes-no), } \\
\text { Frequencies and Percentages }\end{array}$ & $\begin{array}{l}\text { Open-ended explanation accompanying } \\
\text { closed-ended item \#11 } \\
\text { Interview Data } \\
\text { Document Analysis }\end{array}$ \\
\hline Formal instruction in computer use & $\begin{array}{l}\text { Closed-ended item \#12 (yes-no), } \\
\text { Frequencies and Percentages }\end{array}$ & $\begin{array}{l}\text { Open-ended explanation accompanying } \\
\text { closed-ended item \#12 } \\
\text { Interview Data }\end{array}$ \\
\hline Computer prerequisites & $\begin{array}{l}\text { Closed-ended item \#13 (yes-no), } \\
\text { Frequencies and Percentages }\end{array}$ & $\begin{array}{l}\text { Open-ended explanation accompanying } \\
\text { closed-ended item \#13 } \\
\text { Interview Data }\end{array}$ \\
\hline Mandatory computer ownership & $\begin{array}{l}\text { Closed-ended item \#14 (yes-no), } \\
\text { Frequencies and Percentages }\end{array}$ & $\begin{array}{l}\text { Open-ended explanation accompanying } \\
\text { closed-ended item \#14 } \\
\text { Interview Data } \\
\text { Document Analysis }\end{array}$ \\
\hline
\end{tabular}




\begin{tabular}{|c|c|c|}
\hline \multicolumn{3}{|c|}{ Table 3.4 Research Question \#2 Data Analysis } \\
\hline Variables under investigation & Quantitative Data & Qualitative Data \\
\hline Positive aspects of CAI & $\begin{array}{l}\text { Closed-ended item \#4 } \\
\text { (multiple choice) } \\
\text { Frequencies, Percentages, and Mode }\end{array}$ & $\begin{array}{l}\text { Open-ended questionnaire item \#4 } \\
\text { Interview Data } \\
\text { Document Analysis }\end{array}$ \\
\hline Negative aspects of CAI & $\begin{array}{l}\text { Closed-ended item \#5 } \\
\text { (multiple choice) } \\
\text { Frequencies, Percentages, and Mode }\end{array}$ & $\begin{array}{l}\text { Open-ended questionnaire item \#5 } \\
\text { Interview Data }\end{array}$ \\
\hline Type of learning that occurs with CAI & $\begin{array}{l}\text { Closed-ended items \#4 and } 5 \text { (multiple } \\
\text { choice) } \\
\text { Frequencies, Percentages, and Mode }\end{array}$ & $\begin{array}{l}\text { Interview Data } \\
\text { Document Analysis }\end{array}$ \\
\hline Learning style and aptitude & $\begin{array}{l}\text { Closed-ended items \#16 (multiple choice) } \\
\text { Frequencies, Percentages, and Mode }\end{array}$ & \\
\hline Perceived impact & & $\begin{array}{l}\text { Open-ended questionnaire item \#1 } \\
\text { Interview Data }\end{array}$ \\
\hline
\end{tabular}




\begin{tabular}{|l|l|l|}
\hline \multicolumn{2}{|c|}{ Table 3.5 Research Question \#3 Data Analysis } \\
\hline \multicolumn{1}{|c|}{ Variables under investigation } & \multicolumn{1}{|c|}{ Quantitative Data } & \multicolumn{1}{|c|}{ Qualitative Data } \\
\hline Recent purchase of instructional software & $\begin{array}{l}\text { Closed-ended item \#7 } \\
\text { (yes-no) } \\
\text { Frequencies and Percentages }\end{array}$ & $\begin{array}{l}\text { Flosed-ended item \#8 } \\
\text { (yes-no) } \\
\text { Frequencies and Percentages }\end{array}$ \\
\hline Recent discontinuation of instructional software & $\begin{array}{l}\text { Closed-ended item \#10 } \\
\text { (yes-no) } \\
\text { Frequencies and Percentages }\end{array}$ & Open-ended questionnaire item \#2 \\
\hline Faculty designing CAI & $\begin{array}{l}\text { Open-ended questionnaire item \#3 } \\
\text { Document Analysis }\end{array}$ \\
\hline Selection criteria & & \\
\hline Evaluation Criteria & & \\
\hline
\end{tabular}




\begin{tabular}{|l|l|l|}
\hline \multicolumn{2}{|c|}{ Table 3.6 Research Question \#4 Data Analysis } \\
\hline \multicolumn{1}{|c|}{ Variables under investigation } & \multicolumn{1}{|c|}{ Quantitative Data } & \multicolumn{1}{c|}{ Qualitative Data } \\
\hline $\begin{array}{l}\text { Program prepares students for computerized } \\
\text { licensing exam }\end{array}$ & $\begin{array}{l}\text { Closed-ended item \#17 } \\
\text { (yes-no) } \\
\text { Frequencies and Percentages }\end{array}$ & $\begin{array}{l}\text { Open-ended explanation accompanying } \\
\text { questionnaire item \#17 }\end{array}$ \\
\hline $\begin{array}{l}\text { Computerized licensing exam has influenced } \\
\text { decision to integrate CAI }\end{array}$ & $\begin{array}{l}\text { Closed-ended item \#18 } \\
\text { (yes-no) } \\
\text { Frequencies and Percentages }\end{array}$ & $\begin{array}{l}\text { Open-ended explanation accompanying } \\
\text { questionnaire item \#18 }\end{array}$ \\
\hline $\begin{array}{l}\text { Relationship between amount of CAI and average } \\
\text { first-time pass rate }\end{array}$ & $\begin{array}{l}\text { Closed-ended item \#19 } \\
\text { self-reported first time pass rate } \\
\text { Correlated with amount of CAI using } \\
\text { Pearson-product moment correlation } \\
\text { coefficient }(r) \\
\text { Correlated with whether or not computer- } \\
\text { based testing used in program using Point- } \\
\text { biserial correlation coefficient }\left(r_{p b}\right)\end{array}$ & \begin{tabular}{l} 
\\
\hline
\end{tabular}
\end{tabular}




\section{Quantitative Data}

\section{Research Question \#1}

What are the similarities and differences in types and uses of CAI between physical therapist and physical therapist assistant education programs?

PT and PTA programs were compared in the following areas:

1. amount of CAI being used

2. types of CAI being used

3. content area where CAI is being used

4. uses of CAI

5. amount of faculty integrating computers

6. faculty taking continuing education

7. institutional incentive for CAI

8. formal instruction in computer use

9. whether or not the program has a computer prerequisite

10. whether or not the program has a mandatory ownership policy

The amount of CAI used was taken from the table on the questionnaire that allowed respondents to match the type of CAI with the content area of physical therapy education where it is being used. Responses were counted for each program, and the mean amount of CAI was determined for each respondent, and then for PT and PTA programs. The mean amount of CAI between PT and PTA programs was compared using an Independent samples $t$-test. The alpha level was set at $p<.01$. SPSS $^{\circledR}$ for Windows ${ }^{\circledR} 10.0$ (SPSS, Inc. Chicago, IL) was used for all analyses. All other quantitative data were analyzed using frequencies and percentages, and then PT and PTA programs were compared on each item. 


\section{Research Question \#2}

What are faculty's perceptions of: positive aspects, negative aspects, type of learning that occurs, learning style, aptitude, and the overall impact of computers on physical therapy education?

The quantitative data, which included positive aspects, negative aspects, faculty perceptions of learning style and aptitude were analyzed by determining the frequency, percentage, and mode of responses for each item. These were also compared between PT and PTA programs. Positive and negative aspects were further analyzed to determine faculty perceptions of type of learning that occurred with CAI (i.e. problem solving skills and psychomotor skills). Results were analyzed by determining the percentage of responses for each group.

\section{Research Question \#3}

\section{How are faculty selecting and evaluating CAI?}

These data were taken from questionnaire yes-no items asking if (a) they had recently purchased any instructional software programs, (b) they had recently discontinued use of any software, and (c) if they were working to design their own instructional software materials. Yesno responses were counted and percentages were tabulated. Examples given under the description of the yes-no items for (a), recent purchases of instructional software, were listed and tabulated by the frequency of responses for PT and PTA programs.

\section{Research Question \#4}

Do computer-based licensing exams influence faculty decisions to integrate CAI?

Quantitative data were taken from questionnaire yes-no items asking if (a) computer use in their program adequately prepared students for the computer-based licensing exam and (b) if 
the computer-based licensing exam had influenced their decision to integrate CAI. Data were tabulated according to frequency and percentages were reported. In addition, a Pearson productmoment correlation coefficient $(r)$ was used to determine the magnitude and direction of the relationship between the amount of CAI being used and licensing exam pass rate. In addition, a Point-biserial correlation coefficient $\left(r_{p b}\right)$ was used to determine if a relationship existed between integration of computer-based testing and licensing exam scores.

\section{Qualitative Data}

Qualitative data were taken from the questionnaire (open-ended explanations following yes-no items and open-ended items), interviews, and document analysis. These data were analyzed using the qualitative research paradigm through naturalistic inquiry, case analysis, and inductive analysis, as described by Denzin and Lincoln (1998). Naturalistic inquiry is the study of real-world situations, without manipulation of the variables under study (Patton, 1990). The case method was used to describe specific case examples and to capture details from individual programs. Inductive analysis, or the grounded theory approach, is when the researcher generates, verifies, and confirms theories about a particular topic as they emerge from the data (Patton).

Field notes and interview data were transcribed and coded according to concepts that appeared. A concept can be defined as an idea, or understanding, that is derived from a set of experiences. Concepts in the data were identified by key phrases and examples given by participants. These are also known as indigenous concepts (Patton, 1990).

Concepts in the data were clustered and counted. General concepts subsumed more particular ones, and the result was emergent concepts used to describe perceptions of CAI in physical therapy education. Concepts emerged from the data in that as data were collected and analyzed, key concepts appeared, or came into view. Their emergent nature was such that 
openness and flexibility to new concepts remained as data collection and analysis continued (Patton, 1990).

\section{Research Question \#1}

What are the similarities and differences in types and uses of CAI between physical therapist and physical therapist assistant education programs?

Open-ended explanations that accompanied questionnaire yes-no items 9, 11, 12, 13, and 14 provided data to answer research question \#1. Additional qualitative data were provided through interviews and document analysis. Case studies provided in-depth examples of types of CAI being used, courses where it is being used, as well as computer literacy and ownership policies. Data were analyzed as described above, using inductive analysis.

\section{Research Question \#2}

What are faculty's perceptions of: positive aspects, negative aspects, type of learning that occurs, learning style, aptitude, and the overall impact of computers on physical therapy education?

Open-ended questionnaire items \#1, 4, and 5, interview data, and document analysis provided data to answer this research question. Case examples elicited from the interviews and document analysis provided additional data. Data were analyzed as described above, using inductive analysis.

Research Questions \#3

\section{\#3 How are faculty selecting and evaluating CAI?}

Qualitative data were taken from open-ended questionnaire items \#2 and 3 and document analysis. Data were coded according to responses provided by individuals completing the questionnaire. Responses were then categorized, counted, and described. 


\section{Research Question \#4}

\section{Do computer-based licensing exams influence faculty decisions to integrate CAI?}

Open-ended explanations that accompanied questionnaire yes-no items \#17 and 18 were used to answer this research question. Data were coded according to responses provided by individuals completing the questionnaire. Responses were then categorized, counted, and described.

\section{Triangulation}

Triangulation allows the researcher to validate and cross check data, increasing credibility of the research (Patton, 1990). Patton further described triangulation as "a process by which a researcher can guard against the accusation that a study's findings are simply an artifact of a single method, a single source, or a single investigator's biases" (p. 470). Methodological triangulation was used in this study. Methodological triangulation is a way to strengthen a study by employing multiple methods (questionnaires, interviews, document analysis) to study the same phenomenon. Stake (1995) indicated that the use of multiple methods within a single study could illuminate or nullify extraneous variables. Patton reported that a mixed-method approach (quantitative and qualitative) could also be an effective form of methodological triangulation.

Methodological triangulation occurred through the use of different methods of data collection, or measurement: the questionnaire's open-ended items, interviews, and document analysis. Methodological triangulation was used to verify emergent concepts. If a concept emerged from the open-ended questionnaire items, it was substantiated in the interviews and document analysis. Further, if a new theme emerged during the interviews, it too was substantiated in other aspects of the data. Emergent concepts were "key interpretations" of the 
qualitative data and therefore, according to Stake (1995) needed extra effort toward confirmation. 


\section{CHAPTER FOUR: RESULTS}

The results section provides quantitative and qualitative data for each research question. Specific case examples are also presented for research questions \#1 and \#2. The qualitative data are further divided into questionnaire, interview, and document analysis data. A summary of results for each research question is also provided. An outline of results is provided in Appendix E.

\section{Research Question \#1}

What are the similarities and differences in types and uses of CAI between PT and PTA Programs?

\section{Quantitative Data}

\section{Amount of CAI}

Results of closed-ended questionnaire responses indicated that PT programs use a mean of nine different types of CAI ( $S D=7.79$, range $=0-46)$ and PTA programs use eight different types $(S D=8.7$, range $=0-46)$. For the Independent samples $t$-test, assumptions for normality, equality of variances, and independent observations were all satisfied. Results of this $t$-test indicated no significant difference between the amount of CAI used in PT and PTA programs $(t$ $=1.107, p=.270)($ Appendix F).

\section{Types and Uses for CAI}

Seventy-seven percent of PT and 78\% of PTA programs reported using instructional CDROMs. Eighty percent of PT and 43\% of PTA programs reported using web pages. Forty percent of PT and $12.6 \%$ of PTA programs reported using chat rooms designed with course management software. Thirty-seven percent of PT and 22\% of PTA programs reported using online quizzes. 
PT programs reported using CAI most frequently in anatomy, kinesiology, and research courses. PTA programs reported using CAI most frequently in procedures, kinesiology, and therapeutic exercise courses. The most frequently reported types of CAI matched by content area for PT programs were (a) CD-ROMs for anatomy and (b) web pages for research. For PTA programs, the most frequently reported types of CAI matched by content area were (a) CDROMs for procedures and (b) CD-ROMs for anatomy. All types of CAI matched by content area for PT and PTA programs can be found in Appendix G.

Uses for CAI, reported by PT and PTA programs can be found in Figures 4.1a and b. Both PT and PTA respondents reported the most common use of CAI was for optional tutorials. Faculty Integrating CAI

Average size of faculty for PT programs responding was 12 members, and for PTA programs, average size faculty was 4 members. Of the PT programs responding, $8 \%$ reported that all faculty members are integrating CAI. Eighteen percent reported 1-2, 35.5\% reported 3-4, and $35.5 \%$ reported 5 or more (but not all) faculty members are integrating CAI. Three percent of PT programs indicated that no faculty members are integrating CAI.

Of the PTA programs responding, 34.7\% reported that all faculty members were integrating CAI. Forty-six percent reported 1-2, 10.2\% reported 3-4, and 3.1\% reported that 5 or more (but not all) faculty members are integrating CAI. Six percent of PTA programs indicated that no faculty members are integrating CAI. 
Figure 4.1 Uses of CAI Reported PT and PTA Respondents

$\square$ PT $\square$ PTA

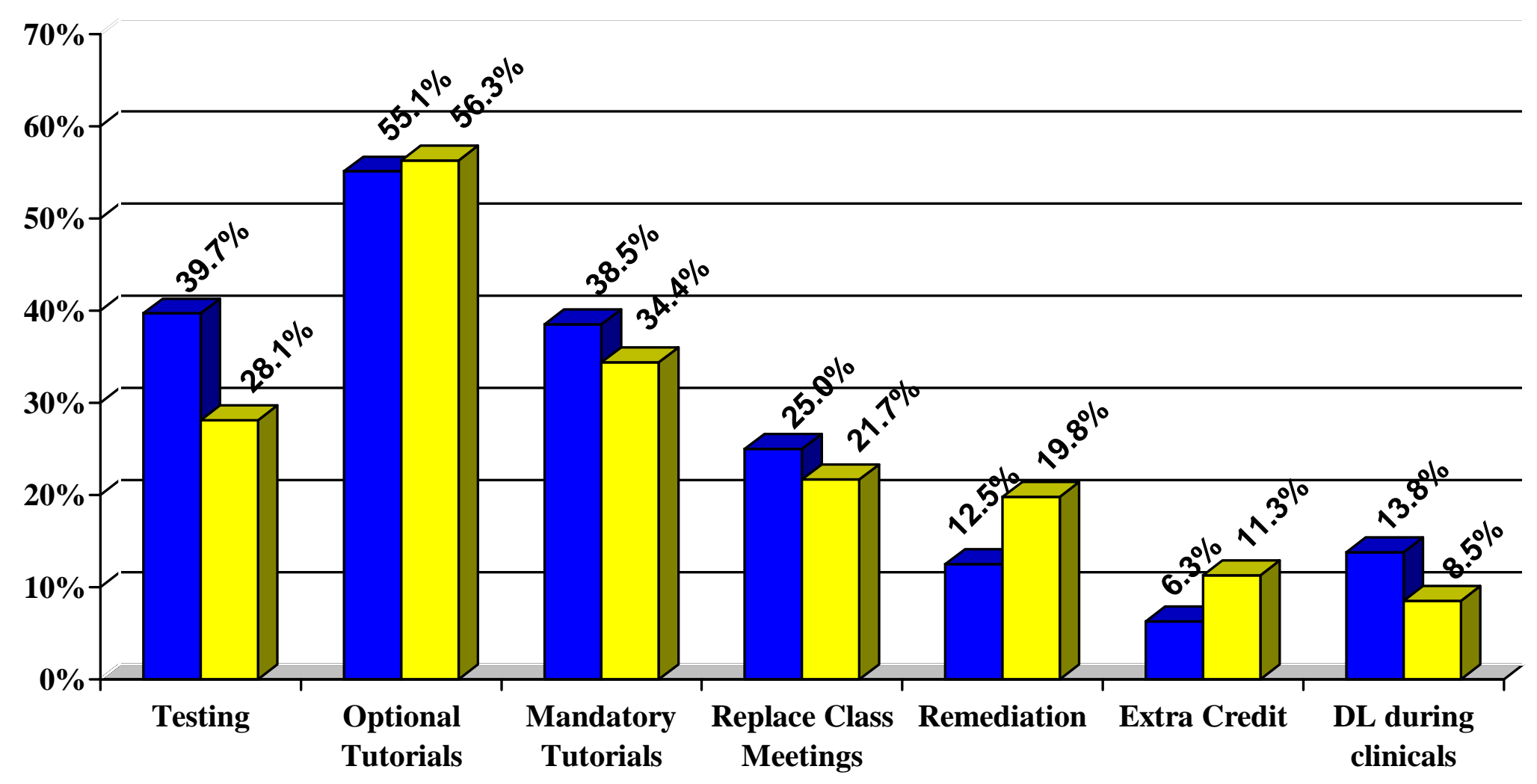




\section{Continuing Education Courses}

Seventy-six percent of PT and 59\% of PTA program respondents indicated taking continuing education courses related to CAI.

\section{Institutional Incentive}

Twenty percent of PT programs and 27\% of PTA programs are being offered incentive from the institution for developing and integrating CAI. Among the institutions where incentive is being provided (PT and PTA combined) there is a mean amount of eight $(S D=7.37$, range $=0$ - 32) different types of CAI being used. In institutions where incentive is not being provided, there is a mean amount of nine $(S D=9.0$, range $=0-46)$ different types of CAI being used.

\section{Formal Computer Instruction and Ownership}

Fifty-seven percent of PT and 33\% of PTA programs indicated they are providing formal computer instruction to students within their programs. Forty-six percent of PT and 47\% of PTA programs indicated they have a computer prerequisite course. Finally, 9\% of PT and none of PTA programs indicated they have a mandatory computer ownership policy.

\section{Qualitative Data}

\section{Types and Uses of CAI}

\section{Instructional CD-ROMs (Interview Data).}

PT Data. In the interviews, PT2, 3, 4, 5, and 6 reported using instructional CD-ROMs for anatomy courses. PT2 and 4 both indicated using the CD-ROMs in place of traditional cadaver dissection, although both participants indicated prosected cadavers were available. PT4 indicated both positive and negative aspects of using software in place of traditional dissection. He said, "In traditional cadaver anatomy courses, a large proportion of time is spent digging and scraping and there is a smaller estimated time on identification of relationships." However, with the 
software, all the time is spent on identification. PT4 went on to say that traditional lab practical exams are identification, so when using the cadaver, the instructional strategy is not consistent with the assessment; whereas with software use, the two methods are consistent. A negative aspect (of replacing traditional dissection with CD-ROMs) reported by PT4 was that students have turned down their program because it did not have traditional dissection. PT4 has found that schools offering traditional cadaver dissection will actually point out to applicants that his program does not use traditional dissection, but uses computer software instead. Another negative aspect of replacing dissection with CAI includes students not being able to handle the body tissues, see structure variations in people, or see joint movement, ligaments, neuromuscular termination, or nerve branching. Therefore, PT4 reports supplementing instruction with prosections to integrate these experiences.

PT4 indicated that he wrote a dissector to correspond with A.D.A.M. ${ }^{\circledR}$ anatomy software that is comparable to Grant's Dissector ${ }^{\circledR}$. (Grant's Dissector ${ }^{\circledR}$ is a textbook to use when performing traditional cadaver dissection). The CD-ROM dissector is used to allow students to develop spatial relationships, primarily depth, and to use as a study guide. It also includes sections on maneuvering through the software and how to use the mouse. PT4 reported that the quality study guide enhances the lab experience. He indicated his observations of student learning during labs now are the same as when he taught cadaver dissection at another institution. Finally, he stated that the accrediting agency for physical therapy education, CAPTE, found the software to be a strength of the program.

Besides anatomy, other types of CD-ROMs were reported in the interviews. PT3 reported recently purchasing $L X R^{\circledR}$ testing software, which according to this participant helped increase the program's licensure exam pass rate. PT1 indicated using a variety of CD-ROMs including 
procedures, therapeutic exercise, modalities, kinesiology, and patient evaluation. PT1 indicated these materials are placed in the library for student use and are assigned as required reading material, although she indicated they do not check to see if the students use it. PT6 indicated having cardiopulmonary and neurology CD-ROMs available for student checkout. PT6 reported that when CD-ROM material is too advanced for entry-level students, she uses it during lecture instead of allowing students to access it independently.

PTA Data. PTA1, 2, 3, and 4 indicated using CD-ROMs for procedures courses (PTA5 reported he was not using any instructional CD-ROMs). These CD-ROMs included goniometry (PTA1, 2, 4), manual muscle testing (PTA1, 2, 4), gait analysis (PTA1, 2), and modalities (PTA3). These are being used in several ways.

PTA1 and 4 indicated using the software during classroom lecture. PTA1 reported that where they used to use videotapes, now they use CD-ROMs. PTA1 and 4 also reported placing the software on reserve in the computer lab, so students can access it during free time for tutorials or to supplement class instruction. PTA3 reported a problem with placing material in computer labs for optional tutorials. PTA3 stated, "Unless you require it, the students will not do it." She went on to say that it might be good for some students, but integration of instructional CD-ROMs needs to be beyond "Here it is."

PTA2 and 3 indicated that students can use the CDs to get the theory, or facts, but both participants indicated the instructor must be the one to provide the higher-level skills. PTA2 went on to say students "can use the CD-ROM until they are blue in the face and they will still not be able to apply the information." PTA2 stated the instructor gives the "how to" and the "how to problem solve". Therefore, it is the responsibility of the instructor to pull the information together for the student after they access the software. 
PTA2 reported two problems encountered with instructional CD-ROMs. She indicated there are often differences in "what they teach and what is demonstrated on the software" or sometimes software demonstrations differ from those presented in class, causing confusion among students. PTA2 indicated that some software shows a variety of ways to perform one skill. She went on to say that students have lost points on practical exams because they perform the skill in a way provided on the CD, but not wanted for the practical exam. Students do this after she specifically tells them the way she wants the skill to be performed for the practical exam. She recommends the instructor should be proactive in explaining differences between the software and classroom instruction. PTA2 also feels that these instructional CD-ROMs are better when they include a variety of media, rather than just text. She reported that recently published software has been nothing more than a reproduction of the textbook.

\section{The Internet (Interview Data).}

PT Data. PT interview participants described many aspects of the Internet that could be used for instruction, including web pages, chat rooms, and online quizzes. All PT interview participants indicated using web pages designed with course management software. PT1, 3, 4, 5, and 6 described using these web pages for communicating with students. Web pages included assignment answer keys (PT1), syllabi (PT4, 5, and 6), and lab practical schedules (PT4). PT1, 5, and 6 also reported they are integrating links to external web sites. PT1, 5, and 6 described placing additional course content on web pages such as pictures and videos. These included pictures of different wheelchairs and video gait analysis (PT1) and Quick Time ${ }^{\circledR}$ movies for pediatrics, gait analysis, and normal development (PT5).

PT 5 and 6 added faculty members are placing class notes on their web pages. PT5 stated that in the first year of the program, students print class notes and bring them to class for 
traditional note taking, however, by the third year, PT5 stated that students bring their laptops to class and take notes directly on their computers. She added that an Internet hook-up is provided at each seat in the classroom. PT5 claimed note taking directly on the computer served a particularly important purpose for students on clinical affiliations. She reported when students use their laptops to take notes, they do not have to take textbooks to their clinic sites but instead students take their laptops, and they have all of their class notes with them. PT6 reported students print notes during all three years of the program, but in those classrooms, Internet hook-ups are not provided at every seat, only along the wall.

Further interview data revealed PT1-6 using the Internet for research activities. PT5 reported students use sites like PubMed, Grateful Med, Merck, Medscape, and many others for research and reference. PT1 indicated using the web for evidence-based projects where part of the student's score is dependent upon their description of the search procedure. PT6 stated that students have the ability to get their hands on a variety of resources, and because of this, they are becoming more skeptical with information obtained from the Internet.

PT6 reported using the Internet to replace a portion of traditional classroom meetings by placing content on the web, and allowing students access it at their convenience. She indicated that $60 \%$ of a pathology course is taught this way, and only $40 \%$ of the course is taught using traditional methods. PT6 stated that students have access to a variety of images available over the web, and she uses tutorial quizzes as a guide for directing their learning. She reported that students have less contact hours in the classroom, and "They love the flexibility."

Instruction that is entirely web-based, or web-based instruction (WBI) is also being used in PT programs. For example, PT5 indicated using this format for delivering advanced electives to third-year PT students who are participating in clinical affiliations. Examples of these 
advanced elective courses include: pharmacology, pediatric orthopedics, advanced anatomy and physiology of the vestibular system, administration, nutrition, sports physical therapy, strength and conditioning, and advanced foot and ankle. Web $C T^{\circledR}$ is used as the delivery platform, and students have required readings, questions to answer, and then application projects under each topic. Students can access the course at their convenience, but they have deadlines for submitting assignments. Assessment in these advanced elective courses is accomplished through portfolio and project evaluation.

PT1, 3, 4, 5, and 6 reported using chat or bulletin boards. PT3 reported using chat during clinical affiliations to encourage dialogue between students. PT3 also stated that chat is being used in a management course. PT5 reported chat is being used in an advanced elective course, Sports Physical Therapy. However, PT5 stated that chat, or synchronous communication, was difficult due to individual time constraints and differing schedules, especially when students are on their clinical affiliations. Therefore, they have started using the bulletin board, or asynchronous communication, more frequently. PT5 also indicated that bulletin boards were better than real-time chat, because bulletin boards allowed students to post information at their convenience, thus allowing more reflective thought.

PT3, 5 and 6 reported using online quizzes. PT3 reported these are being used in the management course, PT5 stated they are being used in almost every course, and PT6 indicated using online quizzes in sections that have larger numbers of students. These three participants indicated that quizzes are linked to course management software. PT5 indicated that they once tried e-mailing quizzes, but there was no test security. Students were downloading the quizzes and saving copies. Now with the instructional packages, there is a lot more security. These participants were asked about students taking quizzes in uncontrolled settings, such as at home, 
or in an unmonitored computer lab. PT5 reported that quizzes were timed so students can't look up the questions. She added, "If you are writing questions that can be looked up that quickly you deserve to be cheated on." Otherwise, PT5 indicated that professional ethics prevents cheating, and she has students sign a form indicating they did not cheat on the exam. When exams need stricter monitoring, students bring their laptops to class and complete the exam in a monitored classroom environment (PT5). In a program where an Internet connection is not provided at every seat, exams are held in monitored computer labs (PT6).

PTA Data. All PTA interview participants indicated placing class material on the Internet and using it as a tool for communication. PTA1 reported using e-mail and PTA2 and 5 indicated posting syllabi, schedules, required readings, and course information. None of the PTA interview participants indicated placing notes on course web pages. PTA1, 2, and 5 reported they were using the Internet for information gathering.

PTA1, 3, and 5 reported they were using the Internet to replace a portion of traditional classroom meetings. At the time of the data collection, PTA1 was working on a course web site to integrate physics, anatomy, and physiology content. The site will contain content, videos, assignments, and testing. For the 15-week semester, the class will have five traditional meetings. PTA5 is using this format for the Physical Agents course and Introduction to Physical Therapy course. He indicated that each week, reading material (in the form of slides) was placed on the course web site. The students must access the information, review it, and then take the online quiz. PTA5 reported that this method allowed for a reduction in the number of on-campus meetings, which is beneficial for students who work and for commuters. In addition, this allowed for in-class time to be spent pulling the facts together and practicing skills at a higher level through case study applications. 
Further interview data indicated PTA2 and 4 using WBI. PTA2 reported two medical ethics courses and a licensure review preparation course being offered through WBI. PTA4 indicated that courses like medical terminology, pathology, and human body structures are being offered as $100 \%$ online courses. She added that at their institution, students have an option to take all general education courses through WBI. PTA4 reported these courses have helped with enrolling students who work full-time. PTA4 also provided an idea that she has, which is to develop an expansion program where all lecture material is online, and students only come to campus for lab experiences.

PTA2 and 5 reported using online chat or bulletin boards. PTA2 reported she preferred bulletin boards because of students misspelling words. However she reported she has little time to use this feature. PTA5 described using bulletin boards during clinical affiliations. He stated the clinical coordinator posts questions on the bulletin board and students must answer them. If students get the questions wrong, then a pop-up screen appears suggesting they meet with their clinical instructors about the content.

PTA1-5 reported using online quizzes. PTA1, 2, 3, and 5 reported using $W e b C T^{\circledR}$ for delivering the quizzes. Both PTA3 and 5 described their uses of the online quizzes. In both cases, students are required to complete the quizzes prior to attending classes. PTA3 and 5 indicated that if students know the facts prior to class, then higher-level concepts could be practiced in the classroom. PTA3 and 4 agree that this process allows students to get more repetitions and have a better understanding of the material. PTA4 added that online quizzes allow underachieving students multiple opportunities to raise self-esteem. PTA3 stated these quizzes help students become more organized and self-directed. PTA3 reported using a weekly self-assessment for students to identify whether they were developing these skills. 
PTA3 and 5 reported limitations with online quizzes. First, these PTA participants utilizing online quizzes were also concerned about cheating. PTA3 and 5 indicated that quizzes are timed so students are unable to look up the correct answers. PTA3 reported giving 2 minutes for a 10-item multiple choice quiz. Second, PTA3 indicated her biggest concern regarding online quizzes was related to instructional technology including slow dial-up connections that become frustrating to students. PTA3 added that computer labs are faster, but that takes away the convenience.

\section{The Internet (Document Analysis).}

PT Data. Document 2 included web pages used to enhance traditional instruction for a Case Conference course and a Medical Management course. For both, there were still traditional class meetings, but the Internet was used as a supplement. Material posted included the syllabus, course objectives, schedules, assignments, lecture notes, discussion questions for that week's class meeting, links to external sites, study questions, and self-study units. Courses were used to pull together several areas of physical therapy, including basic and clinical sciences as well as rehabilitation interventions. Review of the Medical Management course web site included weekly discussion questions on autonomous PT practice and direct access, injury prevention and screening, PT responsibilities, and PT diagnoses. Students were given an assignment to incorporate several physical therapy related readings, including the Guide to Physical Therapist Practice and readings from the professional association's web site.

The Case Conference is a course for both occupational and physical therapist students.

The course web site included a sample patient case presented to students via Power Point ${ }^{\circledR}$ that reviewed patient evaluations performed by an occupational therapist and a physical therapist. Students were provided with treatments and the patient's weekly progress. The patient was given 
a new diagnosis in week three. Students were also provided with the occupational and physical therapists' adaptive equipment recommendations. Students were to review the case prior to class and complete a written report on the following:

1. Primary diagnosis

2. Preexisting problems

3. Similarities and differences in evaluation and treatment approaches

4. Treatment techniques / approaches

5. Patient changes during treatment

6. Treatment adaptations by therapist after change in status

7. Transdisciplinary issues

8. Other professions referred to in the case

9. Benefit to patient related to transdisciplinary approach

Review of Document 6 revealed two different ways the Internet is being used for research in a PT program. First, using course web pages, students are presented with a patient case that included pictures and short video clips. Students must determine impairments and interventions for that patient, and use the Internet to provide evidence that supports the identified treatment. Document 3 included students comparing Internet sites on their usefulness to provide patients and PTs with information.

PTA Data. Document 7 demonstrated two PTA course web sites using $W e b C T^{\circledR}$ as a delivery platform, with factual, or knowledge level material being presented on slides. The information was taken from students' textbooks, and they were given definitions, concepts, and additional factual information related to the topics. Unit objectives, graphics, clip art, guiding 
questions, supplemental reading assignments, external links for obtaining additional information, and homework activities were also posted on the course web site.

Document 9 included online quizzes, using $W e b C T^{\circledR}$ as the delivery platform. Questions were in multiple-choice format and were being asked at the recall level. The instructor was allowing as many as 15 minutes to answer 10 multiple-choice questions at the recall level.

\section{Faculty Continuing Education}

\section{Questionnaire \#9.}

Of the faculty taking continuing education courses related to CAI, open-ended questionnaire explanations indicated 25 PT and 18 PTA respondents taking courses for designing WBI. Six PT and 12 PTA respondents indicated taking courses offered by the physical therapy professional association. Thirteen PT and 19 PTA respondents indicated using on-campus computer courses offered through the institution's technology department.

\section{Institutional Incentive}

\section{Questionnaire \#11.}

Of the faculty being offered incentive for CAI development, open-ended questionnaire explanations indicated one PT and eight PTA questionnaire respondents being offered monetary incentive. This included grant funding, overload pay, and monetary stipends. An additional one PT and seven PTA respondents reported receiving an adjusted workload. Five PT and one PTA respondent reported that CAI development and integration are evaluated either as course development or scholarship activities.

\section{Interview Data.}

In an interview, PTA1 offered an example of an incentive program being offered in her area. There is a group called "Teaching with Technology Fellows." The faculty member submits 
an instructional technology project to the group, and then they are considered for acceptance into “The Fellows." Once accepted, the faculty member gets $\$ 1,000$ to purchase items for the computer lab and take a course on integrating software. “... and the course is great," she added. PTA1 reported that no one takes advantage of this program.

\section{Formal Computer Instruction}

\section{Formal Instruction Provided by Program.}

Questionnaire \#12. For formal instruction provided to students by the programs, openended questionnaire explanations indicated that five PT and one PTA respondent provide formal computer instruction at orientation. This included orientation to library resources and university technology centers. In addition, PT respondents indicated providing a larger variety of computer skills to students including Internet searches, statistical software, database management, electronic mail, spreadsheet development, word processing, and slide fabrication. PTA respondents indicated only providing instruction for Internet searches and word processing. In programs (PT and PTA) where formal instruction is not provided, 11 PT and 3 PTA respondents indicated that formal computer instruction is available through on-campus resources but is not formally provided by the program.

Interview Data. Interview data revealed PT1 using a list of 83 computer skills classified as prerequisite, entry-level, or advanced. The list is sent out to new students, and then during the first week of class, students rank themselves on each item, and faculty use the list to identify weaknesses. Weaknesses are provided to the university's medical library staff who then holds sessions to assist students improve their computer skills. She reported, "Faculty members tell students what they need but do not necessarily teach it. All faculty incorporate elements of technology into what is meaningful for that particular course." PTA1 also reported teaching what 
can be done in the context of the class, but otherwise she directs students toward a support person in the library or Learning Resources Center.

Document Analysis. Document 1 analysis revealed the 10 general computer abilities used by PT1. These are further divided into 26 prerequisite, 29 entry-level, and 28 advanced skills. The general abilities include knowledge of basic computer operations, word processing, information searching, communication tools, data security, environmental computer threats, spreadsheets, presentations, database management, and electronic patient management systems. It is used to evaluate the students' perceptions of their computer skills. The skills are written in both behavioral and cognitive terms, and it includes basic and advanced applications of various software programs and the Internet.

\section{Computer Prerequisite.}

Questionnaire \#13. Of both PT and PTA programs requiring a formal computer prerequisite, open-ended questionnaire explanations indicated 15 PT and 19 PTA respondents reported this was a basic computer literacy course.

Interview Data. In the interviews, PTA4 indicated the general education computer requirement allows students to have the basic skills, and they do not have to use class time once students are in the PTA program. PTA2 reported the institution has a computer graduation requirement called "Tech Tools." "Tech Tool” skills include statistics, word processing, spreadsheets, and Internet searches. Students must either complete a computer proficiency course that teaches these skills, or test out of it. PTA2 reports they are working to formally incorporate all necessary "Tech Tool” components into their program so that upon completion of the PTA program, students will have satisfied the college's computer graduation requirement. 


\section{Mandatory Ownership}

\section{Questionnaire \#14.}

Open-ended questionnaire responses indicated that an additional four PT and three PTA programs have mandatory computer access policies. Two PT respondents indicated that computer ownership was highly recommended. One PTA program respondent indicated they were considering a mandatory ownership policy.

\section{Interview Data.}

Two interview participants (PT5 and 6) indicated having mandatory computer ownership or leasing policies. PT5 reported that mandatory laptop ownership is accomplished through providing students with a list of specifications required in their admissions letter and students agree to comply by signing their acceptance letter. Minimum specifications are in place so that material, assignments, software, and projects can be run on each student's machine. Students are required to purchase the computer independently. PT5 reported the university does provide students with minimal technical support, but students must seek out more complex technical support needs. This mandatory ownership policy is required for all university students.

PT6 indicated using a mandatory laptop lease program. This program is used throughout all medical and allied health programs at the university. The computers are issued to the students by the university. A positive aspect of this lease program is that computers are given more technical support by the institution, and faculty can determine software installations before computers are issued to students. PT6 indicated that students have raised questions about the cost, because they could purchase a more powerful machine at less cost, but then students would not have access to software licenses, university technical support, or the university network. 


\section{Document Analysis.}

Review of Document 5 indicated minimum specifications for computer ownership given by PT5. For Windows-based systems, they were:

1. Pentium III, or better

2. Ethernet/Modem adapter

3. $128 \mathrm{MB}$ RAM

4. $20 \mathrm{~GB}$ hard disk

5. CD-ROM

6. Windows 98 or newer

7. Office 97 or 2000 (Word, Power Point, Excel)

8. Microsoft Internet Explorer

9. Internet access via personal Internet Service Provider

\section{Research Question \#2}

What are faculty's perceptions regarding: positive aspects, negative aspects, type of learning that occurs, learning style, aptitude, and the overall impact of computers on physical therapy education?

\section{Quantitative Data}

\section{Positive and Negative Aspects of CAI}

Positive aspects of CAI are reported in Table 4.1. Positive aspects most often reported by both groups included improved knowledge of technology and improved independence with information gathering. Negative aspects of CAI are reported in Table 4.2. Negative aspects most often reported by both groups included cost and lack of time for development. 
Table 4.1 Positive Aspects of CAI

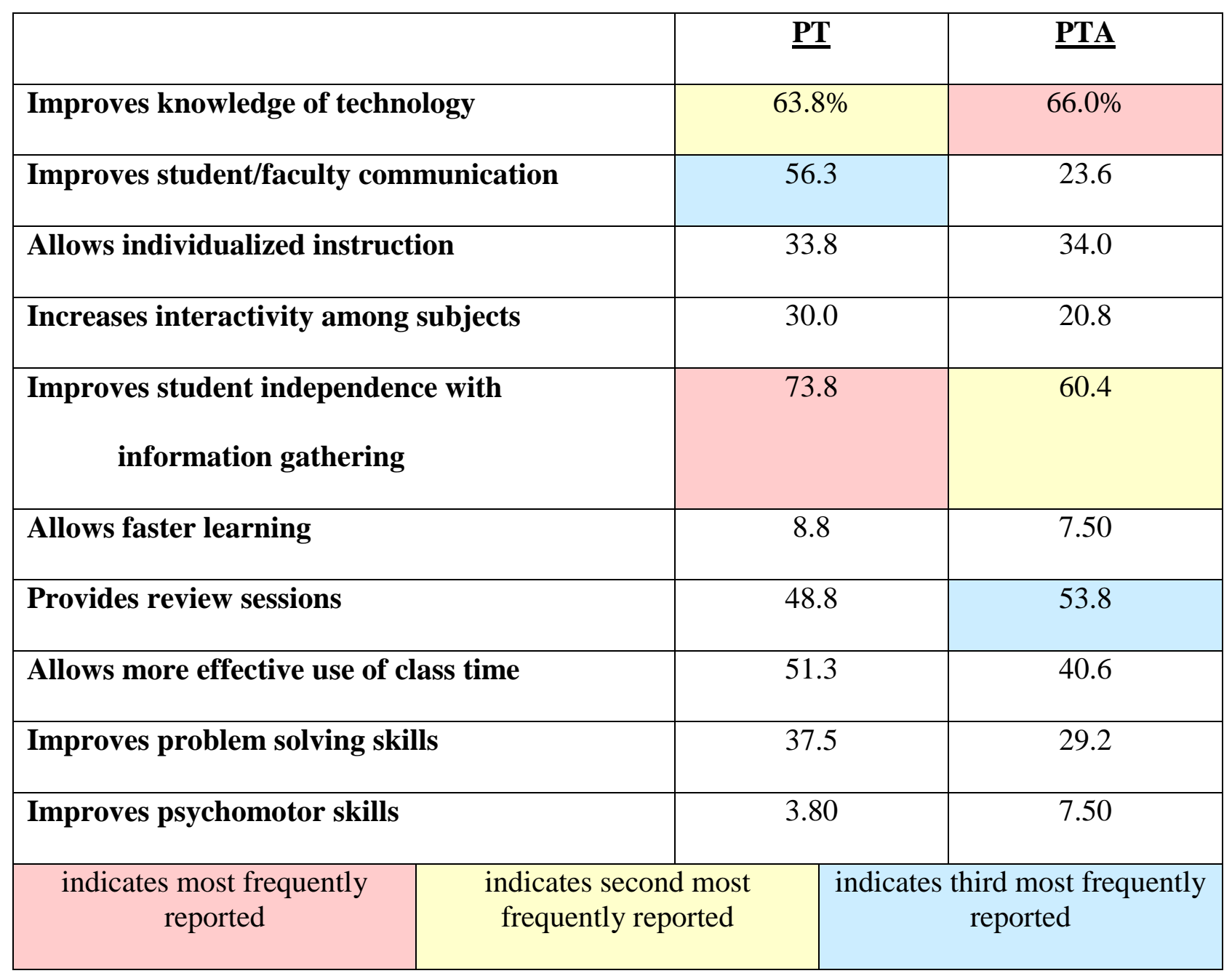


Table 4.2 Negative Aspects of CAI

\begin{tabular}{|c|c|c|}
\hline & $\underline{\text { PT }}$ & $\underline{\text { PTA }}$ \\
\hline Cost & $52.5 \%$ & $60.4 \%$ \\
\hline Rapid obsolescence & 45.0 & 43.4 \\
\hline Lack of research on it's effectiveness & 22.2 & 22.6 \\
\hline No gold standard to evaluate & 18.8 & 27.4 \\
\hline Lack of production of quality items & 21.3 & 25.5 \\
\hline Lack of time for development & 76.3 & 61.3 \\
\hline Lack of time for integration & 40.0 & 47.2 \\
\hline Lack of student interest & 10.0 & 9.4 \\
\hline Lack of faculty interest & 22.5 & 9.4 \\
\hline Little to no faculty incentive & 43.8 & 15.1 \\
\hline Difficult to use & 17.9 & 14.9 \\
\hline Does not improve problem solving skills & 11.5 & 6.90 \\
\hline Does not improve psychomotor skills & 15.4 & 9.90 \\
\hline indicates most frequently reported & $\begin{array}{l}\text { indicates second } \\
\text { most frequently } \\
\text { reported }\end{array}$ & $\begin{array}{l}\text { indicates third most } \\
\text { frequently reported }\end{array}$ \\
\hline
\end{tabular}




\section{Type of Learning that Occurs with CAI}

Questionnaire data from the positive and negative aspect questions (multiple choice \#4 and \#5) were further examined to determine perceptions of the relationships between CAI, problem-solving, and psychomotor skills. Thirty-seven percent of PT and 29\% of PTA respondents indicated that a positive aspect of CAI was that it improved problem-solving skills. Eleven percent of PT respondents and 6.9\% of PTA respondents indicated that a negative aspect of CAI was that it did not improve problem-solving skills. Three percent of PT respondents and 7.5\% of PTA respondents indicated that a positive aspect of CAI was that it improved psychomotor skills. Fifteen percent of PT respondents and 10\% of PTA respondents indicated that a negative aspect of CAI was that it did not improve psychomotor skills.

\section{Learning Style and Aptitude}

Of the PT program respondents, 50\% indicated they were unsure of the predominant learning style among their students. Other PT respondents reported the predominant style was kinesthetic (23.9\%), followed by visual (22.4\%), and then auditory (3.0\%). Of the PTA respondents, $48.4 \%$ reported the predominant learning style among their students was kinesthetic. Others indicated the predominant style was visual (25.3\%) or auditory (5.3\%). Twenty-one percent of PTA program respondents reported they were unsure of the predominant learning style among their students.

Perceptions of the relationship between learning style and CAI for PT and PTA respondents are illustrated in Figure 4.2. Sixty (60.8) percent of PT and 49\% of PTA respondents indicated they were unsure as to what type of learning style benefits most from CAI. Perceptions of the relationship between student aptitude and CAI are illustrated in Figure 4.3. 
Figure 4.2 Perceptions of Learning Styles That Benefit Most Using CAI

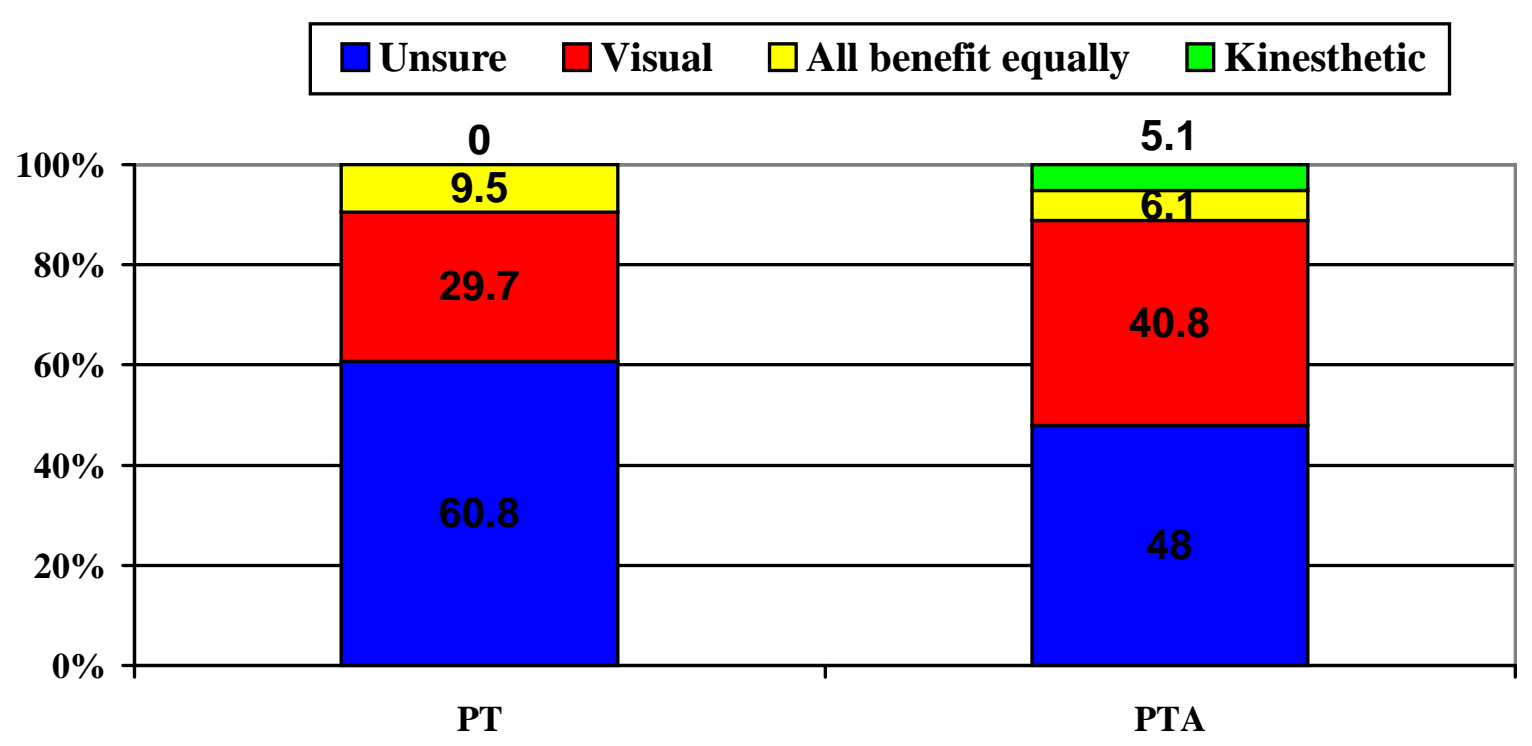

Figure 4.3 Perceptions of Student Aptitude and Benefit of Using CAI

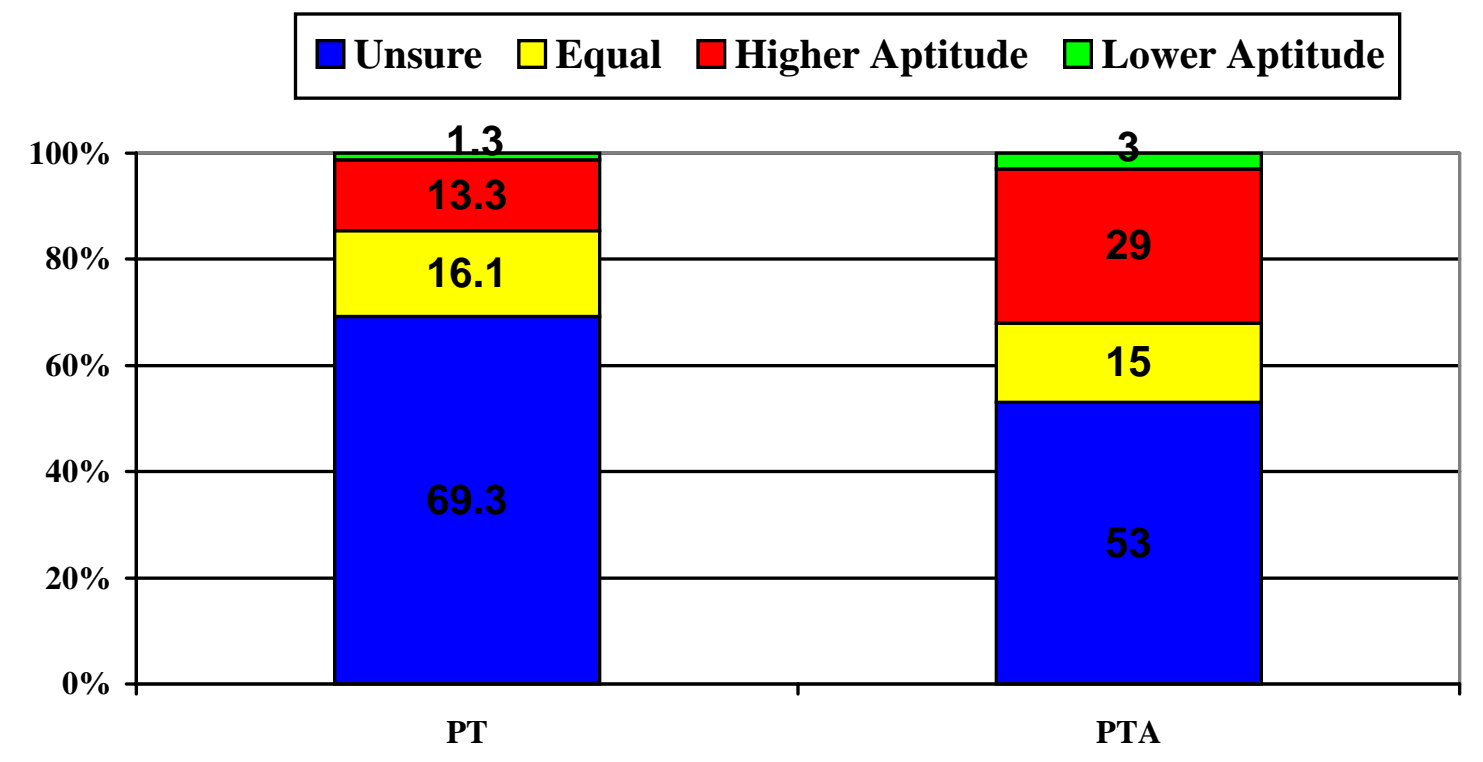


Seventy percent of PT and 54\% of PTA respondents indicated they were unsure as to whether high or low aptitude students benefit more by using CAI.

\section{Qualitative Data}

\section{Positive Aspects of CAI}

\section{Questionnaire \#4.}

When asked what was the most important reason to integrate computers, 11 PT and 11 PTA questionnaire respondents indicated that computer skills are needed for the future. An additional 17 PT and 27 PTA respondents indicated that students must know how to use computers for accessing information, to promote lifelong learning, or to improve clinical practice. PT respondents wrote: The computer's ability "to access information and application within our society will continue to increase in the future," and "Technology is here to stay and will only further become part of our lives." Another PT respondent wrote, "Computer skills facilitate lifelong learning and individual responsibility for continued development, as a person and professional." Comments from PTA respondents included "Society demands it," "Students demand it," "Technology is part of the global world," and "Independent learning is fostered."

Another positive aspect identified by 11 PT and 16 PTA questionnaire respondents was the computer's ability to be used as an educational tool that provides a variety of learning experiences. Examples of written responses from both PT and PTA programs included, CAI "offers multiple modalities," "increases learning opportunities," "captures students with different needs," "adds diversity to the learning environment," and allows "another medium for student learning."

An additional twelve PT and 11 PTA questionnaire respondents indicated the most important reason to integrate computers was to enhance or improve learning. Additional 
comments provided by these respondents were: (a) computers supplement learning and reinforce the ability to review with guidance when not on site (PT); (b) CAI allows development of fundamental concepts and knowledge for integration into advanced courses (PT); and (c) CAI allows repetition of material (PTA). One PT questionnaire respondent added computers offer "opportunities...to optimize education."

Finally, an additional six PT and three PTA questionnaire respondents indicated CAI provides more effective use of classroom time. Examples of written responses related to this from both PT and PTA programs were, CAI "provides better use of classroom time," "may alter percent of time spent on content," and "allows more efficient delivery of learning."

\section{Interview Data.}

Interview data suggested three positive aspects of CAI. First, students like it. PT3 and 6 reported students are enjoying the flexibility associated with CAI. PT2, 3, 5, and PTA3 indicated that students enjoy using CAI. PT5 stated, "Students are loving it," and PT2 indicated, "Students find the computer work intriguing."

Second, participants identified better computing skills since CAI has been used. PT1, 2, 5 and PTA1, 2, 3, and 5 indicated students were becoming more computer savvy since opportunities for computer use have increased. PT3 stated students are "not intimidated by computers," and PTA1 reported students show "decreased computer anxiety.” In fact, PTA1 added that last year the licensure exam pass rate was $100 \%$, and she believed they did not change anything else, nor were the students any different than previous years.

Third, computers provide another way for students to learn. PTA5 stated that computers provide another avenue of learning. PTA1, 3, and 4 indicated CAI allowed students more review. PTA3 added that students get more repetitions with CAI, allowing more exposure to difficult 
material. PTA5 reported that each year since CAI has been integrated, the program has met its computer literacy goal. No PT interview participants reported "review" to be a positive aspect of CAI.

\section{Document Analysis.}

Document analysis revealed positive aspects of CAI as well. Documents submitted by a PT program (Document 4) indicated students developing sophisticated knowledge of computers and multimedia technology. Third year students do terminal projects that can be an educational web site. For example, there was an extensive Neuroanatomy Atlas designed for the Internet. It included slides of brain cross-sections in multiple views, and there were labeled and un-labeled pictures that allowed review. Another example included a site for gait analysis that included normal gait, video clips, and EMG data. This site included examples of pathological gait as well. Another example was on Cardiac Rehabilitation. This site included advanced graphics, and a pre-test and post-test.

Document 9 included a participant's rational for integrating CAI. In this document, he indicated positive aspects of using partial online courses. These were providing immediate feedback, providing hyperlinks to outside educational resources, increasing communication through bulletin boards and e-mail, and improving student's comfort level with the Internet.

Document 10 included reasons why a participant uses WBI. Reasons were:

1. provides a portal to outstanding resources

2. enhances students responsibility for their learning

3. saves time

4. prepares students to participate in, and learn from, the Internet 
5. allows participant to use "feedback lectures," lectures that surround case studies and foster application

6. accessibility

This document also included the following statement: "When you offer internet-based learning activities you have the opportunity to provide learning that is not place- or time-bound." Also, it asked, "Are people more likely to participate in learning activities when this type of flexibility is available?"

\section{Negative Aspects of CAI}

\section{Interview Data.}

PT1-4 offered limitations to courses taught through WBI in physical therapy. PT1 and 4 agree that it would be easier for a post-professional program or transitional Doctorate of Physical Therapy (DPT) program to use WBI, rather than entry-level students. A transitional DPT is designed to bridge a Master's Degree in Physical Therapy to a DPT. PT1 indicated WBI would be better for post-professional students due to timing and convenience, allowing these students to work full-time in a clinical setting. PT1, 2, 3, and 4 indicated that successful integration of WBI in physical therapy would depend upon the material being taught. PT1 offered that it would be harder with entry-level courses because of certain skills that are taught, such as the hands-on, patient care skills. PT2 agreed that you would have to get together for labs, and the WBI should be reserved for more independent work. PT1, 2, and 3 reported that communication and interpersonal skills are lost with WBI. PT1 added that she "has a hard time with entire courses being offered online." PT2 added that interaction and discussion among instructors and students is lost, and it "can't possibly be the same" as traditional instruction. Finally PT3 indicated that WBI misses out on the ability to have everyone in the room at the same time, hearing the 
discussion. He added that he is reluctant to give up the traditional approach because "Students need to experience the material verbally." Nevertheless, PT1 admitted reluctantly, that more WBI might be the future of PT education because of declining enrollment.

The PTA participants offered similar limitations to using WBI in physical therapy. PTA1-4 reported that all material should not be taught over the Internet. PTA1 stated that a course like medical terminology could safely be taught via WBI, but PTA1, 2, 3, and 4 agree that psychomotor skills cannot be taught using this method, and they stated they had to have labs. PTA5 expressed concern about the type of information given with WBI, being mostly factual. PTA3 and 4 noted concern about loss of the face-to-face interaction that occurs with this instructional method. PTA4 added that some students need access to a live person. Finally, PTA3 indicated there is still no evidence that WBI enhances learning, "So why do it?"

Additional negative aspects identified in the interview data included: lack of research on effectiveness (PT3 and PTA3) and no guarantee of additional learning taking place (PT3, PTA2, and 5). Other negative aspects identified included time and cost (PT3 and 4), and PT4 indicated that he did not know how to overcome the "lack of time" factor. Furthermore, PTA3, 4, and 5 reported negative aspects associated with lack of technical support and lack of institutional support. PTA5 stated, "Institutions need to fully appreciate the (faculty's) commitment by protecting (them) with policies and support services. There is nothing worse than having a course fall apart. They (institutions) are already asking faculty to be content experts, educational experts, and now technology experts. We can't be all three." 


\section{Overcoming Barriers Related to CAI}

\section{Questionnaire Item \#5.}

When asked to describe how respondents were overcoming negative aspects of CAI, five PT and 13 PTA questionnaire respondents indicated using slow, strategic planning to incorporate CAI. Of these, two PT and nine PTA respondents indicated they were, "slowly acquiring resources," and "slowly integrating." The others reported using deliberate planning, problem solving, and planned integration.

More specific responses were related to how programs overcome cost and time factors. Two PTA questionnaire respondents indicated cost as the biggest problem to overcome. Nine PT and seven PTA program respondents reported acquiring funding by applying for grants. Three PT and three PTA respondents stated they were sharing costs with other programs. One PT and seven PTA respondents indicated allocating more of the program's budget to technology. Three PTA program respondents indicated seeking out donations. Finally, one PTA respondent wrote, "You find money if it's important."

Three PT and five PTA questionnaire respondents wrote timing was the most difficult aspect of CAI to overcome. One of these PT respondents noted, "The time problem pervades all aspects of higher education." A PTA respondent wrote, "The biggest problems are lack of time to familiarize (myself) with CAI and lack of time to develop our own."

Five PT and two PTA respondents reported being granted release time for CAI development. Four PT and nine PTA respondents reported having to use their personal time. These PT and PTA respondents wrote, they were "putting in extra hours," "doing volunteer work," and "working longer, and harder." Two PT and one PTA respondent reported hiring a tech person, utilizing graduate assistants, or hiring work-study students to assist with CAI. 
Finally, six PTA respondents indicated they were just "making time." These respondents added, "We just accept it takes more time (and) effort but feel the benefits to students are worth it," and "Staying positive and motivated myself (helps)." Another added, "CAI is a supplement to instruction and enhances PT/PTA education-it does not provide all the answers-keeping perspective eliminates the negativity."

Six PT and four PTA questionnaire respondents reported taking advantage of on-campus learning resources and trying to become more knowledgeable in technology and CAI. Two additional PT respondents indicated incorporating CAI into individual goals and professional development plans. Finally, two PT and three PTA program respondents indicated requesting support from the university administration.

While both PT and PTA programs noted strategies to overcome barriers of cost and time, six PT and ten PTA respondents indicated they have been unable to proceed with CAI integration because of these barriers. Two PTA respondents indicated they were "Struggling to keep up." Two additional PTA respondents indicated they were struggling with declining enrollment and one added, "As the quality of students decreases, we spend so much time on basic skills, that time to develop CAI doesn't exist."

\section{Type of Learning that Occurs}

\section{Interview Data.}

PT1, 3, 5, and PTA2, 4, and 5 all agree that CAI provides factual information, and PT3 added that a component of learning is missing with CAI. PT5 and PTA2, 4, and 5 all provided additional information though. PTA2 stated, "The instructor is the key!" She went on to say that instructors should give students assignments requiring them to use information at a higher level, such as choosing exercises from a software package. PTA4 added that although CAI presents 
mostly factual information, the instructor could provide more examples, cases, changes in patient status, and life examples. PTA5 stated, "You can't effectively design CAI that moves beyond the knowledge level," but he went on to say that for analysis and application skills, the faculty must establish a model for student practice. PTA5 then provided details of how he uses CAI: "We use CAI to get out the facts, low on Bloom's Taxonomy. We then use class time to do the higherlevel thinking skills." All of these respondents agree that CAI can promote factual information, however, it is the instructor's role to help students develop higher-level skills. PT5 noted that any course can be taught at a low level. The computer is only the mode for delivering the content. She gave specific accounts of advanced elective courses being taught via WBI, and how these courses, in her opinion, allow development of higher-level thinking skills. The two examples were Pharmacology and Pediatric Orthopedics. For the Pharmacology course, students write essays on (a) whether or not PTs should have prescriptive authority and (b) the role of the PT in providing over-the-counter drug recommendations. Students also interview a pharmacist and research the Joint Commission on Accreditation of Healthcare Organization's (JCAHO) requirements for pain control. Students use all this information to write strategies for a PT department for dealing with medications. The other example included a course on Pediatric Orthopedics. For this course, students have assigned readings, but students must also do observation hours, report on three pediatric case studies they find, and do videotapes of treatment techniques. PT5 believes that in these advanced WBI courses, higher-level thinking skills are being used merely by the way the instructor designed the learning experiences.

\section{Document Analysis.}

Review of Document 3, an advanced elective course web site for the Pharmacology course offered by PT5 verified factual information being taught in the form of reading materials 
and study questions. However, as PT5 noted, there were assignments to integrate higher-level thinking strategies. There were also uses of affective skills identified in these assignments. Assignment \#1 asked students about PTs having autonomous practice and what were legal and ethical responsibilities for PTs counseling patients on medications. For assignment \#2, students had to do a medication history for a patient that included patient's diagnosis, treatment plan, prescription drugs, over-the-counter drugs, vitamins, implications for the PT, and implications of drug knowledge on clinical practice. Assignment \#3 asked students to determine of which drugs PTs should be aware. For assignment \#4, students were required to evaluate web-based drug resources and whether they were appropriate for PTs. They had to "compare and contrast the information presented and available for use by you." They were to determine if these web resources were sufficient or useful.

Document 9 revealed a rationale for using WBI based on Bloom's Taxonomy. It indicated the goal of the instruction was for students to gain skills at the application level of Bloom's Taxonomy (cognitive domain). In the document, application skills were defined as the ability to relate and apply general ideas, procedures, principles, or theories to unique situations. The teaching strategy he uses requires him to teach using activities that match this level of learning. Using this method, lecture and passivity are de-emphasized and both active learning and problem solving are emphasized. This approach came about after realizing that students rarely, if ever, perform assigned readings before class, and they rely heavily on the instructor to give them necessary content. 


\section{The Perceived Impact of CAI on Physical Therapy Education}

\section{Questionnaire \#5.}

When asked how do you think computers have influenced PT/PTA curriculum, 17 PT and 18 PTA program questionnaire respondents indicated that computers have had a positive impact on curriculum because of their ability to allow fast, easy access to information and Internet resources. One PT program respondent indicated that computers probably have "very little impact on content, but (they) have potential to revolutionize the way PT is practiced. Evidence-based practice is grounded in computing. They will fundamentally change the way PT is constructed." Other PT responses included: Computers "increase access to research and literature," they allow "advanced evidence-based concepts and ease information access," and they allow "ease of accessing volumes of information." PTA responses included computers have "broadened access to knowledge," "allowed access to more information outside of class," "provided opportunities for expanded information available to students," and have been great for patient education. Nevertheless, one PTA respondent indicated that the impact of computers has mostly been in PT, rather than PTA because of evidence-based practice, although PTA students may benefit by developing lifelong learning skills.

Fifteen PT and 15 PTA questionnaire respondents indicated that computers have improved faculty content delivery and teaching effectiveness. PT responses included: the computer "increases visuals," "allows enhanced teaching," and "provides alternative ways to present material." PTA written responses were similar to those provided by PT respondents. Four PTA respondents indicated that computers provide better visuals, and one PTA respondent suggested that computers have expanded the capabilities for teaching and learning, kept education exciting, and provided new tools for students. 
Nine PT and one PTA respondent indicated that computers have enhanced communication between students and faculty. One of these PT respondents added that computerbased communication has also enhanced student-faculty discussions and explanations that may be individualized. The PTA respondent indicated electronic communication has also decreased the paper trail.

PTA respondents shared two additional points. First, 12 PTA respondents indicated the influence of computers may be just beginning in PTA programs. One reason for this was the amount of non-traditional students in PTA programs. Second, three PTA respondents indicated computers have forced students to learn computer and Internet search skills.

Eight PT and three PTA respondents provided more skeptical responses when asked about the impact of computers. One PT respondent warned against the overwhelming amount of information available to entry-level students on the Internet. She wrote, "It becomes our job to assist the student to understand the information in a stepwise and organized way." Another PT respondent noted that students are less likely to use the library now that information can be easily accessed via the Internet. In addition, three of these respondents indicated the computer is an instructional tool and just like any instructional tool, "must be used wisely," and "is only as good as the instructor using it." This viewpoint is shared by one PTA respondent who indicated, "Computers are just another tool that we have available." Another PTA respondent indicated, "We all think we should use them, even if there is no evidence that they aid in student learning." Another PT respondent wrote, Computers should be "used in moderation. I believe they are a useful adjunct. Students still need teachers in their presence. Overuse of computer instruction is dangerous to good learning." 


\section{Interview Data.}

Instructional Tool. All PT and PTA participants described ways the computer is being used as an instructional tool in their programs. These examples have been described in detail for Research Question \#1, and are summarized in the following list:

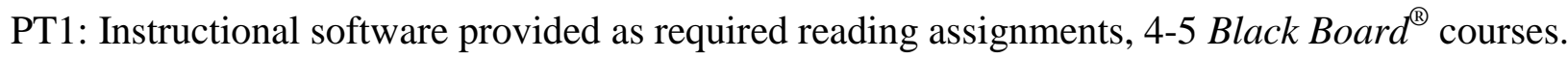
PT2: CD-ROM for supplemental instruction in Human Anatomy and Neuroanatomy courses, supplementing coursework with online resources.

PT3: Black Board ${ }^{\circledR}$ site for clinical courses, chat for Management course, and computer-based testing with $L X R^{\circledR}$ testing software.

PT4: CD-ROM for supplemental instruction in Human Anatomy and faculty-designed web pages linked for communicating schedules, syllabi, and a bulletin board.

PT5: Advanced electives taught via WBI; online quizzes; patient simulations for gait analysis, pediatrics, and normal development via presentation of video clips; faculty web pages providing course information. Reported using e-mail for students to submit all assignments.

PT6: Delivery of partial course content for Pathology course, instructional software for neurology and cardiopulmonary content, online quizzes, anatomy software.

PTA1: Software used for in-class demonstrations, patient simulations such as gait analysis, Internet searches, and delivery of partial course content.

PTA2: Internet to provide extra assignments, delivery of three entirely web-based courses (two medical ethics, licensure review course), CD-ROM to get across factual information.

PTA3: Online quizzes to test factual information. 
PTA4: Courses in medical terminology, pathology, and human body structures offered via WBI, CD-ROMs in the classroom and then provided to students as an option.

PTA5: Partial on-line courses in an Introductory course and Physical Agents course.

Respondents reported their perceptions of using the computer as an instructional tool. PT4 reported that computers provide a tool for instruction by enhancing learning, matching the teaching and learning strategies, and allowing identification of relationships. PTA respondents indicated it individualizes instruction (PTA4) and provides a better understanding (PTA3) of material. Nevertheless, two respondents indicated caveats with using the computer as an instructional tool. PT5 stated, "The computer is only an adjunct, and it has not changed the environment." PTA3 added that computers must be integrated appropriately.

Developing Computing Skills. Participants described their perception of improved computer skills in students and how these skills are important for clinical practice. PT1 and PTA2 responded students needed to be more computer savvy for clinical practice. PT5, PTA1, and 5 emphasized the need for students to be able to use web-based resources and CAI allows them to get these. PTA5 reported that computers help develop computing skills we want for the profession as well as skills we want learners to have.

Accreditation. Additional interview data revealed participants perceptions of integrating CAI into accreditation standards. PT and PTA data are presented separately. PT2 and 5 responded that computer technology should be integrated into our accreditation standards. PT5 stated, "It prepares students in knowledge... and provides a source of keeping up to date. We have an obligation to incorporate." PT1 indicated that perhaps parts of CAI could be integrated into accreditation standards, but not whole scale. PT4 reported that he was not opposed to it, but 
perspective needs to be considered. He went on that we should not force a teaching strategy; we must trust that faculty members determine appropriate strategies, and thoughtful curriculum evaluation should suggest need for change. PT4 also added, that we should change within the mission and philosophy, and if we are doing what we are supposed to be, then (CAI integration) would be a natural progression. Lastly, PT3 urged that CAI mandated by accreditation might not be viewed as being a positive thing because design and development should be left to individual programs. He stated, "I would hate for this to be prescriptive."

PTA1, 2, 4, and 5 suggested it should not be mandatory because some schools may not have adequate resources. PTA1 stated, "We just can't expect it," because students who don't have access are the ones who typically struggle. PTA2 asserted that some programs do not have access, faculty, or student knowledge, and they should not be penalized for this. PTA5 reported that instructional methods should not be "prescriptive", and how standards are met should depend on institutional needs. Finally, PTA3 reported it should not be mandated, because we simply don't have enough evidence that says it's a good thing, and she added that we may just be "jumping on the bandwagon."

\section{Research Question \#3}

How are faculty selecting and evaluating CAI?

\section{Selection}

\section{Quantitative Data}

Sixty-five percent of PT and 52\% of PTA reported recently purchasing new software.

Of those who purchased software, anatomy software (such as A.D.A.M. ${ }^{\circledR}$, Primal $^{\circledR}$, and Netter's Atlas of Anatomy ${ }^{\circledR}$ ) was purchased most frequently for both PT and PTA programs. For PT programs, there were no other recognizable patterns. For PTA respondents, other frequently 
reported software programs purchased were procedural, including goniometry, manual muscle testing, modalities, and therapeutic exercise (Table 4.3).

Table 4.3 Types of Software Purchased for PT and PTA Programs

\begin{tabular}{|r|c|c|}
\hline Software purchased & PT $(\mathbf{n}=\mathbf{5 5})$ & $\underline{\text { PTA }}(\mathbf{n}=\mathbf{6 0})$ \\
\hline Anatomy & $19(34.5 \%)$ & $21(35 \%)$ \\
\hline Manual Muscle Testing & $4(7 \%)$ & $17(28 \%)$ \\
\hline Goniometry & $6(11 \%)$ & $17(28 \%)$ \\
\hline Therapeutic Exercise & $1(2 \%)$ & $16(27 \%)$ \\
\hline Electrical Modalities & $2(4 \%)$ & $9(15 \%)$ \\
\hline
\end{tabular}

Ten percent of PT and PTA programs reported that they had stopped using software they had previously purchased. Sixty-five percent of the PT programs reported designing their own CAI materials compared to $54 \%$ of PTA programs.

\section{Qualitative Data}

Data for this aspect of the research question came from Questionnaire open-ended item \#2, "Please describe the criteria that you or other faculty are using to select instructional software, or other multimedia items?" Responses are listed in Table 4.4.

PT and PTA program questionnaire respondents indicated using practicality, content, and faculty opinions for selecting CAI. For example, both PT and PTA respondents reported using cost, ease of use, and compatibility with current hardware and software as criteria for software selection. Selection criteria related to content including accuracy, appropriate level for students, fit with course, and fit with curriculum. One PTA respondent reported that software had to match 
the level of learning for a PTA, rather than a PT. Finally, both PT and PTA respondents indicated that the faculty members' opinions about the software were considered important when determining whether or not software would be purchased.

Table 4.4 Instructional Software Selection Criteria for PT and PTA Programs and Frequency of Responses

\begin{tabular}{|l|l|}
\hline \multicolumn{1}{|c|}{ PT } & \multicolumn{1}{|c|}{ PTA } \\
\hline *Utility/Ease of use (14) & *Fits with course content (24) \\
\hline Cost (12) & Cost (18) \\
\hline None (12) & Utility/Ease of use (18) \\
\hline Faculty review (11) & None (16) \\
\hline Fits with course content (10) & Faculty review (14) \\
\hline Evidence-based (accurate) material (7) & Appropriate to level of students (8) \\
\hline Written software reviews or word of mouth (6) & Student needs (6) \\
\hline Compatible with hardware (4) & Faculty review (5) \\
\hline Appropriate to level of the students (3) & Allowed by the university (5) \\
\hline Curriculum fit (3) & Written software reviews or word of mouth (4) \\
\hline Instructional design (1) & Instructional design (0) \\
\hline
\end{tabular}

* These are listed in order of occurrence for each program, beginning with the one that occurred most often.

One respondent indicated using an instructional design strategy. This respondent wrote, “(Software) must meet instructional design criteria we set." Nevertheless, there were PT and 
PTA respondents who indicated not using any selection criteria. One PT respondent indicated not using any criteria other than personal interest.

\section{Evaluation}

\section{Qualitative Data}

\section{Questionnaire Data.}

Data for this aspect of the research question came from Questionnaire open-ended item \#3, "Please describe how you or other faculty are evaluating the effectiveness of CAI in your program?" Responses are listed in Table 4.5.

Both PT and PTA programs indicated using a variety of methods for evaluating CAI. Respondents from both groups indicated using student performance outcomes such as exams, clinical performance, and student assignments. Also, both groups indicated examining program outcome assessments, such as employer and graduate surveys. Both PT and PTA respondents indicated using formal and informal instructor and student feedback, during discussions, course reviews, and exit interviews. One PTA respondent indicated that technology evaluation had been incorporated into an overall institution technology assessment plan.

Members from both groups reported not using any formal evaluation process for CAI. One PTA respondent indicated evaluating all aspects of the program, but not necessarily focusing on CAI materials. In addition, one PT respondent indicated they "do not evaluate CAI anymore than (they evaluate) the use of transparencies-It is only a tool." 
Table 4.5 CAI Evaluation Procedures for PT and PTA Programs and Frequency of

\section{Responses}

\begin{tabular}{|l|l|}
\hline \multicolumn{1}{|c|}{ PT } & \multicolumn{1}{c|}{ PTA } \\
\hline *None (21) & *Student feedback (28) \\
\hline Exam scores (12) & None (19) \\
\hline Student feedback (11) & Instructor feedback (14) \\
\hline Course evaluations (10) & Exam scores (13) \\
\hline Instructor feedback (7) & Program outcome assessment tools (10) \\
\hline Program outcome assessment tools (5) & Course evaluations (9) \\
\hline Student use (3) & Evaluating quality if student work (3) \\
\hline Clinical performance (3) & Campus plan (2) \\
\hline
\end{tabular}

* These are listed in order of occurrence for each program, beginning with the one that occurred most often.

\section{Document Analysis.}

Document 10 provided examples for "evaluating and improving your course" web sites. Strategies listed included were (a) the constructivists approach to learning, (b) Perry's positions of intellectual development, (c) Bloom's Taxonomy, and (d) Bandura's perspectives on selfefficacy. Explanations of the approaches were provided. 


\section{Research Question \#4}

Do computer-based licensing exams influence faculty decisions to integrate CAI?

\section{Quantitative Data}

Sixty-four percent of PT and 56\% of PTA educators responded that CAI use in their program adequately prepares students for the computer-based licensing exam. Thirty-four percent of PT and $40 \%$ of PTA educators reported that the computer-based licensing exam had influenced their decision to incorporate CAI.

Results of the Pearson product-moment correlation coefficient indicated no correlation ( $r$ $=.088$ ) between the amount of CAI used and licensing exam pass rate. Also, results of the pointbiserial correlation coefficient indicated no correlation between pass rate and whether or not the program integrated computer-based testing $\left(r_{p b}=.097\right)$.

\section{Qualitative Data}

These qualitative data were taken from the questionnaire open-ended explanations that accompanied questions \#17 and \#18.

\section{Questionnaire \#17}

Respondents were asked to explain their rationale for why computer use in their program adequately prepares students for the computer-based licensing exam. Of the respondents who answered yes, computer use adequately prepares students, reasons given included: similar software helps increase comfort (10 PT, 25 PTA), increase familiarity with this type of testing (1 PT, 7 PTA), and decrease anxiety (3 PT, 5 PTA). Of the respondents who answered no, 6 PT and 5 PTA respondents indicated that minimal computer skills are required to take the exam and that using the computer for the exam is a relatively simple skill. One of these respondents reported, 
"Anyone can do the computer-based licensing exam, the tutorial prepares the applicant at the beginning...(I) don't think this is the reason for the CAI." Also, 2 PT respondents indicated they have heard little complaints from students about the delivery of the exam. Finally, 1 PTA respondent indicated students still have computer phobia when taking the test, no matter what.

\section{Questionnaire \#18}

Respondents were asked to explain why (or why not) incorporation of the computerbased licensing exam had encouraged them to integrate more technology. Of the respondents who indicated that computer-based testing influenced their decision, four PT and nine PTA respondents explained that CAI allowed the students to be better prepared. Two additional PT and four PTA respondents indicated CAI allows students to have less anxiety about the test. One PTA respondent indicated the computer-based test had influenced her decision to integrate CAI because students have reported feeling lost on the exam. Another PTA respondent indicated, "Students have reported on graduate surveys that lack of computer skills affected their ability to answer questions on the national exam."

Of the respondents who reported computer-based testing did not influence their decision to integrate, reasons given included: They were already integrating computers before the exam went to a computer based mode (3 PT and 7 PTA), students were already familiar enough with computers (3 PTA), and there is no correlation between the two (3 PT and 1 PTA). 


\section{Summary of Results}

\section{Research Question \#1}

What are the similarities and differences in types and uses of CAI between PT and PTA Programs?

\section{Quantitative Data}

An overview of quantitative data is provided in Table 4.6.

\section{Qualitative Data}

Qualitative data revealed similarities and differences between PT and PTA programs. Differences included PT participants' descriptions of in-depth anatomy software use and PTA participants described in-depth procedural software use. Also, PT participants reported using the Internet for in-depth, structured research activities. For institutional incentive for CAI development, PTA programs reported having monetary incentive and release time granted, and PT programs indicated having it evaluated as course development or as a scholarship activity. Also, PT students receive formal computer instruction that includes a wider variety of computer skills than PTA students.

Data also indicated similarities between the PT and PTA participants. Both groups reported using web pages for communicating course information. Also, both groups indicated using web-enhanced instruction and WBI. Both PT and PTA respondents indicated using online quizzes, and they had similar solutions for preventing cheating. Finally, both groups reported using synchronous and asynchronous communication, but PT and PTA respondents preferred the asynchronous method, via bulletin boards, rather than chat. Of the programs requiring a computer prerequisite, respondents from both groups reported using a basic computer literacy course. 
Table 4.6 Overview of Quantitative Results for Research Question \#1

\begin{tabular}{|c|c|c|c|c|c|}
\hline $\begin{array}{l}\text { Indicates } \\
\text { similarity }\end{array}$ & \begin{tabular}{|l} 
Indicates \\
difference
\end{tabular} & \multicolumn{2}{|c|}{$\underline{\mathbf{P T}}$} & \multicolumn{2}{|c|}{$\underline{\text { PTA }}$} \\
\hline \multicolumn{2}{|c|}{ Amount of CAI } & \multicolumn{4}{|c|}{ No significant difference } \\
\hline \multicolumn{2}{|c|}{$\begin{array}{l}\text { Using instructional CD- } \\
\text { ROMs }\end{array}$} & \multicolumn{2}{|c|}{$77 \%$} & \multicolumn{2}{|c|}{$78 \%$} \\
\hline \multicolumn{2}{|c|}{ Web pages } & \multicolumn{2}{|c|}{$80 \%$} & \multicolumn{2}{|c|}{$43 \%$} \\
\hline \multicolumn{2}{|c|}{ Chat rooms } & \multicolumn{2}{|c|}{$40 \%$} & \multicolumn{2}{|c|}{$12.6 \%$} \\
\hline \multicolumn{2}{|c|}{ Online quizzes } & \multicolumn{2}{|c|}{$37 \%$} & \multicolumn{2}{|c|}{$22 \%$} \\
\hline \multicolumn{2}{|c|}{ Uses of CAI } & \multicolumn{2}{|c|}{ Optional Tutorials (55\%) } & \multicolumn{2}{|c|}{ Optional Tutorials (56\%) } \\
\hline \multicolumn{2}{|c|}{$\begin{array}{l}\text { Content area where CAI is } \\
\text { being used }\end{array}$} & \multicolumn{2}{|c|}{$\begin{array}{l}\text { 1. Anatomy } \\
\text { 2. Kinesiology } \\
\text { 3. Research }\end{array}$} & \multicolumn{2}{|c|}{$\begin{array}{l}\text { 1. Procedures } \\
\text { 2. Kinesiology } \\
\text { 3. Therapeutic Exercise }\end{array}$} \\
\hline \multicolumn{2}{|c|}{$\begin{array}{l}\text { Type of CAI matched by } \\
\text { content area }\end{array}$} & \multicolumn{2}{|c|}{$\begin{array}{l}\text { 1. CD-ROMs for Anatomy } \\
\text { 2. Web pages for Research }\end{array}$} & \multicolumn{2}{|c|}{$\begin{array}{l}\text { 1. CD-ROMs for Procedures } \\
\text { 2. CD-ROMs for Anatomy }\end{array}$} \\
\hline \multirow{5}{*}{\multicolumn{2}{|c|}{ Faculty Using CAI }} & All: & $8 \%$ & All: & $34.7 \%$ \\
\hline & & 5 or more: & $35.5 \%$ & 5 or more: & $3.1 \%$ \\
\hline & & 3-4: & $35.5 \%$ & 3-4: & $10.2 \%$ \\
\hline & & 1-2: & $18.4 \%$ & $1-2:$ & 45.9 \\
\hline & & None: & $3 \%$ & None: & $6 \%$ \\
\hline \multicolumn{2}{|c|}{$\begin{array}{l}\text { Faculty taking continuing } \\
\text { education courses }\end{array}$} & \multicolumn{2}{|l|}{$76 \%$} & \multicolumn{2}{|l|}{$59 \%$} \\
\hline \multicolumn{2}{|c|}{$\begin{array}{l}\text { Receiving incentive from the } \\
\text { institution }\end{array}$} & \multicolumn{2}{|l|}{$20 \%$} & \multicolumn{2}{|l|}{$27 \%$} \\
\hline \multicolumn{2}{|c|}{$\begin{array}{l}\text { Provide formal computer } \\
\text { instruction within the } \\
\text { program }\end{array}$} & \multicolumn{2}{|l|}{$57 \%$} & \multicolumn{2}{|l|}{$33 \%$} \\
\hline \multicolumn{2}{|c|}{ Computer prerequisite } & \multicolumn{2}{|l|}{$47 \%$} & $48 \%$ & \\
\hline $\begin{array}{l}\text { Mandator } \\
\text { lease }\end{array}$ & nership or & $9 \%$ & & 0 & \\
\hline
\end{tabular}


Finally, both groups demonstrated deliberate planning for incorporating CAI materials. This included well-planned instructional methods, such as guided discovery, reflection, portfolio assessment, project method, case studies, and part-to-whole learning.

\section{Research Question \#2}

What are faculty's perceptions regarding: positive aspects, negative aspects, type of learning that occurs, learning style, aptitude, and the overall impact of computers on physical therapy education?

\section{Quantitative Data}

Positive aspects of CAI most frequently reported by both PT and PTA respondents included improved knowledge of technology and improved independence with information gathering. PT respondents also reported improved communication between students and faculty, whereas PTA program respondents selected providing review sessions more frequently than improved communication.

Negative aspects of CAI most frequently reported by both groups included cost and lack of time for development. PT respondents also indicated that rapid obsolescence of hard/software was a negative aspect, but PTA respondents reported lack of time for integration more frequently than rapid obsolescence. Furthermore, PT respondents reported lack of faculty incentive more frequently than lack of time for integration.

One-third of PT and PTA educators indicated that CAI could improve problem-solving skills. Also, $3 \%$ of PT and $7.5 \%$ of PTA respondents reported that CAI could not effectively improve psychomotor skills. Both PT and PTA respondents indicated they were unsure as to what types of students benefit most from CAI (learning style and aptitude). 


\section{Qualitative Data}

\section{Positive Aspects of CAI.}

Qualitative data revealed student's development of computer skills as one positive aspect of CAI. This knowledge includes improved independence with information gathering and development of skills needed for clinical practice. An additional positive aspect was that CAI can be an effective educational tool. It can be used as a tool for traditional teaching by allowing better visual aides, or graphics. Or, CAI can be used for an alternative content delivery method, such as through a CD-ROM, or the Internet. In addition, the computer's use as an educational tool provides students with a variety of learning experiences. Other positive aspects included: more effective use of class time, student enjoyment, ability to provide immediate feedback, ability to provide hyperlinks, increased communication, ability to foster independent student work, and accessibility. Positive aspects of CAI were consistent for PT and PTA data.

\section{Negative Aspects of CAI.}

Qualitative data revealed cost and time to be negative aspects of CAI. Both cost and time were reported as being difficult to overcome. Additional negative aspects included lack of research on its effectiveness, lack of ability to develop psychomotor skills, and lack of institutional support. Also, both PT and PTA participants offered the same limitations for WBI in physical therapy education; these included its inability to develop psychomotor skills, and its inability to provide face-to-face interaction among students and faculty.

Programs provided information on how they are overcoming these negative aspects. These included: acquiring grant funding, sharing costs with other programs, allocating budget money, and seeking out donations. Strategies identified to overcome the time factor included: negotiating release time, using personal time, acquiring a graduate assistant or work-study 
student, or just keeping perspective. Negative aspects were consistent between PT and PTA respondents. Two PTA respondents indicated having problems related to declining enrollment and student quality that supersede those related to CAI.

\section{Type of Learning that Occurs.}

The perception of PT and PTA program respondents is that CAI can and does provide factual information. However, both PT and PTA respondents indicated that CAI can be used as an adjunct in attaining higher-level skills. This requires the instructor to design learning experiences effectively incorporating CAI with opportunities for students to achieve higher-level skills. Here, these learning opportunities were being provided through integration of case studies in class, web-based cases requiring viewing of real or simulated patients, and use of action research by developing strategies for addressing medications in a PT department.

\section{The Perceived Impact of Computers on PT/PTA Education.}

Qualitative data revealed both PT and PTA educators' perceptions of the overall impact of computers on physical therapy education. First, data suggest that computer skills are needed so students can access information quickly and easily. PT respondents specifically indicated accessing information for evidence-based practice, whereas PTA respondents did not. Second, computers have improved content delivery and provide alternative methods for content delivery. Third, both PT and PTA respondents offered skeptical views of the impact of CAI, suggesting the CAI is only a tool, and should be used wisely.

PT and PTA interview participants offered dissimilar responses when asked if CAI should be incorporated into accreditation criteria. PTA participants reported that some PTA students might lack adequate resources to warrant this type of experience. Two PT interview 
participants indicated being in favor of incorporating CAI into accreditation standards, where three others were more skeptical.

\section{Research Question \#3}

How are programs selecting and evaluating CAI?

\section{Selection}

\section{Quantitative Data.}

Sixty-four percent of PT and 52\% of PTA reported recently purchasing new software. Of those who purchased software, both PT and PTA programs indicated that anatomy software was purchased most frequently. Ten percent of PT and PTA programs reported that they had stopped using software. Sixty-five percent of PT and 54\% of PTA programs reported designing their own CAI materials.

\section{Qualitative Data.}

Both PT and PTA program respondents indicated using practicality, content, and faculty opinions for selecting instructional software materials, although 12 PT respondents and 16 PTA respondents reported they were not using any selection criteria. One PT respondent indicated using an instructional design strategy.

\section{Evaluation}

\section{Qualitative Data.}

Both PT and PTA programs indicated using a variety of methods for evaluating CAI.

These included student performance outcomes, program outcome assessments, and instructor and student feedback. There were, however, members from both groups who reported not using any formal evaluation process for CAI. One reason given for this was the computer is only a tool for the delivery and does not need to be evaluated. 


\section{Research Question \#4}

Do computer-based licensing exams influence faculty decisions to integrate CAI?

\section{Quantitative Data}

Sixty-four percent of PT and 56\% of PTA educators responded that CAI use in their program adequately prepares students for the computer-based licensing exam. Thirty-four percent of PT and $40 \%$ of PTA educators reported that the computer-based licensing exam had influenced their decision to incorporate CAI. Results indicated no correlation $(r=.088)$ between amount of CAI used and the licensing exam pass rate. Also, results indicated no correlation between pass rate and whether or not the program integrated computer-based testing $(\mathrm{r}=.095)$.

\section{Qualitative Data}

Respondents were asked to respond to why computer use in their program does or does not prepare students for the computer-based licensing exam. Of those who reported computer use adequately prepares students, reasons given were that CAI increases comfort, increases familiarity with this type of testing, and decreases anxiety. A reason given for why computer use does not prepare students was that minimal computer skills are required to take the exam.

Reasons given by respondents who indicated computer-based testing influenced their decision to use CAI were to improve student preparation and decrease anxiety. Reasons given by respondents who indicated computer-based testing did not influence their decision to use CAI were: They were already integrating computers before the exam went to a computer based mode, students were already familiar enough with computers, and there is no correlation between the two. 


\section{CHAPTER FIVE: INDUCTIVE ANALYSIS AND DISCUSSION}

The purpose of this chapter is to present the emergent concepts from the qualitative data. Methodological triangulation of these concepts is also described and illustrated. This section includes a discussion of all results, quantitative and qualitative, answering the four research questions. Results are then compared with current literature on CAI.

\section{Inductive Analysis}

Qualitative data were transcribed and coded according to concepts that appeared. A concept can be defined as an idea, or understanding, that is derived from a set of experiences. Concepts in the data were identified by key phrases and examples given by participants. These are also known as indigenous concepts (Patton, 1990).

Concepts in the data were clustered and counted. General concepts subsumed more particular ones, and the result was emergent concepts used to describe perceptions of CAI in physical therapy education. Concepts emerged from the data in that as data were collected and analyzed, key concepts appeared, or came into view. Their emergent nature was such that openness and flexibility to new concepts remained as data collection and analysis continued (Patton, 1990).

\section{Emergent Concepts from Qualitative Data}

The following concepts emerged from the qualitative data to describe perceptions of CAI for participants in this study.

\section{CAI can help students develop computer skills}

Questionnaires, interviews, and document analysis suggest that CAI has provided students with improved computer skills. Interview participants noted that students have become 
Table 5.1 Frequency of Appearance of Major Concepts in all Qualitative Data

\begin{tabular}{|l|l|}
\hline CAI is an instructional tool & 20 \\
\hline Improves communication & 20 \\
\hline Does not develop psychomotor skills & 14 \\
\hline $\begin{array}{l}\text { CAI allows factual information while the instructor should incorporate it in a } \\
\text { way that higher-level skills are achieved }\end{array}$ & 11 \\
\hline Institutional support must be considered & 9 \\
\hline CAI helps develop computer skills needed for the future & 8 \\
\hline PTA students may lack adequate access & 8 \\
\hline Lack of research on its effectiveness & 7 \\
\hline Computers allow access to information & 6 \\
\hline CAI viewed with skepticism & 6 \\
\hline
\end{tabular}


Table 5.2 Particular Concepts Subsumed by More General Ones

\begin{tabular}{|c|c|}
\hline General & Particular \\
\hline 1. CAI is an instructional tool & \\
\hline $\begin{array}{l}\text { 2. CAI helps students develop computer } \\
\text { skills }\end{array}$ & $\begin{array}{l}\text { Computers allow students to access } \\
\text { information }\end{array}$ \\
\hline 3. Context & Institutional support must be considered \\
\hline & PTA students may lack adequate access \\
\hline $\begin{array}{l}\text { 4. CAI allows factual information while } \\
\text { the instructor should incorporate it } \\
\text { in a way that higher-level skills are } \\
\text { achieved }\end{array}$ & \\
\hline 5. Improves communication & \\
\hline $\begin{array}{l}\text { 6. Limitations of CAI (CAI viewed with } \\
\text { skepticism) }\end{array}$ & Lack of research on its effectiveness \\
\hline & WBI does not develop psychomotor skills \\
\hline
\end{tabular}


more computer "savvy" since opportunities for computer use have increased. Students will need these computer skills for clinical practice, especially searching the Internet to access current information. One respondent indicated, "Computers have potential to revolutionize the way PT is practiced. Evidence-based practice is grounded in computing. They will fundamentally change the way PT is constructed." Document analysis revealed students using the Internet for seeking out patient treatment information and for developing advanced educational web sites.

Questionnaire respondents indicated that "Technology is here to stay" and students need to become familiar with its use. Additional questionnaire data indicated that we have an obligation to students to prepare them for the future, and that includes computer use.

\section{The computer can be an instructional tool}

All interview respondents indicated how they are using the computer as an instructional tool. Participants indicated using the computer to provide better "visuals" through integration of QuickTime $^{\circledR}$ movies and enhanced graphics during lecture. Also, participants indicated using the computer to deliver content through web pages. In these cases, the amount of web-based content varied. There were programs using the web to provide a portion of content, via web-enhanced instruction; whereas other programs noted delivering all of a course's content via web-based instruction, or WBI. There were also participants using instructional CD-ROMs to provide enhanced visual aides to students. These CD-ROMs were also used for students to access outside of class to review content and view psychomotor skills. Participants also described using the computer for administration of online quizzes. Review of items submitted by participants substantiated their claims that the computer is being used as an instructional tool. Questionnaire data further indicated that the computer is another tool we have available. 
Questionnaire data also indicated that the computer has the ability to be used as an instructional tool that provides a variety of learning experiences. Examples of written responses include that it "offers multiple modalities," "increases learning opportunities, "captures students with different needs, "adds diversity to the learning environment", and "provides another medium for student learning."

\section{CAI allows factual information while the instructor should incorporate it in a way that higher- level skills are achieved.}

Respondents agree that CAI can be used to present factual information. Definitions, concepts, and facts can be easily posted for student access. Yet interviews, document analysis, and questionnaire data indicate, "The instructor is the key" for incorporating activities that allow students to engage in higher-level thinking activities and go beyond the factual level. Case examples indicate that course web pages can be designed to provide assignments requiring application, analysis, and evaluation of material. These examples also show how students are using the discovery method to answer guiding questions provided by the instructor. Finally, other cases include students accessing CAI to get the factual information, and then during traditional class meetings, the instructor presents case studies, requiring students to apply the information. So, whether it is through designing the CAI itself, or through application during class time, the instructor's responsibility is to assure that higher-level learning experiences are provided.

\section{Computers have improved communication among students and faculty}

Qualitative data indicate that both PT and PTA program faculty are placing course information on web sites for students to access at their convenience. This includes copies of syllabi, lab schedules, practical schedules, and class announcements. Course material is also 
being placed on these web sites. Lecture notes, discussion questions, assignments, and answer keys are among materials being posted for both PT and PTA students.

Also, five PT and two PTA interview respondents indicated using chat rooms or bulletin boards while students are on their clinical affiliations to encourage discussion among students and faculty. Faculty members are posting questions, and the students must respond based on their experiences at the clinical site. Students respond not only to the instructor, but also to each other.

\section{The context of the program should be considered when choosing to incorporate CAI}

The setting of the educational experience is important and requires consideration before integrating CAI. One PTA interview participant offered the following, "Institutions need to fully appreciate the (faculty's) commitment by protecting them with policies and support services." This may be happening more in some institutions than others. For example, participants indicated taking continuing education courses, on and off-campus, receiving funding or release time, adding money to the program budget, sharing costs, and having a variety of on-campus support services. These may not be offered in all settings and must be considered before integrating CAI.

Also, some PT or PTA programs may have computer course requirements because of institutional demands. Also, some schools may have more developed computer policies than others, such as mandatory ownership policies or laptop leasing programs. Because of this, use of CAI in these schools may be more widespread.

The types of students must also be considered when integrating CAI. Interview respondents suggest teaching strategies should not be forced, but should evolve from an ongoing program review process. If strategies are forced, some students may not benefit because they may be limited in their resources, or access to technology. Also, PT and PTA students require 
different learning experiences, and strategies should be geared toward needs of the group.

Furthermore, if students already have good computer skills upon entering the program, then instructors may not feel the need to incorporate CAI. Finally, two PTA programs indicated struggling with decreasing student quality, and one indicated having to spend a lot of time on basic information. Therefore, because of these differences, student-related issues should be considered when deciding to use CAI.

\section{CAI has limitations}

Although many positive aspects of CAI were indicated in the qualitative data, both interview participants and questionnaire respondents indicated that CAI has limitations. Many specific examples of these limitations were provided in the qualitative data. A discussion of these CAI limitations is provided here. First, there may be differences in what we teach and what is on the software. PTA2 indicated that some software shows a variety of ways to perform a skill. She went on that students have lost points on practical exams because they perform the skill in a way provided on the $\mathrm{CD}$, but not wanted for the practical exam. Students do this after she specifically tells them the way she wants the skill to be performed for the practical exam. She adds this is confusing for some students.

Both PT and PTA programs reported placing instructional software in the computer lab for students to access. Yet, PTA3 reported that unless it is mandatory, students would not use it. She reported that integration of computer-assisted instructional materials should be beyond "Here it is."

Another limitation of CAI is due to the fact that physical therapy practice requires a considerable amount of hands-on, or psychomotor skills. PT1, 2, 3, and 4 as well as PTA1, 2, 3, and 4 agree that students cannot develop necessary psychomotor skills in courses taught entirely 
online. PT1 suggested that it would be too difficult to teach entry-level courses through a total web-based format, such as WBI, because of these hands-on skills. PT2 and PTA 1, 2, 3, and 4 added that students and faculty have to get together for lab work.

Furthermore, qualitative data indicated that instruction offered entirely over the web causes students and faculty miss out on face-to-face discussions. Both PT and PTA interview participants indicated that students should be exposed to interaction and discussion that take place during traditional classroom meetings. These respondents are reluctant to give up the traditional approach because of the lack of professional level interaction in a web-based classroom.

Another example of a CAI limitation is the lack of evidence that it provides superior learning experiences. PTA3 posed the following question, "If there is no evidence that it enhances learning, then why use it?" Other interview participants indicated that there is no guarantee that additional learning is taking place. Finally, one questionnaire respondent reported, "We all think we should use (computers), even if there is no evidence that they aid in student learning."

Additional limitations of CAI include the cost of the materials and time required for integration. Questionnaire and interview data indicated that cost and time factors have limited use in some schools. PT4 reported that he did not know how to overcome the "lack of time factor." Other questionnaire respondents indicated they were "struggling to keep up."

\section{Methodological Triangulation of the Emergent Concepts}

The six emergent concepts that have been identified and described above were verified through methodological triangulation (Table 5.3). Methodological triangulation occurred through the use of different methods of data collection, the questionnaire's open-ended items, interviews, 
and document analysis. If a concept emerged from the open-ended questionnaire items, it was substantiated in the interviews and document analysis. Further, if a new theme emerged during the interviews, it too was substantiated in other aspects of the data.

Table 5.3 Methodological Triangulation

\begin{tabular}{|c|c|c|c|c|c|c|c|}
\hline & & 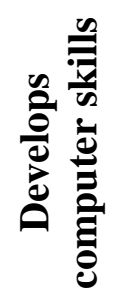 & 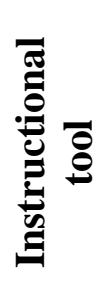 & 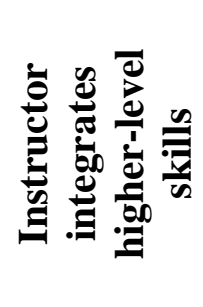 & 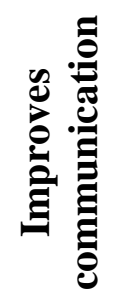 & ن̃ & م \\
\hline \multirow{11}{*}{ 离 } & PT1 & $\mathrm{x}$ & $\mathrm{x}$ & $\mathrm{X}$ & $\mathrm{X}$ & $\mathrm{x}$ & $\mathrm{X}$ \\
\hline & PT2 & $\mathrm{X}$ & $\mathrm{x}$ & & & & $\mathrm{X}$ \\
\hline & PT3 & & $\mathrm{X}$ & $\mathrm{X}$ & $\mathrm{x}$ & $\mathrm{x}$ & $\mathrm{X}$ \\
\hline & PT4 & & $\mathrm{X}$ & & $\mathrm{X}$ & $\mathrm{x}$ & $\mathrm{X}$ \\
\hline & PT5 & $\mathrm{x}$ & $\mathrm{X}$ & $\mathrm{X}$ & $\mathrm{x}$ & $\mathrm{x}$ & \\
\hline & PT6 & & $\mathrm{X}$ & & $\mathrm{x}$ & $\mathrm{x}$ & \\
\hline & PTA1 & $\mathrm{X}$ & $\mathrm{x}$ & & & $\mathrm{x}$ & $\mathrm{X}$ \\
\hline & PTA2 & $\mathrm{x}$ & $\mathrm{X}$ & $\mathrm{X}$ & & $\mathrm{x}$ & $\mathrm{X}$ \\
\hline & PTA3 & $\mathrm{x}$ & $\mathrm{x}$ & $\mathrm{X}$ & & $\mathrm{x}$ & $\mathrm{X}$ \\
\hline & PTA4 & & $\mathrm{X}$ & $\mathrm{x}$ & & $\mathrm{x}$ & $\mathrm{x}$ \\
\hline & PTA5 & $\mathrm{x}$ & $\mathrm{X}$ & $\mathrm{X}$ & & $\mathrm{x}$ & $\mathrm{X}$ \\
\hline \multirow{2}{*}{ 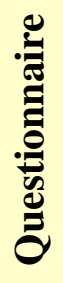 } & PT & $X$ & $\mathrm{X}$ & $X$ & $X$ & $\mathrm{X}$ & $\mathrm{X}$ \\
\hline & PTA & $\mathrm{X}$ & $\mathrm{X}$ & $\mathrm{X}$ & $\mathrm{X}$ & $\mathrm{X}$ & $\mathrm{X}$ \\
\hline \multirow{10}{*}{ 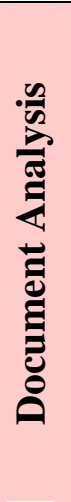 } & 1 & $\mathrm{X}$ & & & & & \\
\hline & 2 & & $\mathrm{x}$ & $\mathrm{X}$ & $\mathrm{X}$ & & \\
\hline & 3 & $\mathrm{x}$ & & $\mathrm{x}$ & & & \\
\hline & 4 & $\mathrm{x}$ & & & & & \\
\hline & 5 & & & & & & \\
\hline & 6 & $\mathrm{X}$ & & $\mathrm{X}$ & & & \\
\hline & 7 & $\mathrm{x}$ & $\mathrm{x}$ & $\mathrm{x}$ & $\mathrm{X}$ & & \\
\hline & 8 & & $\mathrm{x}$ & $\mathrm{X}$ & & & \\
\hline & 9 & & $\mathrm{X}$ & $\mathrm{X}$ & & & \\
\hline & 10 & $x$ & $\mathrm{X}$ & $\mathrm{X}$ & & $\mathrm{x}$ & \\
\hline
\end{tabular}




\section{Discussion of Results}

\section{Research Question \#1}

What are the similarities and differences in amount and uses of CAI in PT and PTA programs?

\section{Similarities}

This is the first study to describe and compare CAI use in PT and PTA programs.

Quantitative data indicate no significant difference in the amount of CAI being used between PT and PTA programs. Also, the number of programs using instructional CD-ROMs (77\% PT, 78\% PTA) and online quizzes (37\% PT, 22\% PTA) is comparable between PT and PTA programs. Both groups are also using CAI most frequently for optional tutorials (55\% PT, 56\% PTA). Other similarities include the percentages of faculty members taking continuing education courses (76\% PT, 59\% PTA) and receiving institutional incentive (20\% PT, 27\% PTA). The percentages of programs that have a computer prerequisite are also similar (47\% PT, 48\% PTA).

It is interesting to note that PT and PTA schools offering incentive to faculty use an average amount of eight $(S D=7.37$, range $=0-32)$ different types of CAI. Also, where incentive is not being provided, there is a mean amount of nine $(S D=9.0$, range $=0-46)$ different types of CAI being used. There were no statistical analyses done to determine significance, although it is unlikely based on the large standard deviations and ranges of CAI reported. Nevertheless, this still is interesting because of the financial and time commitments required for integration of CAI.

Only 9\% of PT and no PTA programs require students to own a computer. A study by McAuley in 1998 indicated that $10 \%$ of the nation's medical schools were requiring students to have computers. Results of this study suggest the importance of the context of the program, in that the institution may dictate whether or not a program has mandatory ownership or access. 
Mandatory ownership may be more feasible in institutions where (a) computers are required, (b) network access is available, (c) software is standardized, (d) technical support is provided, and (e) when a majority of course material is provided via the web.

Qualitative data indicated similar concepts emerged for both PT and PTA participants. All six of the emergent concepts reported previously appeared in the data for both groups. These include that CAI helps develop computer skills, the computer is an instructional tool, one role of the instructor is to incorporate higher-level learning, computers have improved communication, the context of the program is important, and that CAI has limitations for physical therapy education.

\section{Differences}

Quantitative data indicated differences between PT and PTA programs including use of web pages (80\% PT, 43\% PTA) and use of chat rooms (40\% PT, 12.6\% PTA). PT programs reported using CAI most frequently in anatomy, kinesiology, and research; whereas PTA programs' most frequently reported content areas were procedures, kinesiology, and therapeutic exercise. Types of CAI matched by content area for PT programs were (a) CD-ROMs for anatomy and (b) web pages for research, and for PTA programs were (a) CD-ROMs for procedures and (b) CD-ROMs for anatomy. More PT programs are providing formal instruction in computer use than PTA programs (57\% PT, 33\% PTA).

These differences are expected due to different contexts and goals of PT and PTA programs. PT programs are more focused on research and evidence-based practice, and the reason (why) to carry out physical therapy procedures. Therefore, PT programs use the Internet more frequently to carry out this research. Also, PTA programs are more likely to be focused on how to carry out physical therapy procedures, and are more likely to use procedural-type 
software. Furthermore, PTA programs are more likely to be community college based and enroll more non-traditional students who may be more intimidated by computers. These non-traditional students may be less likely to access the Internet when searching for information. Results suggest more PT programs are providing formal computer instruction than PTA programs. This finding may also be due to differences of the two programs. First, in addition to physical therapy related content, PT students are exposed to research methods, statistical packages, and presentation skills, so these computer skills may be provided in PT programs that are not provided in PTA programs. Also, the length of time spent in PT programs is considerably longer than PTA programs, and therefore PTA programs may not have enough time for these additional learning experiences.

\section{Research Question \#2}

What are faculty's perceptions regarding: positive aspects, negative aspects, type of learning that occurs, learning style, aptitude, and the overall impact of computers on physical therapy education?

\section{Positive Aspects of CAI}

Quantitative data indicated the two most frequently reported positive aspects of CAI were improved independence with information gathering (73.8\% PT, 60.4\% PTA) and improved knowledge of technology (63.8\% PT, 66.0\% PTA). This was consistent for both PT and PTA programs. Qualitative data (PT and PTA) also suggested that CAI allows students to develop computer skills needed to access information. In addition, qualitative data suggested that computers provide educators with another instructional tool. The ability of the computer to be used as "an instructional tool" was not provided as a choice for positive aspects on the questionnaire. The computer can be used as a tool for traditional teaching by allowing better 
video clips, graphics, and links to external sites. It can also be used as an alternative delivery method. Furthermore, the computer can provide students with multiple mediums for learning, create diversity in the learning environment, and increase opportunities for learning.

Other positive aspects reported by PT and PTA respondents warrant further discussion. First, $56.3 \%$ of PT and only $23.6 \%$ of PTA respondents indicated that increased communication was a positive aspect of CAI. Contextual differences between PT and PTA programs may account for this difference. PT programs have more faculty members and students, perhaps requiring additional means of communication. Also, PT students typically travel further and spend more time in clinical education, away from the faculty and the institution, again requiring additional means of communication. This combination may be a reason for additional communication needs for PT programs, thus accounting for the higher communication response in this group.

For communication, there was discrepancy between quantitative and qualitative data. While quantitative data indicated a higher communication response for PT programs, qualitative data suggested that computers have improved communication among faculty and students for both PT and PTA programs. It is possible that although computers have improved communication for both PT and PTA, PTA questionnaire respondents might see other aspects of CAI being more important than communication. For example, 53.8\% of PTA indicated the ability to provide review sessions was a positive aspect of CAI. Perhaps in PTA programs, the need for review sessions surpasses the need for better communication. Also, PTA programs are shorter and may not have enough time for providing students with formal review sessions. Therefore, faculty members use CAI to provide additional needed review. 
This is the first study to examine perceptions of CAI's positive aspects in physical therapy education. However, results are consistent with positive aspects reported elsewhere in the literature. Henry (1990) and Osheroff (1997) indicated that computers afford students with ways to access relevant and timely information. Griffin and Schumm (1992) and Mangrulker, Whelan, and Williams (1999) reported CAI improves students' information search abilities. Cohen (1995) reported CAI offers better visualization, student interest, clarity, and ability to review. Chodorow (1996) reported that better communication between faculty and students and review sessions were positive aspects of CAI. Finally, Hoffman and Ritchie (1997) reported the computer could be used as a tool for improving learning, especially in delivering case studies to students because of opportunities with graphics, animation, still images, video, and audio. They reported the computer could provide patient case information salient to the students' understanding that is not available through paper-based cases. Hoffman and Ritchie also reported that computers could be used to allow students to see real life situations, enhancing the fidelity of the scenario. Using CAI to deliver patient cases would be appropriate for both PT and PTA students.

\section{Negative Aspects of CAI}

Both PT and PTA respondents most frequently reported cost (52.5\% PT, 60.4\% PTA) and lack of time for development (73.6\% PT, 61.3\% PTA) as negative aspects of CAI. Qualitative data also indicated that cost and time are limitations associated with CAI. Cost and time constraints associated with CAI have also been reported in the literature (Chin \& Horton, 1993; Christie, 1990; Chodorow, 1996; Coggan, Hoppe \& Hadac, 1984; Friedman, 1996; Hoffer, 1986; Muma \& Mayta, 1998; Piemme, 1988; Rizzolo, 1990; Weiss, 1990). 
Qualitative data suggested additional limitations of CAI. For example, both PT and PTA participants agree that interaction and discussion, or "face-to-face interaction," among instructors and students is lost with this method, and some "students still need teachers in their presence." Lack of face-to-face interaction with CAI was not provided as a choice on the questionnaire under negative aspects. This limitation (lack of face-to-face interaction) that emerged from qualitative data is consistent with findings from Faux and Hughes (2000) who reported on students' comments after reading material posted on a course web site and completing a worksheet. Comments provided included lack of interaction, feedback, and auditory stimulation with the Internet assignment. These findings have important implications for allied health educators in that we must consider the importance of human relations and interactions needed for our professions, and this must be considered when designing, selecting, or implementing CAI.

There were discrepancies between CAI limitations given in qualitative data and negative aspects of CAI indicated in the quantitative data. First, interview participants agreed that instruction that is entirely web-based does not allow students to develop necessary psychomotor skills. The inability for CAI to develop psychomotor skills was listed as a negative aspect by only $15 \%$ of PT and $9.9 \%$ of PTA questionnaire respondents. In addition, qualitative data indicated that a limitation of CAI is the lack of research on its effectiveness. Twenty-two percent of PT and PTA questionnaire respondents indicated that lack of research was a negative aspect of CAI.

Results indicate that both PT and PTA programs are exploring solutions to overcome barriers associated with CAI integration. These strategies include detailed strategic planning, acquisition of grant funding, slow integration occurring each year, acquisition of donations, increasing budget money allotted for CAI, and sharing with other programs. These strategies are 
consistent with those reported in the literature for overcoming barriers associated with CAI (Chin \& Horton, 1993; Hoffer, 1986; Muma \& Mayta, 1998; Rizzolo, 1990; Weiss, 1990). Other strategies reported in the literature include schools providing continuing education, release time, and a reward system (Chin \& Horton).

\section{Type of Learning that Occurs with CAI}

\section{Problem Solving Skills.}

In 1997, an evaluation of instructional software indicated that most software offers just the facts, using a "transmission model" without showing students how to make sense of the information. Also, it suggested that software had a high entertainment value, but little educational value (Fenmore, as cited in Educational Software gets a Failing Grade. Bioscience, 1997). Qualitative results in this research indicate that factual information can easily be taught via CAI. However, in this study, $37 \%$ of PT and $29 \%$ of PTA program respondents indicated that a benefit of CAI was that it improving problem-solving skills. Nevertheless, these questionnaire respondents may have had different definitions for problem-solving skills, and the questionnaire did not elicit or give information regarding these definitions.

Qualitative data suggest that the role of the instructor is to integrate CAI so that higherlevel thinking skills, like problem solving, are embedded into courses with the CAI. The instructor must integrate CAI to meet a specific educational goal, and this goal might be presentation of facts. If so, qualitative data suggest that it is the role of the instructor to determine how the student will use the facts to achieve higher-level thinking skills. PT5, PTA5, and 6 indicated that CAI, when appropriately designed, could provide students with these experiences. For example, one respondent indicated presenting facts via CAI and then using class time to review case studies. Another respondent indicated using CAI for students to take online quizzes 
to be sure the facts were known and then, using class time to integrate higher-level skills. Others suggested presenting cases with video and audio clips, presenting cases where the patient's status changes, providing students with guided discovery questions, or requiring assignments that encourage higher-level thinking skills.

Other research suggests that individuals have started to design CAI that might allow students to develop higher-level thinking skills. Boyle (1991) suggests that computer-based patient simulations that incorporate factual information, simulation projects, and testing can allow students to develop skills for gathering and interpreting information. Hooper, O'Connor, and Cheesmar (1996) also reported development of a prototype software program using interactive clinical cases that allows students to make diagnoses and informs students of the results of their actions. However, neither of these software programs has been formally evaluated. Frear and Hirschbuhl (1999) reported that a CAI module, where the students assume the role of an investigator and are then forced to make critical decisions about data presented, improved problem solving skills. These latter authors suggest that it is important for the CAI to be interactive and engage the students. This was the only study that formally tested development of higher-level thinking skills with CAI.

\section{Psychomotor Skills.}

Three (3.8) percent of PT and 7.5\% of PTA respondents indicated that a positive aspect of CAI was that it improved psychomotor skills. Fifteen (15.4) percent of PT and 9.9\% of PTA respondents indicated that a negative aspect of CAI was that it cannot improve psychomotor skills. PT and PTA interview participants agree that students cannot develop necessary psychomotor skills in courses taught entirely online. Both groups also agree that these skills should be taught via traditional laboratory format. By integrating psychomotor skills in a 
traditional format, students gain the hands-on experience under direct supervision of an instructor who can provide them with immediate feedback. Immediate feedback is necessary when students are practicing psychomotor skills in order to correct hand placement, speed or direction of movement, patient position, or other necessary components of physical therapy procedures. While the student can access the visual demonstration of a skill, via CD-ROM or the Internet, these means of transmission do not provide students with necessary feedback needed for skill development.

In PTA programs, procedural software (goniometry and manual muscle testing), kinesiology, and therapeutic exercise were reported to be the most popular content areas where $\mathrm{CAI}$ is being used. This is interesting given the previous discussion on the perception of psychomotor skill acquisition. Although, video clips and graphics used in instructional software can provide students with a review of the actual laboratory session. Students can use CAI materials to review, practice, and reinforce psychomotor skills when the instructor is not available. Yet no matter how beneficial these software items may be, during these practice experiences students are still not provided with feedback from an expert for technique correction. This requires the instructor to design adequate traditional laboratory and practice experiences for students so that feedback is provided at necessary intervals in their learning.

According to Dowding (1994), using CAI as the only format to teach psychomotor skills could result in students learning incorrect techniques. Dowding argues that if psychomotor skills are learned wrong and practiced wrong, then later correction of that skill could cause confusion and possibly hinder retention. More importantly, he urges that learning these skills incorrectly could result in harm to a patient. 


\section{Learning Style and Aptitude}

Previous research suggests that CAI might appeal more to visual learners (Halloran, 1995), that student's learning style (inductive or deductive) should be matched with the type of instruction (Carlson, 1991), and that field-dependence should be determined in order to match the students with program or learner-controlled situations (Khine, 1996; Yoon, 2000). Other research suggests that students benefit when there is a combination of learning styles incorporated into the software (MacDonald \& Caverly, 1999; Levin, 2000; Washington \& Parnianpour, 1997). Results of this study indicate that $60 \%$ of PT and $49 \%$ of PTA respondents are unsure as to what type of learning style (auditory, visual, or kinesthetic) benefits most from CAI; while $29.7 \%$ of PT and $40.8 \%$ of PTA indicated that the kinesthetic learning style benefits most. This is interesting given the previous discussion of psychomotor skills and the ability of the computer to enhance the visual experience. It seems as though the visual learner would benefit most with this type of instruction, and the kinesthetic learner would benefit least because of their need to perform the skill. More research on learning style and CAI is needed to determine if one style benefits more with this type of instruction. In addition, results indicate that $70 \%$ of PT and $54 \%$ of PTA educators are unsure as to whether aptitude influences learning with CAI. Data from the qualitative aspect suggest that CAI offers many different possibilities for learning, and therefore might appeal to a variety of learners.

\section{Perceived Impact of CAI on Physical Therapy Education}

This is the first research to assess the perceived impact of computers on physical therapy education. Emergent concepts from qualitative data provide several perceptions related to the impact of computers. First, some respondents indicated that there is little impact on content, but computers allow students to develop computer skills needed for accessing information. Also, 
they can serve as effective tools for instruction, and they have improved communication among faculty and students.

More skeptical respondents however indicated limitations associated with CAI. For example, one respondent indicated that the wealth of information available on the Internet might be overwhelming to entry-level students, and faculty need to make sure students understand it in a "stepwise and organized way." Kuriloff (2000) also urges that we need to guide students when using the Internet, teach them to think critically, and analyze information. Then with our help, students can learn to gather appropriate information and reach thoughtful conclusions. Roschelle (1994) also reports that creating, discovering, and negotiating are far more important than just “accessing information.” Therefore, both PT and PTA instructors should help students develop skills not only to access important information but also to determine what information is important for physical therapy practice. This provides further evidence that the instructor must design appropriate learning experiences.

Furthermore, computer use in PT and PTA education should be context-based; PT and PTA students require different computer skills based on their scopes of practice. Finally, there was discrepancy between PT and PTA interview participants regarding their opinion of CAI in accreditation standards. PT responses varied from "We have an obligation to incorporate," to “This may not be viewed as a positive thing." However, all PTA participants indicated that some PTA programs might lack adequate resources needed for this type of experience. 


\section{Research Question \#3}

How are faculty selecting and evaluating CAI?

\section{Selection Criteria}

Results indicate that $65 \%$ of PT and 52\% of PTA programs have purchased instructional software. This included anatomy software for PT and PTA programs, as well as procedural and exercise software for PTA programs. Qualitative results indicated only one respondent using instructional design for software selection. These results point out that selection is based more on practical issues such as cost, ease of use, and compatibility with current operating systems. Results further suggest that selection is also based upon the content of the CAI materials and faculty interest.

Authors have reported the need for both a learning theory and instructional design embedded into CAI (Koller and Frankenfeld, 2000). Other authors have suggested using behaviorism and cognition when selecting or designing CAI (Bailey, 1996; Hardin, 1997; Hartley, 1999; Lawless \& Brown, 1997; Lee \& Boling, 1999; Shellnut, Knowlton, \& Savage, 1999; Sherry, 1998; Sponder \& Hilengfeld, 1994; Yang, 1996). Therefore, faculty members must consider the goal of the instruction when reviewing CAI materials. It is the role of the instructor to determine the appropriate level of learning, and then select or design CAI using the appropriate theoretical foundation. This will allow educators to determine whether CAI materials are consistent with the desired educational outcome.

\section{Evaluation Criteria}

Qualitative data indicate both PT and PTA programs using various methods for evaluating CAI. These included use of student performance outcomes, program outcomes data, student feedback, and instructor's feedback. Other authors have reported on the importance of 
having both formative and summative evaluation procedures that include quantitative and qualitative methods (Kaufman \& Lee, 1993; McNaught, 1999). Table 2.5 describes the questions asked during the evaluation processes reported by these authors.

\section{Research Question \#4}

Do computer-based licensing exams influence faculty decisions to integrate CAI?

\section{Programs Providing Adequate Preparation}

Sixty-four percent of PT and 57\% of PTA educators responded that CAI use in their program adequately prepares students for the computer based licensing exam. Of these, respondents indicated that computer use decreases anxiety associated with the exam and allows testing under the same conditions. These results are consistent with those of Bugbee (1996), who reported that computer anxiety might affect the test taker. He also reported that students with more computer experience had a less negative attitude toward computer-based testing. Given these results, one might suggest that programs have a responsibility to prepare students for this kind of testing medium when students have computer anxiety. Regardless, there were still respondents who indicated that computer-based testing is a relatively simple skill not requiring much preparation.

\section{The Decision to Integrate Computers}

Thirty-four percent of PT and $41 \%$ of PTA educators reported that the computer-based licensing exam had influenced their decision to incorporate CAI. Reasons given by these respondents included increasing student comfort and decreasing anxiety. However, quantitative results indicate no correlation $(r=.088)$ between the amount of CAI used in PT or PTA programs and licensing exam pass rate. Also, there was no correlation between licensing exam pass rate and whether or not the program uses computer-based testing $\left(r_{\mathrm{pb}}=.097\right)$. 
Of those who reported the licensing exam had not influenced their decision indicated they were already using CAI before the exam went to a computer-based mode, that students were already familiar enough with computers, and that there is no correlation between the two. One must consider the context of the program, and if students are already computer savvy, then it is likely that programs will not have to spend time preparing students for this type of testing. However, if computers intimidate students, then programs may have to spend more time on preparing students for computer-based testing. 


\section{CHAPTER SIX: IMPLICATIONS, FUTURE RESEARCH, AND CONCLUSIONS}

This chapter outlines important implications this research has for physical therapy education. Also, areas for future research on CAI in physical therapy are provided. Finally, conclusions are made regarding the perceived impact of CAI in physical therapy.

\section{Implications for Physical Therapy Education}

Results of this research have important implications for physical therapy educators. Consideration must be given to the six emergent concepts when designing instruction that includes CAI. Consideration must also be given to learning theories and instructional design when selecting and designing software. Finally, we need to perform an adequate evaluation to be sure that this method is superior to cheaper, traditional instructional methods

\section{The Emergent Concepts}

\section{CAI can help students develop computer skills}

We should identify computer skills needed for clinical practice and skills students need for the future. The requirement for PTs and PTAs to use computers in the clinical setting increases each year. As the need for evidence-based practice expands, clinicians will have to justify their actions using current information that is readily available. Also, more clinics are using computerized documentation and billing packages, therapeutic exercise programs, and computerized equipment. Busy clinicians need to be comfortable and efficient with technology to keep pace with the rapidly changing environment.

\section{The computer can be an instructional tool}

We should recognize the possibilities available with the computer and its abilities to meet needs of different students. The computer can be used to enhance traditional instruction by 
providing students with better visual aides. Also, it can be used for review outside of class and as a means of delivering course content. Nevertheless, instructors must keep perspective that the computer is only a tool for delivery, and we should not make our instructional goals to fit the computer, but the CAI should fit with the instructional goals. We need to determine if content delivery is more effective with the computer than with traditional methods, and we need to ask ourselves, "What is it about the computer that provides a better learning experience?" We also need to be aware of the limitations associated with using a computer as an instructional tool. CAI allows factual information while the instructor should incorporate it in a way that higherlevel skills are achieved

CAI should be incorporated in a way that allows students to learn the factual information and apply the facts using higher-level thinking skills. Case examples provide us with examples from the field of instruction being designed to incorporate factual and higher-level thinking. They need to determine the best mode of delivery to accomplish their goals and design learning experiences that are authentic, and simulate the clinical setting.

\section{Computers have improved communication among students and faculty}

Examples for using the computer to improve communication among students and faculty have been provided. These include the use of web pages to communicate course information and content, and use of synchronous and asynchronous communication during clinical rotations. Differences in quantitative and qualitative results suggest that different programs might have different communication needs. Therefore, we should not only be aware of ways computers improve communication, but also determine if these computerized methods could be integrated into existing programs in a meaningful way. 


\section{The context of the program should be considered when choosing to incorporate CAI}

When deciding to incorporate CAI, we should identify all resources available, including technical support, financial support, continuing education opportunities, and time required and allotted for development. Also, we should be aware of students' needs, program goals, program strengths and weaknesses, and current teaching strategies. Understanding the setting in which we operate will allow us to know what resources we have available, what our limitations are, and what learning experiences would be appropriate for the students and feasible for the setting.

\section{CAI has limitations}

Many limitations have been identified for CAI, and examples have been given. We need to adequately review software to determine learning opportunities it provides. Consistency between what is on the software and what is taught in the courses is important. We also need to decide if the CAI materials will be mandatory or optional and how we will have student access it. It has been proposed that unless it is mandatory, students will not use it. In addition, we need to design instruction so that skills not developed with CAI can be implemented using other methods. For example, participants agree that students cannot develop necessary psychomotor skills in courses taught entirely online. Instructional design should allow the computer to enhance traditional methods. Also, when using procedural software, students do not get adequate feedback that they would in a traditional format, from an instructor. Finally, with CAI, students miss out on face-to-face interaction. Developing human relations are vital to students because of the nature of our profession.

\section{Selection, Learning Theory, and Instructional Design}

Participants in this study indicated largely using practicality for selecting CAI materials. When faculty members select or design CAI materials, they must be aware of where the 
instructional goals fall on the teaching-learning continuum. The teaching-learning continuum encompasses factual learning, inquiry, and guided discovery. With factual learning, students are introduced to facts, information dissemination is emphasized, material is presented in a simple to complex manner, and retention occurs through drill and practice, rehearsal, programmed instruction, or mastery learning. Using this approach, instruction is designed so that objectives are clearly defined and hierarchical, as they have been seen in Bloom's Taxonomy and Gagne's Levels of Learning (Jacka, 1985; Joyce, Weil, \& Calhoun, 2000; Ornstein \& Hunkins, 1998). Some authors have advocated using this approach with CAI (Hardin, 1997; Sponder \& Hilgenfeld, 1994). Results of this study indicate that some CAI used in physical therapy education lies at this level. Learning at this level is appropriate for some material given the amount of factual information students need for clinical practice.

At the other end of the teaching-learning continuum is inquiry. The inquiry method of teaching emphasizes the process entirely, not facts. Using the inquiry method, instruction is designed so that students engage in opportunities that allow them to define a hypothesis, interpret data, and develop constructs. Once students have created meaning for their experiment, students work together to share their meanings with each other. Students engaged in inquiry exercises collaborate, theorize, problem-solve, interact, and defend. Methods useful for incorporation of inquiry include the scientific method, creative thinking, reflective exercises, and critical thinking. (Joyce, Weil, \& Calhoun, 2000). Inquiry involves the constructivist learning theories, and several authors have advocated implementing constructivism into CAI (Bailey, 1996; Burgess, 1996; Lawless \& Brown, 1997; Sherry, 1998; Yang, 1996; Koller \& Frankenfeld, 2000). These authors agree that CAI can allow interactivity, exploration, non-linear approaches to information gathering, learner control, and collaboration. Results presented here indicate that some CAI 
materials designed by physical therapy faculty members lie at this level. Also, this approach is similar to what physical therapists do when deciding on a treatment plan for patients. Therefore, this approach would be beneficial in some situations.

Between factual learning and inquiry, is guided discovery. Using guided discovery, the teacher designs instruction by providing a starting point, coordinating activities with students, and then directing students toward salient points. Student experiences are coordinated with predetermined goals and end points. Using guided discovery, the student's are presented with realistic problems or questions, and their role is to actively seek out information to assist in solving these problems (Joyce, Weil, \& Calhoun, 2000). John Dewey (1944) emphasized the need for linking education to these realistic experiences students will encounter in everyday life. Using guided discovery, the student is taught how to think, rather than what to think (Ornstein \& Hunkins, 1998). Results of this study indicate several schools using CAI at this level. Both PT and PTA students could benefit from CAI designed and integrated using guided discovery. Physical therapy education requires skills from all aspects of the teaching-learning continuum. Learning theory and instructional design are inherent within each aspect of the continuum. Sherry (1998) advocated using a "theoretical continuum" in teaching as well. In phase one, a foundation of information is established. In phase two, students are given a concept and must elaborate on it with specific examples, and for phase three, students become engaged in concept development.

When selecting or designing CAI materials, we need to recognize where our instructional goals fall on the continuum and associate them with the type of instruction provided by CAI. Once we recognize our goals, we need to have a theoretical framework that guides the instructional design process and allows us to make intellectual decisions about CAI material 
selection. The theoretical framework allows us to determine what learning experiences are provided with CAI and what experiences are missing. Croft (1993) suggested that we consider the computer's value in providing an educational experience. He goes on to say that unless the computer increases effectiveness and enhances meaning better than less-expensive tools, then it is "pointless to spend the money on it" (p. 302). Using an appropriate theoretical foundation, we will recognize the experiences provided through the CAI and determine its ability to provide meaning for our students. Finally, awareness of the instructional goals and the educational experience provided with CAI allows thoughtful selection and design decisions based on a theoretical framework, rather than practicality.

\section{Evaluation}

Through thorough evaluation processes, we can decide if CAI was beneficial and improved the learning environment. Authors have reported on their experiences for evaluating CAI incorporating both formative and summative evaluation and both quantitative and qualitative methods (Kaufman \& Lee, 1993; McNaught, 1999). In addition, Kaufman and Lee advocated using Stake's Countenance Model as a framework for evaluating educational software.

Stake $(1967,1983)$ provided a matrix (Table 6.1) for evaluating educational materials. Stake $(1967,1983)$ reported that decisions regarding educational materials should be based upon observing their use in action and discovering their purposes important to the group. Also, he reported that the evaluation process should examine participants 1) before engaging with the material (antecedents), 2) during the engagement (transactions), and 3) after their interaction with the material (outcomes). Using this model, intents of the educational material are determined, observations are made of students using the material, standards are applied to the 
descriptive data, and finally judgments are made. All four of these areas are evaluated before, during, and after the engagement. This model allows the observer to evaluate the differences between the intended and observed instruction as well as the strength of the observed outcomes and the observed transactions (Stake 1983).

Table 6.1 Data to be Collected During Educational Evaluation

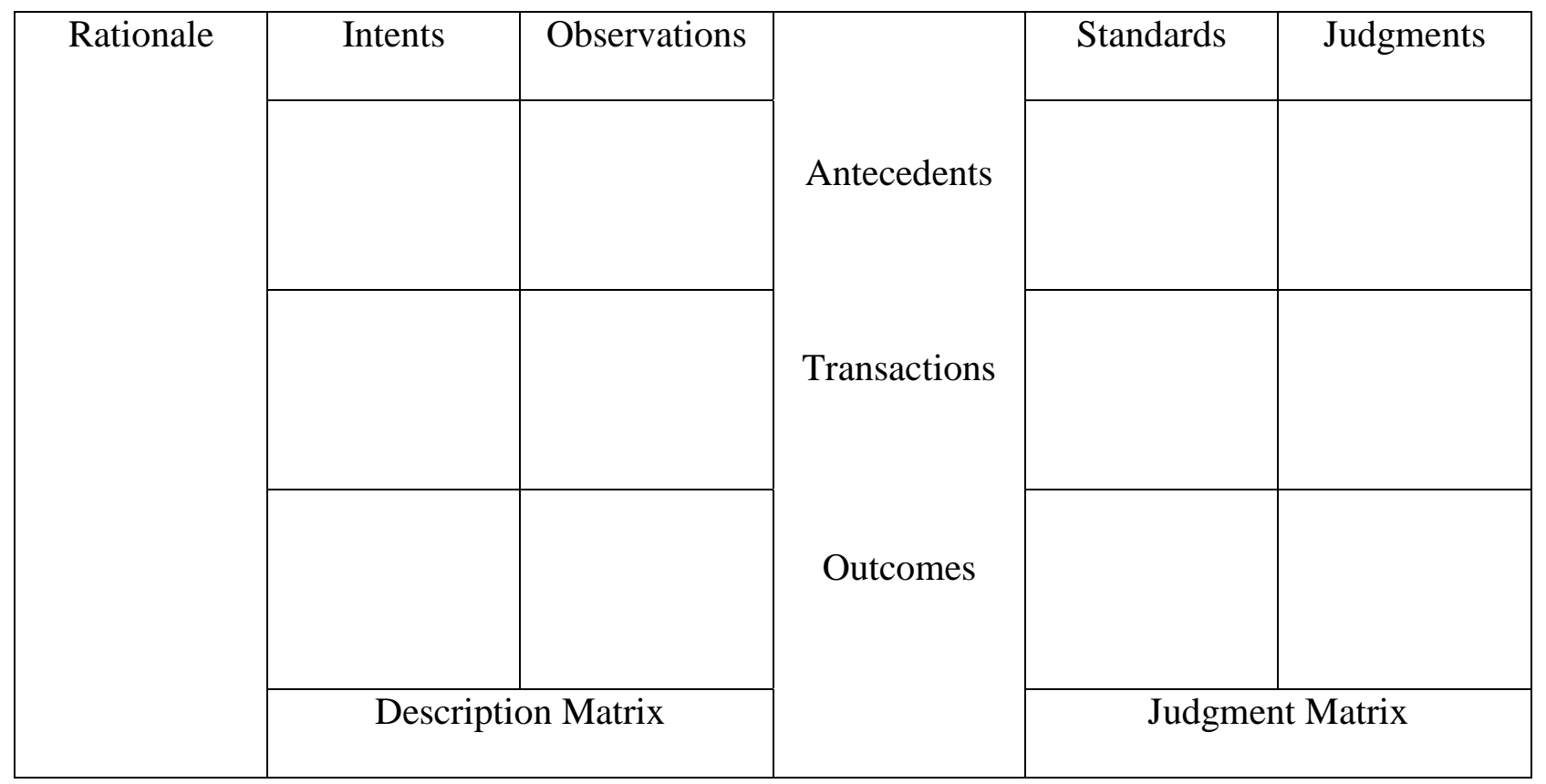

Taken from: Stake, R. E. (1983). Program Evaluation, Particularly Response Evaluation. In

Maudus, G. F., Scirven, M., \& Stufflebeam, D. L. (Eds.). Evaluation Models: Viewpoints on educational and human service education. Boston, MA: Kluwer-Nijhoff Publishing.

\section{Future Research}

The goal of this research was to describe current perceptions and uses of CAI in physical therapy education. It allows us to identify the "present state of affairs" while allowing us to 
examine areas for development and improvement within our own programs. It also has provided strategies for integration, selection, and evaluation. Results of this study also provide a research agenda so that we can decide if the computer provides appropriate experiences for physical therapy education. These areas of future research include examining the effects of CAI on immediate recall, retention, higher-level thinking skills, and application of material to clinical practice for PT and PTA students. In addition, a study is needed describing the effectiveness of computer-based simulations, quizzes, case studies, and guided discovery questions on improving entry-level students' clinical problem-solving skills. Also, a comparison of CAI with traditional instruction (textbooks, handouts, discussion, lecture, etc) for PT and PTA students is also warranted.

Further studies to examine learner attributes and CAI are also warranted so that we understand ways CAI affects different students. For example, we need to understand the effects of CAI on high and low aptitude students, and whether it functions differently across PT and PTA students. A study is also needed to determine the effects of CAI on students with different learning styles. Furthermore, because conflicting results were found between quantitative and qualitative data concerning the computer-based licensing exam, it is necessary to examine computer anxiety among students preparing for the computer-based licensing exam. Finally, it would be interesting to repeat this study in five, and ten years so that we can identify trends in computer use within physical therapy.

\section{Conclusion}

In conclusion, the perceptions of CAI in physical therapy education have been listed and strategies for using CAI have been provided through case studies. There is no difference in the amount of CAI between PT and PTA programs, although uses vary due to the educational goals 
of the academic programs. More research needs to be done to determine if one type of student benefits more than the other. Also, positive aspects of CAI, improved independence with information gathering and improved knowledge of technology, are vital for the future of our profession in terms of reimbursement and independent practice. Negative aspects, time and cost, have always been barriers for implementing new programs in all of higher education, and through strategic planning and slow implementation, programs may be able to determine solutions acceptable for their setting. What works in one setting, may not be appropriate for others.

Furthermore, we need to be aware of the instructional goals, content, and learners when selecting, designing, and using CAI. The teaching-learning continuum can provide educators with a theoretical framework that allows intellectual decisions regarding software selection to be made. Finally, the need for CAI should evolve from a thorough evaluation of the program, students, and clinical environment. 


\section{REFERENCES}

Abdullah, M. H. (1998). Guidelines for evaluating web sites. (Report No. EDO-CS-98-10). Washington, DC: Office of Educational Research and Improvement. (ERIC Document Reproduction Service No. ED426440)

American Physical Therapy Association. Names of Program Directors for Physical Therapy and Physical Therapist Assistant Education Programs. Retrieved November 15, 2001, from http://www.apta.org

Bailey, D. H. (1996). Constructivism and multimedia: Theory and application, innovation and transformation. International Journal of Instructional Media. 23(2), 161-166.

Bishop, B. (1970). Innovations in teaching physical therapy. Physical Therapy. 50(1), 46-51.

Boling, N. C. \& Robinson, D. H. (1999). Individual study, interactive multimedia, or cooperative learning: Which activity best supplements lecture based distance education. Journal of Educational Psychology. 91(1), 169-174.

Boyle, J. (1991). Ventilatory control (Ventrol) simulation for education. American Journal of Physiology. 261(6), S25-29.

Branch, R. M., Kim, D., \& Koenecke, L. (1999). Evaluating on-line educational materials for use in instruction. (Report No. EDO-IR-1999-07). Washington, DC: Office of Educational Research and Improvement. (ERIC Document Reproduction Service No. ED430564)

Brudenell, I. \& Carpenter, C. S. (1990). Adult learning styles and attitudes towards computerassisted instruction. Journal of Nursing Education. 29(2), 79-83.

Bruning, R. H., Schraw, G. J. \& Ronning, R. R. (1999). Building knowledge and reflective thought. In: Cognitive Psychology and Instruction. Upper Saddle River, NJ: PrenticeHall, Inc. 
Bugbee A. C. (1996). The equivalence of paper-and-pencil and computer-based testing. Journal of Research on Computing in Education. 28(3), 282-90.

Burgess, G. W. (1996). The design of adult learning around multimedia delivery. Journal of Interactive Instruction Development. 9(1), 3-9.

Carlson, H. L. (1991). Learning style and program design in interactive multimedia. Educational Technology Research and Development. 39(3), 41-48.

Chin, S. S. \& Hortin, J. A. (1993). Teachers' perceptions of instructional technology and staff development. Journal of Educational Technology Systems. 22(2), 83-98.

Chodorow, S. (1996). Educators must take the electronic revolution seriously. Academic Medicine. 71(3), 221-226.

Chrisite, A. (1990). The use of interactive videodisc in the teaching of orthopedics in physiotherapy. Medical Teacher. 12(2), 175-179.

Clark, R. A. \& Raffin, T. A. (1992). Efficacy of computers in teaching arterial blood gas analysis. Academic Medicine. 67(7), 365-366.

Coggan, P. G., Hoppe, M. \& Hadac, R. (1984). Educational applications of computers in medical; education. J Family Practice. 19(1), 66-71.

Cohen, P. A. \& Dacanay, L. S. (1994). A meta-analysis of computer based instruction in nursing education. Computers in Nursing. 12(2), 89-97.

Cohen, S. T. (1995). Computer-assisted instruction as a learning resource for applied anatomy and kinesiology in the occupational therapy curriculum. American Journal of Occupational Therapy. 49(5), 821-827.

Day, R. \& Payne, L. (1984). Comparison of lecture presentation versus computer managed instruction. Computers in Nursing. 2(6), 236-240. 
Denzin, N. K. \& Lincoln, Y. S. (1998). Collecting and Interpreting Qualitative Materials. Newbury Park, CA: Sage Publications, Inc.

Dewey, J. (1944). Democracy and education. New York: Macmillan Company. [Reprinted 1966, the Free Press].

Dillon G. F. \& Clyman, S. G. (1992). The computerization of clinical science examinations and its effect on performance of third year medical students. Academic Medicine. 67(10), S66-8.

Dowding, T. J. (1994). Virtual reality: Is it real? Performance and Instruction. 33(7), 20-23.

Educational Software gets a Failing Grade. (1997). Bioscience. 47(10), 720.

English, T., Harrison, A. L., Hart, A. L. (1998). A distance-learning model in a physical therapy curriculum. Journal of Allied Health. 27(4), 228-232.

Farmer, J. (1996). Using Technology. In: Gaff, J. G. \& Ratcliff, J. L. (Eds.). Handbook of the Undergraduate Curriculum, pages 476-492. San Francisco, CA: Jossey-Bass Publishers.

Faux, T. L. \& Black-Hughes C. (2000). A comparison of using the Internet versus lectures to teach social work history. Research on Social Work Practice. 10(4), 454-467.

Frear, V. \& Hirschbuhl, J. J. (1999). Does interactive multimedia promote achievement and higher level thinking skills for today's science students? British Journal of Educational Technology. 30(4), 323-9.

Friedman, R. B. (1996). Top ten reasons why the world wide web may fail to change medical education. Academic Medicine. 71(9), 979-981.

Froman, R., Hence, C. \& Neafsey, P. J. (1993). A comparative assessment of interactive videodisc instruction. Computers in Nursing. 11(5), 236-241. 
Fulkerson, P. K. Miller, A., Lizer, S. (1999). Using world-wide-web based instruction modules and e-mail for a remote neurology course. Academic Medicine. 74(5), 1999.

Gagne, R. M., Briggs, L. J. \& Wager, W.W. (1988). Principles of Instructional Design. (3 ${ }^{\text {rd }}$ edition). New York, NY: Holt, Rinehart, and Winston.

Garg. A. (1998). Virtual anatomy: new opportunities for educational research. Academic Medicine. 73(12), 1217-1218.

Gay, G. (1986). Interaction of learner control and prior understanding in computer-assisted video instruction. Journal of Educational Psychology. 78(3), 225-227.

Gilbert, D. A. \& Kolacz, N. G. (1993). Effectiveness of computer-assisted instruction and small group review in teaching clinical calculation. Computers in Nursing. 11(2), 72-77.

Glass, G. V., McGraw, B. \& Smith, M. L. (1986). Meta-analysis in social research. Beverly Hills, CA: Sage Publications.

Griffin, N. L. \& Schumm, R. W. (1992). Instructing occupational therapy students in information retrieval. American Journal of Occupational Therapy. 46(2), 158-161.

Halloran, L. (1995). A comparison of two methods of teaching: Computer managed instruction and keypad questions versus traditional classroom lecture. Computers in Nursing. 13(6), 285-288.

Hardin, P. C. \& Reis, J. (1997). Interactive multimedia software design: concepts, process, and evaluation. Health Education Behavior. 24(1), 35-53.

Harless, W. G. (1967). The development of a computer-assisted instruction program in a medical center environment. Journal of Medical Education. 42(2), 139-145.

Harper, J. Beck, G., \& McCurdy, F. (1999). The collaborative self-study site for on-line selfassessment for medical students. Academic Medicine. 74(5), 573. 
Hartley, K. W. (1999). Media overload in instructional web pages and impact on learning. Educational Media International. 36(2), 145-150.

Henry, J. B. (1990). Computers in medical education: information and knowledge management, understanding, and learning. Human Pathology. 21(10), 998-1002.

Hoffer, E. P. \& Barnett, G. O. (1986). Computers in medical education: observations from 15 years of experience. MD Computing. 3(3), 6-7.

Hoffman, B. \& Ritchie, D. (1997). Using multimedia to overcome the problems with problem based learning. Instructional Science. 25, 97-115.

Holleque, K. \& Cartwright G. P. (November/December1997). Assessing the notebook initiative. Change. 10-12.

Hooper, J., O’Connor, J., \& Cheesmar, R. (1996). Learning clinical biochemistry using interactive clinical cases. Clinica Chimica Acta. 248, 119-123.

Hsin, Y. S. \& Brown, S. W. (1995). Learner control: The effects on learning a procedural task during computer-based videodisc instruction. International Journal of Instructional Media. 22(3), 217-32.

Jacka, B. (1985). The teaching of defined concepts: A test of Gagne and Briggs' model of instructional design. Journal of Educational Research. 78(4), 224-227.

Joyce, B., Weil, M., \& Calhoun, E. (2000). Models of teaching ( $2^{\text {nd }}$ edition). Boston, MA: Allyn and Bacon.

Kaufman, D. \& Lee S. (1993). Formative evaluation of a multimedia CAL program in an ophthalmology clerkship. Medical Teacher. 15(4), 327-341.

Keller, J. M. (1987). Development and use of the ARCS model of instructional design. Journal of Instructional Development. 10(3), 2-10. 
Khine, M. S. (1996). The interaction of cognitive styles with varying levels of feedback in multimedia presentation. International Journal of Instructional Multimedia. 23(3), 229237.

Kinney, P., Keskula, D. R. \& Perry, J. (Spring 1997). The effect of a computer-assisted instructional program on physical therapy students. Journal of Allied Health. 57-61.

Kolb, D. (1984). Experiential learning: Experience as the source of learning and development. Englewood Cliffs, NJ: Prentice Hall.

Koller, C. A. \& Frankenfield, J. J. (2000). Twelve tips for developing educational multimedia in a community based teaching hospital. Medical Teacher. 22(1), 7-11.

Koschmann, T. (1995). Medical education and computer literacy: Learning about, through, and with computers. Academic Medicine. 70(9), 818-821.

Kuriloff, P. (2000). If John Dewey were alive he'd be a webhead. Chronicle of Higher Education. 156(34), A72.

Lawless, K. A. \& Brown, S. W. (1997). Multimedia learning environments: issues of learner control and navigation. Instructional Science. 25, 117-131.

Lee, S. H. \&Boling, E. (1999). Screen design guidelines for motivation in interactive multimedia instruction: a survey and framework for designers. Educational Technology. 39(3), 19-26.

Lehmann, H. P., Lehmann, C. U., \& Freedman, J. A. (1997). The use of simulations in computeraided learning over the World Wide Web. Journal of the American Medical Association. $278(21), 1788$.

Levin, J. (2000). Multiplicity in learning and teaching: A framework for developing innovative online education. Journal of Research on Computing Education. 32(2), 256-70, 
Liao, Y. C. (1998). Effects of hypermedia versus traditional instruction on students' achievement: A meta-analysis. Journal of Research on Computing in Education. 30(4), 341-360.

MacDonald, L. \& Caverly, D. C. (1999). Techtalk: Technology and developmental math. Journal of Developmental Education. 22(3), 32-33.

Mangrulker, R. S., Whelan, C. T., \& Williams, B.C. Teaching medical information retrieval skills to internal medicine residents at the terminal site. Academic Medicine. 74(5), 573-4.

Mayor, S. (1975). Construction of a mastery oriented teaching unit using a computer. Ohio State Medical Journal. 75(5), 297-299.

McAuley, R. J. (1998). Requiring students to have computers: Questions for consideration. Academic Medicine. 23(6), 669-73.

McClelland, B. (2001). Digital learning and teaching: Evaluation of developments for students in higher education. European Journal of Engineering Education. 26(2), 107-115.

McGown, H. L. \& Faust, G. W. (1971). Computer-assisted instruction in physical therapy: a pilot program. Physical Therapy. 51(10), 1113-1120.

McVeigh S., Williams, R. Pangaro, L. (1997). An internet home page to log students' patient contacts. Academic Medicine. 72(5), 417-8.

Miller, J. A. (1998). Enhancement of achievement and attitudes through individualized learning style presentations of two allied health courses. Journal of Allied Health. 27(3), 150-156.

Mishra, Y. Z. (1999). From concept to software: Developing a framework for understanding the process of software design. Journal of Research on Computing in Education. 32(2), 22039. 
Mulligan, R. \& Wood, G. J. (1993). A controlled evaluation of computer-assisted training simulations in geriatric dentistry. Journal of Dental Education. 57(1), 16-24.

Muma R. D. \& Mayta, M. D. (1998). Developing CD-ROM applications for allied health science students at remote sites. Journal of Allied Health. 27(4), 233-237.

Napholz, L. \& McCanse, R. (1994). Interactive video instruction increases efficiency in cognitive learning in a baccalaureate nursing education program. Computers in Nursing. 12(3), 149-153.

Ogilvie, R. W., Blue, A. V., \& Trusk, T. (1999). Computer administered formative quizzes in a basic science course. Academic Medicine. 74(5), 574.

Ornstein, A.C. \& Hunkins, F.P. (1998). Curriculum: Foundations, principles, and issues. Boston, MA: Allyn and Bacon.

Patton, M. Q. (1990). Qualitative Evaluation and Research Methods. Second Edition. Newbury Park, CA: Sage Publications, Inc.

Piemme, T. E. (July 15,1988). Computer-assisted learning and evaluation in medicine. JAMA. 260(3), 367-372.

Plack, M. M. (2000).Computer-assisted instruction versus traditional instruction in teaching human gross anatomy. Journal of Physical Therapy Education. 14(1), 38-43.

Rasheed, K. S. \& Cohen, P. A. (1990). An evaluation of computer based instruction versus printed study guides in a dental materials course. Journal of Dental Hygiene. 64(1), 3639.

Rizzolo, M. A. (1990). Factors influencing the development and use of interactive video in nursing education. Computers in Nursing. 8(4), 151-159. 
Roschelle, J. (May 1994). Collaborative inquiry: reflections on Dewey and learning technology. The Computing Teacher. 6, 8-9.

Sandroni, S. (1998). Integrating computers into medical education. Academic Medicine. 73(12), 1217.

Schmidt, S. M., Arndt, M. J., Gaston, S. \& Miller, B. J. (1991). The effectiveness of computer managed instruction versus traditional classroom lecture on achievement outcomes. Computers in Nursing. 9(4), 159-163.

Schumacher, K., Brodnik, M., Sachs, L., \& Schiller, M. R. (1997). Therapists' anxiety and attitudes toward computerized documentation in the clinical setting. Journal of Allied Health. 26(4), 151-158.

Shellnut, B., Knowlton, A. \& Savage, T. (1999). Applying the ARCS model to the design and development of computer based modules for manufacturing engineering courses. Educational Technology Research and Development. 47(2), 100-110.

Sherry, A. (1998). Evaluation of multimedia authoring instruction based in a behavioristcognitive-constructivist continuum. International Journal of Instructional Media. 25(2), 201-217.

Sponder, B. \& Hilgenfeld, R. (Nov 1994). Cognitive guidelines for teachers developing computer-assisted instruction. The Computing Teacher. 9-15.

Stake, R. E. (1967). The countenance of educational evaluation. Teachers College Record. 68, $523-40$.

Stake, R. E. (1983). Program Evaluation, Particularly Response Evaluation. In Maudus, G. F., Scirven, M., \& Stufflesbeam, D. L. (Eds.). Evaluation Models: Viewpoints on educational and human service education. Boston, MA: Kluwer-Nijhoff Publishing. 
Stake, R. (1995). The Art of Case Study Research. Newbury Park, CA: Sage Publications, Inc.

Stearns, J., Londo, R. A., Glasser, M. Using laptop computers for teaching and evaluation in extended community preceptorship. Academic Medicine. 74(5), 575-6.

Stephens, P. J. \& Doherty, J. A. (1992). The use of apple macintosh computers and hypercard in teaching physiology laboratories. American Journal of Physiology. 263, S23-S28.

Washington, N. \& Parnianpour, M. (1997). Using CAI to accommodate a variety of learning styles in a biomechanics course. Biomedical Science Instruments. 33, 41-6.

Weed, L. L. (1990). The problem knowledge coupler: Applications in health care delivery. Lecture Notes in Medical Informatics. 39, 75-82.

Weiss, P. (1990). The integration of computers in the occupational therapy department. Journal of Occupational Therapy. 44(6), 527-534.

Williams, C. S., Chalmers, R. J., Salter, P.M. (1982). Microcomputers in physiotherapy education. Physiotherapy. 68(10), 318-319.

Wise, S. L. \& Plake, B. S. (1990). Computer-based testing in higher education. Measurement and Evaluation in Counseling and Development. 23(1), 3-11.

Witzke, D. B., Koff, A. N., McGeagh, A. M., \&Skinner, P. D. (1990). Developing a computerbased system to document and report students' clinical patient encounters. Academic Medicine. 65(7), 440-1.

Yang, S. C. (Nov-Dec 1996). Designing instructional applications using constructive hypermedia. Educational Technology. 45-50.

Yoon, G. (1994). The effects of instructional control, cognitive style, and prior knowledge on learning of computer-assisted instruction. Journal of Educational Technology Systems. 22(4), 357-370. 
APPENDIXES 


\section{Appendix A Questionnaire}

I. Closed-ended items

1. Which of the following best describes your position?

Program Director ___ Full-time Faculty

Part-time Faculty

Other

2. Please match the computer-assisted instructional (CAI) material with the area of Physical Therapy Education in which it is being used in your program. (Check all that apply. If you are not using any instructional multimedia, go to question \#4.)

\begin{tabular}{|l|l|l|l|l|l|l|l|l|}
\hline & $\begin{array}{l}\text { CD- } \\
\text { ROM }\end{array}$ & $\begin{array}{l}\text { Patient } \\
\text { Simulation }\end{array}$ & $\begin{array}{l}\text { Interactive } \\
\text { Tutorials }\end{array}$ & $\begin{array}{l}\text { Web } \\
\text { Pages }\end{array}$ & $\begin{array}{l}\text { Chat } \\
\text { Rooms }\end{array}$ & $\begin{array}{l}\text { Online } \\
\text { Quizzes }\end{array}$ & $\begin{array}{l}\text { Online } \\
\text { Courses }\end{array}$ & Other \\
\hline Anatomy with cadaver & & & & & & & & \\
\hline Anatomy without cadaver & & & & & & & & \\
\hline $\begin{array}{l}\text { Basic Sciences, i.e. } \\
\text { Physiology, Pathology }\end{array}$ & & & & & & & & \\
\hline $\begin{array}{l}\text { Procedures, i.e. } \\
\text { Goniometry, MMT }\end{array}$ & & & & & & & & \\
\hline Therapeutic Exercise & & & & & & & & \\
\hline Modalities & & & & & & & & \\
\hline Kinesiology/Biomechanics & & & & & & & & \\
\hline $\begin{array}{l}\text { Psychosocial Aspects of } \\
\text { Patient Care/Ethics }\end{array}$ & & & & & & & & \\
\hline Research & & & & & & & & \\
\hline Patient Evaluation & & & & & & & & \\
\hline $\begin{array}{l}\text { Critical Thinking/ } \\
\text { Problem Solving Skills }\end{array}$ & & & & & & & & \\
\hline $\begin{array}{l}\text { Integration of basic and } \\
\text { clinical sciences }\end{array}$ & & & & & & & & \\
\hline Other (please describe): & & & & & & & & \\
\hline
\end{tabular}

3. How are you or other faculty using the CAI materials listed in Question \#2? (check all that apply) testing optional tutorials mandatory tutorials extra credit other (please describe) remediation online degree distance learning during clinicals replacement of traditional classroom meetings

4. Which of the following do you or other faculty consider to be benefits of CAI? (check all that apply) improved knowledge of technology improved student/faculty communication individualization of instruction increased interactivity among subjects improved student independence with information gathering other (please describe) learning occurs faster with CAI provides review sessions more effective use of class time improves problem solving skills improves psychomotor skills 
5. Which of the following do you or other faculty consider to be barriers to integrating CAI? (check all that apply) cost rapid obsolescence of hard/software lack of research on its effectiveness no gold standard to evaluate software items lack of production of quality items lack of time for development lack of time for integration other (please describe)

6. Including yourself, how many faculty members are there for your program?

Part-time Full-time

Including yourself, how many faculty members integrate CAI into existing courses?
All faculty
1-2 faculty
3-4 faculty
5 or more faculty

7. Has your program purchased any instructional software programs that you or other faculty are currently using or plan to start using soon?

No Yes, if so, what

8. Has your program purchased any instructional software programs that you or other faculty have stopped using or plan to stop using?

No _ Yes, if so, what

Why will you stop using them?

9. Have you or any other faculty members attended continuing education courses to increase knowledge in instructional software/technology and it's implementation?

No

Yes, if so, please describe

10. Are you or any other faculty members working to design instructional software or web pages (either independently or with a computer programmer/web designer)?

No Yes, if so, please describe

11. Is your institution providing incentive for instructional software/web page development equal to that of teaching, research, and service?

No Yes, if so, please describe

12. Does your program provide students with formal instruction in computer use (i.e. word processing, slide fabrication)? No Yes, if so, please describe:

13. Does your program have a computer prerequisite?

No Yes, if so, please describe:

14. Does your program require students to own a computer?

No Yes, if so, please describe policy 
15. Which of the following represents the predominant learning style among students in your program?

visual learner

auditory learner

kinesthetic learner

unsure

16. Do you see certain types of students benefiting more from CAI? (check one from each category)

a. Learning Style: All students benefit equally visual learner

b. Aptitude: lower aptitude All students benefit equally auditory learner kinesthetic learner Unsure if one type of student benefits more than others

higher aptitude

Unsure if one type of student benefits more than others

17. Do you think computer use in your program adequately prepares students for the computer-based licensing exam?

No ___ Yes Why or why not?

18. Has the integration of the computer-based licensing exam encouraged you to integrate more technology into your program?

No _ Yes Why or why not?

19. What is your average first-time licensing exam pass rate?

\section{Open-ended items.}

1. How do you think computers have influenced PT/PTA curriculum?

2. Please describe the criteria that you or other faculty are using to select instructional software or instructional multimedia items.

3. Please describe how you or other faculty are evaluating the effectiveness of CAI in your program.

4. In your opinion, what is the most important reason to integrate CAI?

5. Describe how you are overcoming the negative aspects of CAI (costs, time, resources).

Would you be interested in participating in additional telephone interview regarding the uses of computer-assisted instruction at your institution and its implementation into PT/PTA education?

Yes

No

Maybe

If you would like to see results of this pilot study, please indicate how you would prefer these data sent:

reference list outline of results 
December 1, 2001

Dear Program Director,

I am a Physical Therapist and Doctoral Student at West Virginia University, and for my dissertation, I am assessing the impact of computers on Physical Therapist and Physical Therapist Assistant Education. You have been selected to participate in this study that consists of questions regarding uses of computer-assisted instruction at your institution.

The questionnaire includes 19 closed-ended questions that will take a minimal amount of time to complete. There are also 5 open-ended items, which may require more time. Please feel free to keep your answers as short as necessary for your participation is valued It will take approximately 10 to 15 minutes to complete.

Coding will be used to coordinate responses to specific programs. I will be the only one with access to raw data provided, and tour responses will be kept anonymous and confidential. I would like to identify "best practices" and write case studies regarding computer-assisted instruction, but if your program is selected, the name will not be used. Your participation is voluntary, and you have the right to leave any item blank. Completing and returning this questionnaire will serve as your consent to participate.

Finally, I am seeking additional participants to discuss these and other areas of computer-assisted instruction as they relate to PT and PTA education. If interested, just check yes in the space provided. When finished, place in the envelope provided and return to me by February 1, 2002. Also I would be happy to provide you with information regarding my results, if interested, check the box that corresponds to the way you prefer to receive this information. If you have any questions, you can contact me by phone at (301) 784-5535 or by e-mail at merickson@ac.cc.md.us.

Thank you in advance for your participation.

Respectfully,

Mia Erickson, MS, PT, ATC 
Appendix B Table of Specifications

\section{Table B.1 Research Question \#1}

\section{What are the similarities and differences in types and uses of CAI between physical therapist and physical therapist assistant education programs?}

\begin{tabular}{|l|l|}
\hline Questionnaire Items & $\begin{array}{l}\# 2 . \text { Please match the computer assisted instructional (CAI) } \\
\text { material with the area of Physical Therapy Education in which it } \\
\text { is being used in your program. }\end{array}$ \\
\hline $\begin{array}{l}\# 3 . \text { How are you or other faculty using the CAI materials listed } \\
\text { in Question \#1? }\end{array}$ & $\begin{array}{l}\text { \#6. How many faulty members integrate CAI into existing } \\
\text { courses? }\end{array}$ \\
\hline $\begin{array}{l}\text { \#9. Have you or any other faculty members attended continuing } \\
\text { education courses to increase knowledge in instructional } \\
\text { software/technology and it's implementation? }\end{array}$ \\
\hline $\begin{array}{l}\# 12 . \text { Does your program provide students with formal instruction } \\
\text { in computer use? (i.e. word processing, slide fabrication) }\end{array}$ \\
\hline \begin{tabular}{l} 
\#13. Does your programs have a computer prerequisite? \\
\hline \#14. Does your programs require students to own a computer?
\end{tabular} \\
\hline
\end{tabular}




\section{Table B.2 Research Question \#2}

What are faculty perceptions regarding positive and negative aspects of CAI; the relationship between CAI and learner attributes such as learning style and aptitude; and the overall impact of CAI on physical therapy education?

\begin{tabular}{|l|l|}
\hline Questionnaire Item & $\begin{array}{l}\text { \#4. Which of the following do you or other faculty consider to be } \\
\text { benefits of computer assisted instruction? }\end{array}$ \\
\hline & $\begin{array}{l}\text { \#5. Which of the following do you or other faculty consider to be } \\
\text { barriers to integrating computer-assisted instruction? }\end{array}$ \\
\hline & $\begin{array}{l}\text { \#16. Do you see certain types of students benefiting more from } \\
\text { PT/PTA curriculum? }\end{array}$ \\
\hline & $\begin{array}{l}\text { Open-ended Item \#4. In your opinion, what is the most important } \\
\text { reason to integrate CAI? }\end{array}$ \\
\hline & $\begin{array}{l}\text { Open-ended Item \#5. Describe how you are overcoming the negative } \\
\text { aspects of CAI (costs, time resources)? }\end{array}$ \\
\hline
\end{tabular}




\section{Table B.3 Research Question \#3}

\section{How are programs selecting and evaluating CAI?}

\begin{tabular}{|l|l|}
\hline Questionnaire Items & $\begin{array}{l}\# 7 . \text { Has your program purchased any instructional software programs } \\
\text { that you or other faculty are currently using or plan to start using soon? }\end{array}$ \\
\hline & $\begin{array}{l}\# 8 . \text { Has your program purchased any instructional software programs } \\
\text { that you or other faculty have stopped using or plan to stop using soon? } \\
\text { instructional software or web pages (either independently or with a } \\
\text { computer programmer/web designer)? }\end{array}$ \\
\hline & $\begin{array}{l}\text { Open-ended Item \#2. Please describe the criteria that you are using to } \\
\text { select instructional software or instructional multimedia items. }\end{array}$ \\
\hline & $\begin{array}{l}\text { Open-ended Item \#3. Please describe how are you evaluating the } \\
\text { effectiveness of computer-assisted instruction in your program. }\end{array}$ \\
\hline
\end{tabular}

\begin{tabular}{|c|c|}
\hline \multicolumn{2}{|c|}{ Table B.4 Research Question \#4 } \\
\hline \multicolumn{2}{|c|}{ Have computer-based licensing exams have influenced faculty decisions to integrate CAI? } \\
\hline Questionnaire Items & $\begin{array}{l}\# 17 . \text { Do you think computer use in your program adequately prepares } \\
\text { students for the computer-based licensing exam? }\end{array}$ \\
\hline & $\begin{array}{l}\# 18 . \text { Has the integration of the computer-based licensing exam } \\
\text { encouraged you to integrate more technology into your program? }\end{array}$ \\
\hline & $\# 19$. What is your average first-time licensing exam pass rate? \\
\hline
\end{tabular}




\section{Appendix C Interview Protocol}

\section{Script for Interview}

Good morning (afternoon, evening). Thank you for agreeing to participate in my research. The goal of this project is to assess the perceived impact of computers on PT and PTA education. The information gathered will be used to meet partial requirements for my doctoral dissertation and to disseminate information to professional audiences.

I would like to advise you of the following:

1. Your participation is voluntary and you do not have to respond to every question.

2. Your responses will be maintained anonymous and confidentiality will be maintained at all times during the study.

3. With your permission, I would like to audiotape our conversation. I would like to tell you that blind coding will be used when storing and analyzing the audiotapes. All tapes will be destroyed upon completion of the study.

4. Neither your professional status nor your job status will not be affected by refusing to participate, refusal to answer a question, or voluntary withdrawal from the study.

\section{Interview Protocol}

1. Describe how you are using CD-ROM? Web Pages? Patient Simulation Software?

2. How have faculty reacted to the increased use of technology and computer software?

3. How have students reacted to the increased use of technology and computer software?

4. Do you see your program moving toward more courses that are entirely web-based? degrees that are entirely web-based? What about PT education in general?

5. What things do you feel students gain from using the software or web page? What things do you feel are lost with using software or web pages?

6. How do you feel about integration of CAI into the Evaluative Criteria or Normative Model?

7. What type of learning (rote, factual, application) do you believe occurs with CAI? 


\section{Appendix D Document Analysis Checklist}

1. This example outlines a type of instruction (Go to Question \#2) a school computer policy (Go to Question \#12)

Types of Instruction:

2. In this example CAI is being used for testing supplementing class instruction a tutorial on line course

3. CAI in this example is mandatory optional

4. How is it being explained to the students?

5. When is it being introduced?

6. Who are the students?

7. Is there class time given for use?

8. What is the content?

9. How do students access the CAI?

10. What is the learning theory?

11. What is the instructional design?

Policies:

12. What is the policy?

13. How is it implemented?

14. Who does the policy affect?

15. Can a theory or instructional design be identified? 
16. Why was the policy started?

17. How did it come about?

18. Who is responsible for writing the policy?

19. Who is responsible for implementing the policy?

20. What effects does the policy have on the program?

21 . Is there a cost to anyone? 


\section{Appendix E Outline of Results}

I. Research Question \#1

A. Quantitative Results

1. Amount of CAI

2. Types and uses of CAI

3. Faculty integrating CAI

4. Faculty taking continuing education courses

5. Institutional incentive

6. Formal computer instruction and ownership

B. Qualitative Results

1. Types and uses of CAI

a. Instructional CD-ROMs

i. Interview Data

b. The Internet

i. Interview Data

ii. Document Analysis

2. Faculty continuing education

a. Questionnaire

3. Institutional incentive

a. Questionnaire

b. Interview Data

4. Formal Computer Instruction 
a. Formal instruction provided by program

i. Questionnaire

ii. Interview Data

iii. Document Analysis

b. Computer prerequisite

i. Questionnaire

ii. Interview Data

c. Mandatory Ownership

i. Questionnaire

ii. Interview Data

iii. Document Analysis

II. Research Question \#2

A. Quantitative Results

1. Positive and Negative aspects of CAI

2. Type of learning that occurs with CAI

3. Learning style and aptitude

B. Qualitative Results

1. Positive aspects of CAI

i. Questionnaire

ii. Interview Data

iii. Document Analysis

2. Negative Aspects of CAI

i. Interview Data 
3. Overcoming barriers associated with CAI

i. Questionnaire Data

4. Type of learning that occurs with CAI

i. Interview Data

ii. Document Analysis

5. Perceived impact of computers

i. Questionnaire

ii. Interview Data

III. Research Question \#3

A. Selection

1. Quantitative Results

2. Qualitative Results

B. Evaluation

1. Qualitative Results

IV. Research Question \#4

A. Quantitative Results

1. Pearson product-moment correlation coefficient

2. Point biserial correlation coefficient

B. Qualitative Results

1. Questionnaire 


\section{Appendix F Independent $t$-test}

\begin{tabular}{|r|c|c|c|c|c|c|c|}
\hline \multicolumn{7}{|c|}{ Appendix F Amount of CAI Used in PT and PTA Programs (t-test) } \\
\hline & $\underline{\text { Mean }}$ & $\underline{\text { SD }}$ & $\underline{\text { Range }}$ & $\underline{\underline{t} \text {-value }}$ & $\underline{\mathbf{d f}}$ & $\underline{\text { p-value }}$ \\
\hline PT & 85 & 9.46 & 7.79 & $0-46$ & 1.107 & 181 & .270 \\
\hline PTA & 116 & 8.09 & 8.68 & $0-46$ & -- & --- & --- \\
\hline
\end{tabular}


Appendix G Type of CAI Matched by Content Area for PT and PTA Programs 
Table G.1 Courses Matched with Type of CAI used in PT Programs $(n=85)$

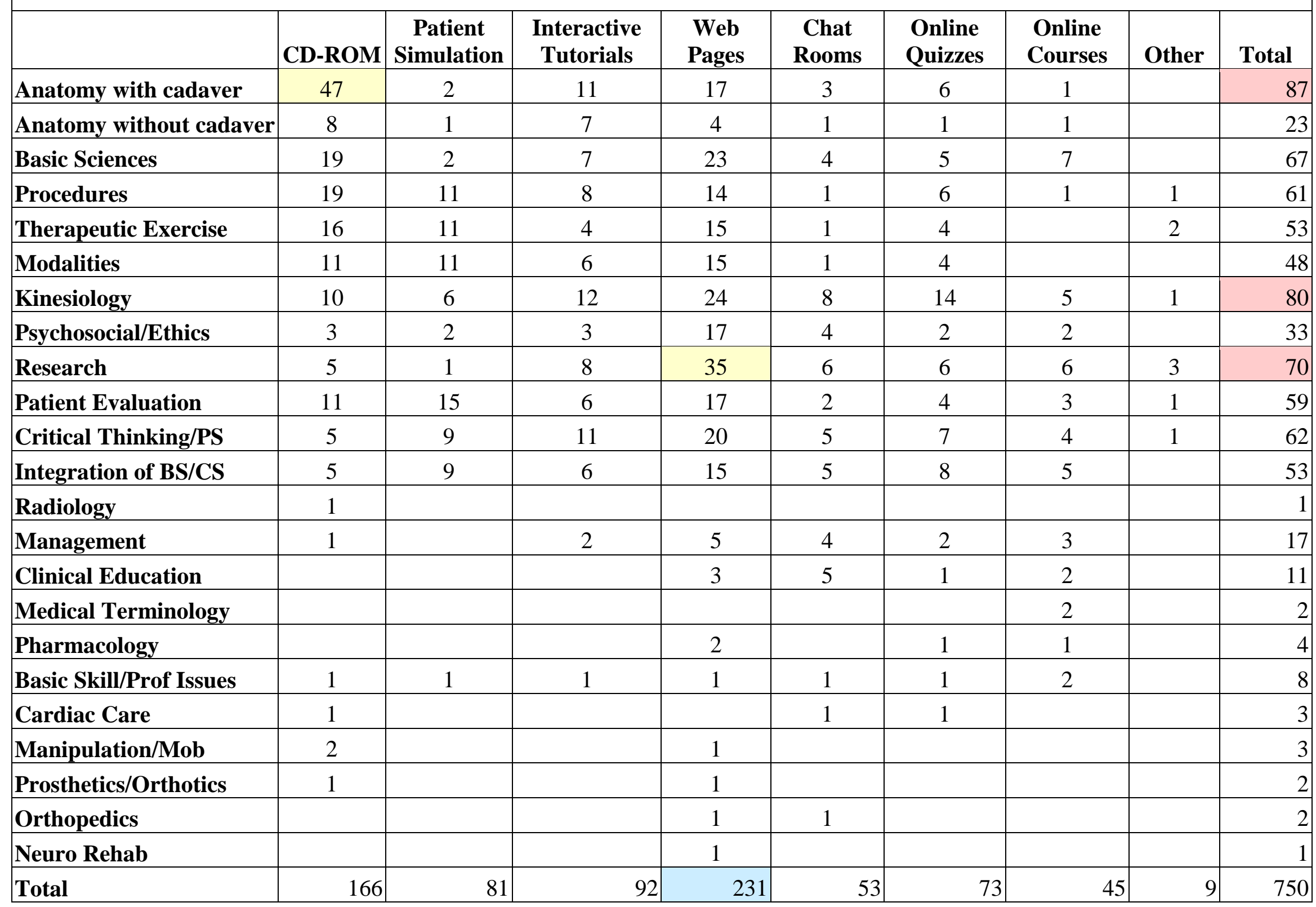




\begin{tabular}{|c|c|c|c|c|c|c|c|c|c|}
\hline \multicolumn{10}{|c|}{ Table G.2 Courses Matched with Type of CAI used in PTA Programs $(n=116)$} \\
\hline & CD-ROM & $\begin{array}{c}\text { Patient } \\
\text { Simulation } \\
\end{array}$ & $\begin{array}{c}\text { Interactive } \\
\text { Tutorials }\end{array}$ & $\begin{array}{c}\text { Web } \\
\text { Pages }\end{array}$ & $\begin{array}{c}\text { Chat } \\
\text { Rooms }\end{array}$ & $\begin{array}{l}\text { Online } \\
\text { Quizzes }\end{array}$ & $\begin{array}{c}\text { Online } \\
\text { Courses }\end{array}$ & Other & Total \\
\hline Anatomy with cadaver & 19 & 3 & 8 & 3 & & 1 & & 2 & 36 \\
\hline Anatomy without cadaver & 44 & 6 & 14 & 13 & 1 & 6 & 4 & 5 & 93 \\
\hline Basic Sciences & 31 & 8 & 10 & 15 & 3 & 9 & 9 & 3 & 88 \\
\hline Procedures & 47 & 22 & 19 & 12 & 2 & 7 & 2 & 5 & 112 \\
\hline Therapeutic Exercise & 29 & 19 & 16 & 15 & 4 & 8 & 4 & 6 & 98 \\
\hline Modalities & 26 & 21 & 16 & 11 & 2 & 8 & 4 & 5 & 93 \\
\hline Kinesiology & 28 & 19 & 18 & 17 & 4 & 9 & 5 & 6 & 106 \\
\hline Psychosocial/Ethics & 2 & 10 & 5 & 11 & 3 & 4 & 4 & 6 & 44 \\
\hline Research & 1 & 2 & 2 & 16 & 1 & & 2 & 6 & 30 \\
\hline Patient Evaluation & 7 & 6 & 5 & 7 & 2 & 1 & 2 & 4 & 34 \\
\hline Critical Thinking/PS & 2 & 14 & 5 & 10 & 5 & 5 & 2 & 8 & 51 \\
\hline Integration of $\mathrm{BS} / \mathrm{CS}$ & 9 & 9 & 6 & 11 & 3 & 4 & 3 & 4 & 49 \\
\hline Exam prep & 6 & 1 & 3 & 1 & & 1 & & & 12 \\
\hline Documentation & & & 1 & & & & & & 1 \\
\hline Management & & & & 1 & & 1 & 1 & & 3 \\
\hline Clinical Education & & & & & 2 & 1 & & 1 & 4 \\
\hline Medical Terminology & 2 & 1 & 1 & & & & 2 & & 6 \\
\hline Intro Course & & 1 & & & & 1 & 3 & & 5 \\
\hline Total & 253 & 142 & 129 & 141 & 32 & 64 & 45 & 62 & 865 \\
\hline
\end{tabular}




\section{Mia Lane Corley Erickson, EdD, PT, ATC}

\section{EDUCATION:}

1998-2002

1994-1996

1990-1994
West Virginia University

School of Human Resources and Education

Doctor of Education

Major: Curriculum and Instruction

Minor: Physical Therapy

Dissertation Title: Assessing the Perceived Impact of Computer

Assisted Instruction on Physical Therapy Education

University of Indianapolis

Krannert School of Physical Therapy

Master of Science in Physical Therapy

Research: The Effects of Footwear on Q-angle and Transverse

Plane Tibial Rotation in Individuals with Anterior Knee Pain

West Virginia University

Bachelor of Science in General Science Education

Minor in Athletic Training

Summa Cum Laude

Student Teaching Experience:

South Junior High School Seventh and Ninth Grade

Sixteen-Week General Science Education Rotation

\section{ACADEMIC EMPLOYMENT:}

July 2001-present Program Director

Associate Professor

Allegany College of Maryland

Physical Therapist Assistant Program

Courses taught: Procedures, Pathology I and II, Kinesiology,

Rehabilitation, Therapeutic Exercise, and Introduction to PTA

August 2000-July $2001 \quad$ Instructor of Physical Therapy

Allegany College of Maryland

Physical Therapist Assistant Program

Kinesiology Lecture and Lab Instructor

1998-present Instructor of Athletic Training

West Virginia University Undergraduate and Graduate Athletic

Training Programs

Biomechanics Lecture and Lab Instructor

Assist Graduate Athletic Training Director with Graduate Research

Projects 


\section{ADDITIONAL ACADEMIC EXPERIENCE:}

$2001-2002$

Admissions Committee

West Virginia University Physical Therapy Program

Fall 2000, $2001 \quad$ Guest Lecture Rehabilitation of the Elbow, Wrist, and Hand West Virginia University Undergraduate Athletic Training Program

Fall 1999

Guest Lecture Gait and Posture Lectures and Labs

West Virginia University Division of Occupational Therapy

Spring 1998, 1999 Assisted with Upper Extremity Splinting Lab

West Virginia University Division of Physical Therapy

Fall 1998, 1999 Assisted with Wrist and Hand Evaluation Lecture and Lab

West Virginia University Division of Physical Therapy

\section{GRANT ACTIVITY:}

2001-2001

Secured grant funding for PTA program

1) Health Manpower Shortage Grant

2) Perkins Grant

Worked as team member on FIPSE Grant for integrating physical therapy math applications into developmental math courses, using a problembased learning approach; Contributing editor for developmental math textbook (In progress)

\section{CLINICAL EMPLOYMENT:}

1997-present

1997-1999

1997

1995-1996
Physical Therapist, Healthworks Rehab and Fitness, Outpatient Hand Service, Morgantown, WV

- CHT eligible

- Additional experience in Pediatrics, Acute Care, Skilled Nursing, and Long Term Care

- Center Coordinator for Clinical Education (June 1998-July 2001)

- Educational Programs Committee

- Peer Chart Review Committee

Contract Physical Therapist, Care Partners Home Health, Inc. Morgantown, WV

Pediatric Physical Therapist in Monongalia County School System, Morgantown, WV

Outreach Athletic Trainer, St. Francis Hospital

Indianapolis, IN 


\section{PUBLICATIONS:}

Erickson, ML The effects of closed versus surgical reduction and smoking on outcome after distal radius fracture. Abstract PL-37. Journal of Orthopedics and Sports Physical Therapy. January 2001

Corley ML for the University of Indianapolis Class of 1996. Judgment Call—and advocate for her patient. Physical Therapy Magazine. February, 1997.

Corley ML, Hasson PM, Worrell TW, McPoil T. The effects of footwear on Q-angle and transverse plane tibial rotation in individuals with anterior knee pain. Lower Extremity. December, 1997.

\section{PROFESSIONAL PRESENTATIONS:}

May 2002

May 2002

March 2001

February 2001

November 2000

February 1997
Gait Analysis

HealthWorks Rehab and Fitness 2002 Spring Symposium

Biomechanical Examination Lecture and Lab

HealthWorks Rehab and Fitness 2002 Spring Symposium

Lower Extremity Biomechanics and Their Relationship to Patellofemoral Pain Syndrome, HealthWorks Rehab and Fitness 2001 Spring Symposium

The Effects of Surgical versus Closed Reduction and Smoking on Outcome after Distal Radius Fracture, Combined Sections Meeting of the APTA, San Antonio, TX

Therapist's Management of Phalangeal Fractures West Virginia University Department of Orthopedic Surgery Reunion Day

The Effects of Footwear on Q-angle and Transverse Plane Tibial Rotation in Individuals with Anterior Knee Pain. Combined Sections Meeting of the APTA, Dallas, TX

\section{PROFESSIONAL MEMBERSHIPS:}

1998-present

1994-present 1994-present 1999-present

1994-present

1990-present
American Society of Hand Therapists (ASHT)

American Physical Therapy Association (APTA) APTA Orthopedic Section and Foot and Ankle Special Interest Group APTA Education Section and Academic Administrator's and Clinical Faculty Special Interest Groups

West Virginia Physical Therapy Association (WVPTA)

National Athletic Trainer's Association (NATA) 
1990-present

West Virginia Athletic Trainer's Association (WVATA)

1998-present

WVATA Government Affairs Committee

PROFESSIONAL CONFERENCES ATTENDED:

American Physical Therapy Association, Combined Sections Meeting

February 2001

February 1997

San Antonio, TX

Dallas, TX

American Physical Therapy Association, Academic Administrator's Special Interest Group Meeting

October $2001 \quad$ Portland, OR

National Athletic Trainer's Association, Annual Conference

June 2000

June 1995

June 1993

Nashville, TN

Indianapolis, IN

Kansas City, MO

\section{CONTINUING EDUCATION ATTENDED:}

May 2002

Biomechanical Approach to Treatment of Lower Extremity Disorders

HealthWorks Rehab and Fitness 2002 Spring Symposium, Morgantown, WV

March 2002

Surgery and Rehabilitation of the Hand-The Philadelphia Meeting

Thomas Jefferson University, Philadelphia, PA

July 2001

APTA Clinical Instructor Certification Course

West Virginia University, Morgantown, WV

March 2001

A Functional Approach to the Treatment of Patellofemoral Pain Syndrome HealthWorks Rehab and Fitness 2001 Spring Symposium, Morgantown, WV

December $2000 \quad$ Integrating Efforts: Sharing Best Practices and Working Towards the Future, Technology, Teacher Education, Tomorrow Fall Conference, Morgantown, WV

November $2000 \quad$ Upper Extremity Trauma

West Virginia University Department of Orthopedic Surgery Reunion Day Morgantown, WV

September $2000 \quad$ Rehabilitation of the Shoulder in Active Individuals, by Phillip Donnolly, PT, ATC, Morgantown, WV 
June 2000

Current Concepts in Orthotic Prescription and Athletic Footwear, by Thomas McPoil, PhD, PT, Nashville, TN

Uses of Multimedia in Education, Nashville, TN

Management of Common Finger Injuries, Nashville, TN

February 2000

American Society of Hand Therapist's Virtual Annual Meeting

March 1999

Surgery and Rehabilitation of the Hand-The Philadelphia Meeting Thomas Jefferson University, Philadelphia, PA

October 1998 Disorders of the Wrist and Hand-Allegheny University Medical Center Pittsburgh, PA

September 1998 Evaluation and Treatment of the Shoulder Joint Complex, by Kevin Wilk, PT, Indianapolis, IN

March 1998 Evaluation and Treatment of Spinal Disorders, by H. Duane Saunders, MS, PT, Columbus, $\mathrm{OH}$

October 1997 Introduction to Neurodevelopmental Treatment in Adults with Hemiplegia Drake Center, Cincinnati, $\mathrm{OH}$

August $1997 \quad$ Risk Management in Physical Therapy Practice (WVPTA)

Clarksburg, WV

May 1997

Where to Begin: A Workshop for Clinical Instructors

West Virginia University, Morgantown, WV

February 1997 Physical Therapy in Educational Settings-Generating Solutions for Today's Problems (WVPTA), Sutton, WV

February $1997 \quad$ Lower Extremity Biomechanics: Applications for Orthotic Prescription in Children (APTA Combined Sections Meeting), Dallas, TX

\section{WORKSHOPS ATTENDED:}

March 2002

Beginning PhotoShop

February $2002 \quad$ Using Adobe Acrobat for Preparing Your Electronic Thesis or Dissertation

January $2002 \quad$ Using Blackboard

Reaching the "At Risk" Student 
Spring $2001 \quad$ Web Based Instructional Design

Multimedia Presentation Hardware

Winter $2000 \quad$ Using Microsoft Front Page for Web Page Development

Using Web CT

HONORS AND AWARDS:

1994-1996 Krannert School of Physical Therapy Scholarship Award

1994 Delivered Benediction and Invocation at West Virginia University School of Human Resources and Education Commencement Ceremony

1994 School of Human Resources and Education Most Outstanding Student

1993 National Athletic Trainer's Association Annual Scholarship (Inaugural Thomas J. "Tim" Kerin Award)

1993 Mid-Atlantic National Athletic Trainer's Association Scholarship Award

1993 West Virginia University A.C. Whitey Gwynn Scholarship Award

NATIONAL ATHLETIC TRAINERS ASSOCIATION CERTIFICATION NUMBER:

\#069402515 Certified in June 1994

PHYSICAL THERAPY LICENSE NUMBER:

West Virginia \#1599 Licensed in February 1997 